\title{
Tinkering at the Edges of Public Education Teacher and Parent Perceptions of West Virginia Universal Pre-kindergarten
}

\author{
Bethanie Morris Stiles \\ West Virginia University
}

Follow this and additional works at: https://researchrepository.wvu.edu/etd

\section{Recommended Citation}

Stiles, Bethanie Morris, "Tinkering at the Edges of Public Education Teacher and Parent Perceptions of West Virginia Universal Pre-kindergarten" (2012). Graduate Theses, Dissertations, and Problem Reports. 609.

https://researchrepository.wvu.edu/etd/609

This Dissertation is protected by copyright and/or related rights. It has been brought to you by the The Research Repository @ WVU with permission from the rights-holder(s). You are free to use this Dissertation in any way that is permitted by the copyright and related rights legislation that applies to your use. For other uses you must obtain permission from the rights-holder(s) directly, unless additional rights are indicated by a Creative Commons license in the record and/ or on the work itself. This Dissertation has been accepted for inclusion in WVU Graduate Theses, Dissertations, and Problem Reports collection by an authorized administrator of The Research Repository @ WVU.

For more information, please contact researchrepository@mail.wvu.edu. 


\section{TINKERING AT THE EDGES OF PUBLIC EDUCATION}

Teacher and Parent Perceptions of West Virginia Universal Pre-kindergarten

Bethanie Morris Stiles

B.S., West Virginia University, 2003

M.S., West Virginia University, 2005

Dissertation submitted to the

College of Human Resources and Education

West Virginia University

in partial fulfillment of the requirements for the degree of

Doctor of Education

in

Curriculum and Instruction

Joy Faini Saab, Ed.D. - Chair

Allison Swan Dagen, Ph.D.

Sebastian Diaz, Ph.D.

Carol Markstrom, Ph.D.

Aimee Morewood, Ph.D.

Department of Curriculum and Instruction/Literacy Studies

Morgantown, West Virginia

2012

Keywords: universal pre-kindergarten, parent and teacher perceptions, early childhood education 
DOCTOR OF EDUCATION DISSERTATION

OF

BETHANIE MORRIS STILES

APPROVED:

Dissertation Committee:

Joy Faini Saab, Ed.D. - Chair

Allison Swan Dagen, Ph.D.

Sebastian Diaz, Ph.D.

Carol Markstrom, Ph.D.

Aimee Morewood, Ph.D.

Elizabeth Dooley - Interim Dean of HR\&E

West Virginia University

2012 


\begin{abstract}
West Virginia commenced the state universal pre-kindergarten program in 2002, being one of the first states to implement a universal early childhood education program for all fouryear-olds. Ten years later the program is approaching the goal year of full implementation. Research in the field was examined to identify past and current conditions of UPK in WV and throughout the nation. In this study, key informants - teachers and parents-were interviewed and asked to share their perceptions on elements of the program that they encountered to be challenging and successful. Participants in this qualitative study allowed the researcher to gain rich insights on the experiences within the classroom and the effects that it has on children and families. It was ascertained that there are some concerns that can readily be addressed to enhance the pre-k services available to children, but there are many aspects of the program that parents and teachers perceive to be flourishing. The characteristics will be discussed through the words of participants and then interpreted of how their stories can be used to improve WV UPK in years to come.
\end{abstract}




\section{ACKNOWLEDGEMENTS}

At the near culmination of my doctoral experience I seized an amazing opportunity of personal challenge, exploration and growth. I, along with my husband and thirteen friends, hiked the Inca Trail to Machu Picchu, one of the New Seven Wonders of the World. Before I left for Peru, this dissertation was at the top of my list of things to think about. It is what I thought about on purpose, and when I was lying awake at night wondering why I could not fall asleep. Though I made a promise to myself at the beginning of this process that it would not consume me, at some point I lost this vow without even realizing it. I wanted to carry along a copy of my manuscript in my minimalistic pack that would be all that would sustain me for eight days; my advisor and mentor brilliantly advised me to have a phenomenal trip without this in tow.

My life has been altered in many ways as a result of this travel. It is not the first time that I have been out of the county, nor to a third-world county. It was, however, the first experience in which I had to fully rely on myself, my companions, and God to complete a journey that was immeasurably demanding of the mind and body. The trail was not easy, I could not turn back, and it felt like it was never going to end-but, every time I looked up I saw and appreciated the wonderment of unexplored valleys and mountains. Much like my passage has been to completing this degree, I am not the same person that I started out at the beginning of the journey. My trek to accomplishing this goal has also been a full reliance on myself, my family and God-but has taken place over a span of four years, not four days. It also has not been easy, I would not give up, and I was not sure when it would end-but, every time I look back I am thankful that I trekked the doctoral journey. As I continue to write my own story 
of trials and accomplishments, I hope that both of my recent undertakings will inspire my son, Henley, to strive for things that seem beyond his reach and are out of his comfort zone.

What I have re-realized is that I am blessed beyond belief that I have opportunities and liberties that much of the world does not know exist. Unlike those families in the Peruvian mountains, my day-to-day existence is not concentrating on survival; I can focus my efforts on others and making a difference for our current and future generations. A friend wrote of our journey in Peru, "May our hearts be broken enough for those around us that we cannot help but enter into each other's story. May He teach us through our own brokenness to care, rather than to simply cure" (Girle, B., 2012). Though this research is not about absolute brokenness and desperation, it is about an open opportunity to make instigate change and improve early educational experiences for children and families. 
TABLE OF CONTENTS

Chapter ONE: INTRODUCTION TO THE STUDY 1

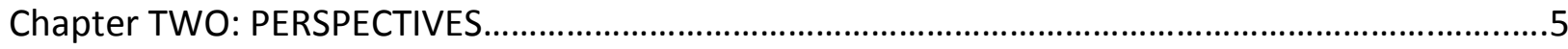

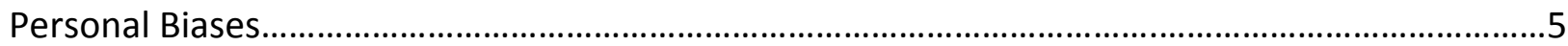

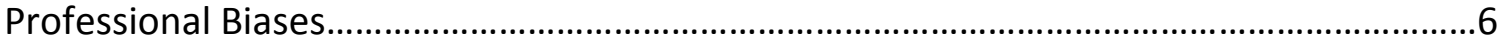

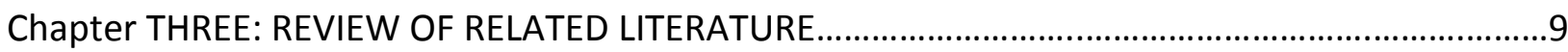

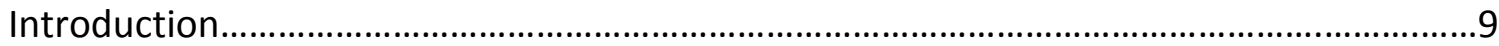

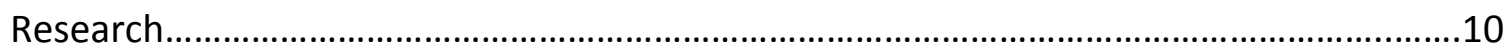

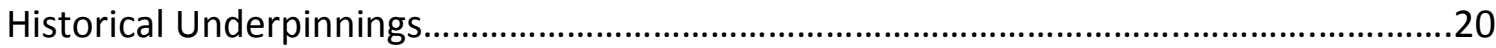

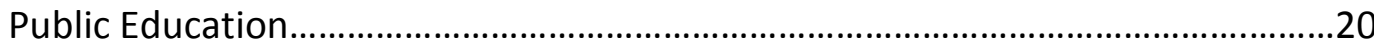

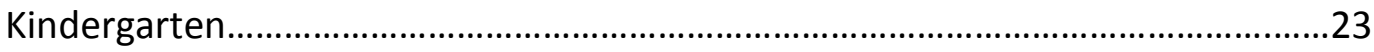

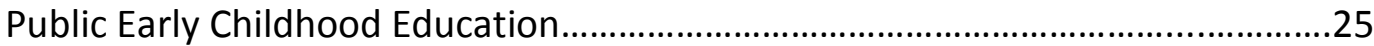

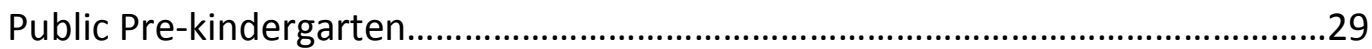

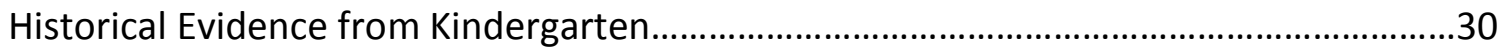

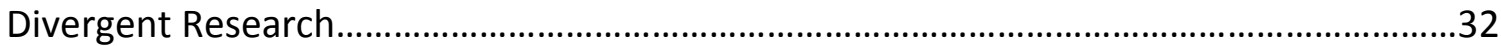

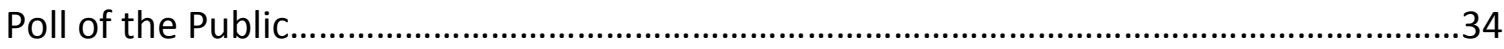

Diagram 1: Tag Cloud of the Edutopia Poll.............................................................35

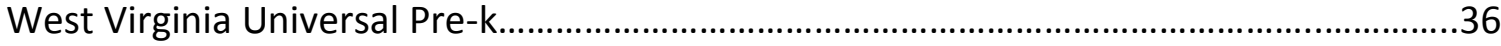

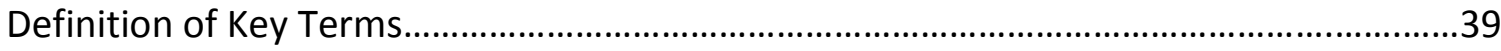

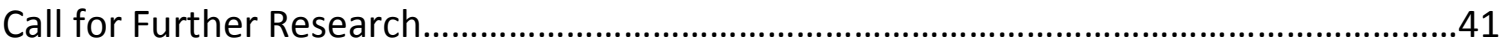

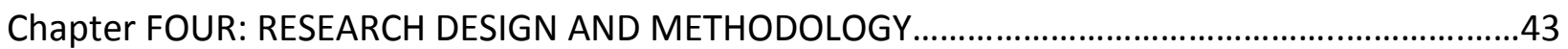

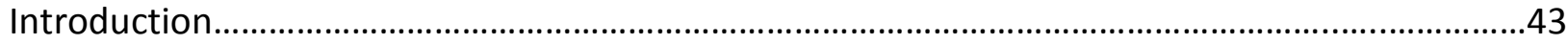

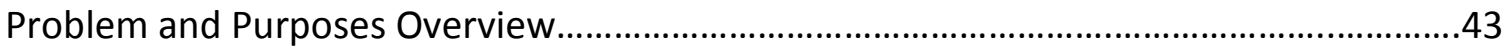

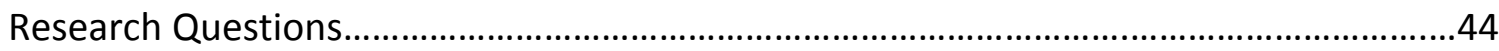

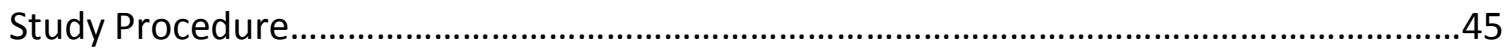

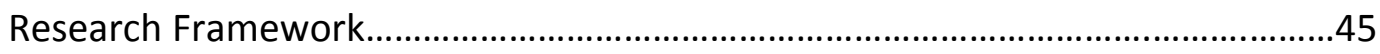

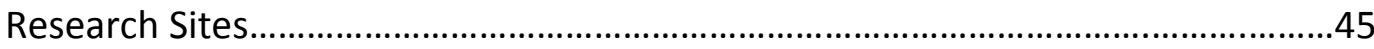

Table 1: Demographics of Pre-k Research Sites........................................46

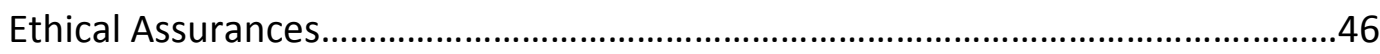

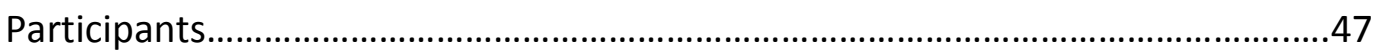

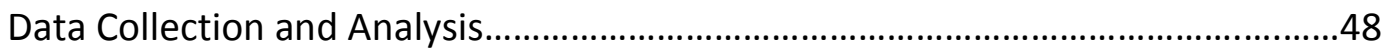

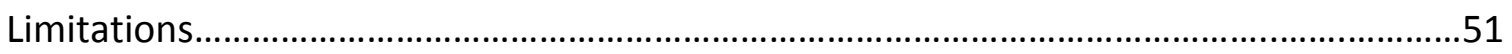

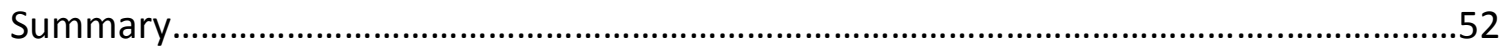




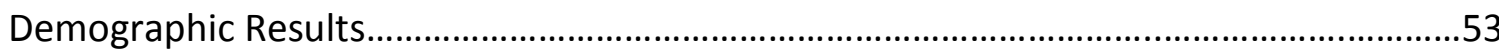

Table 2: Demographics of Parent Interviewees....................................................55

Table 3: Demographics of Teacher Interviewees....................................................55

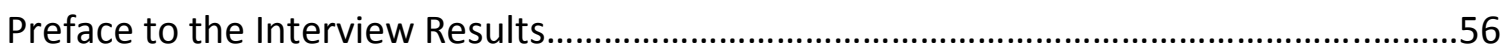

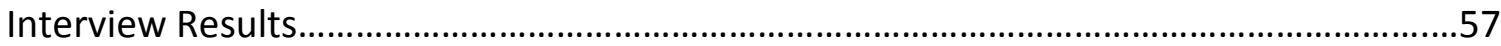

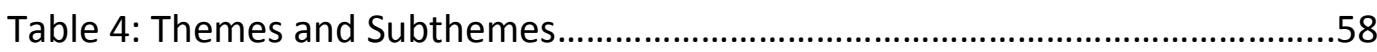

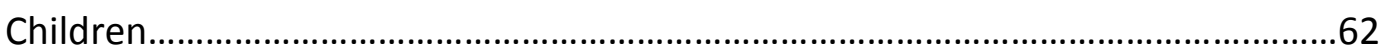

(RQ1: Why are children participating in public pre-kindergarten programs in WV?)

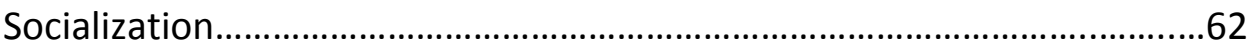

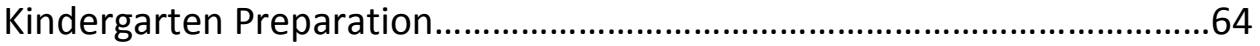

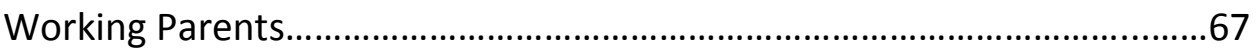

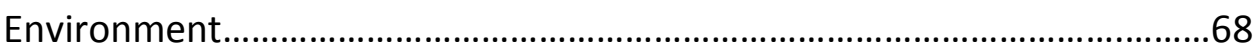

Lack of Confidence in Own Ability..................................................................70

(RQ3: What do parents and teachers perceive as the outcomes of WV UPK?)

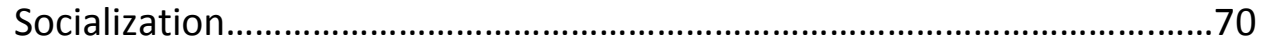

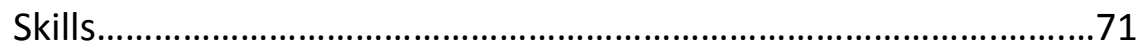

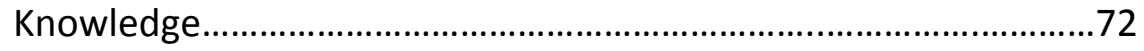

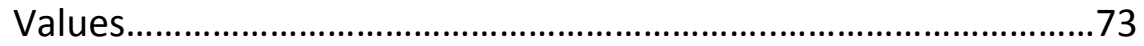

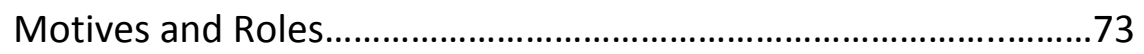

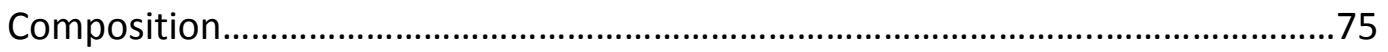

(RQ2: How would parents and teachers adapt the structure of the WV universal pre-kindergarten program?

RQ5: What do parents and teachers perceive as challenging elements of the WV universal preschool program?)

Table 4: Participant Pre-k Ratings................................................................75

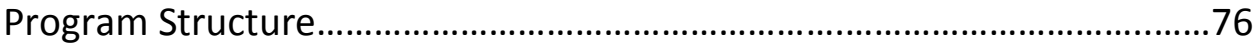

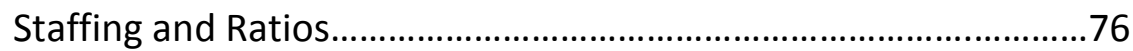

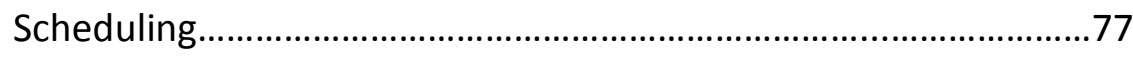

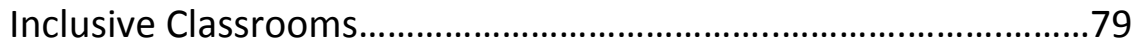

Concerns about Availability and Equality......................................80

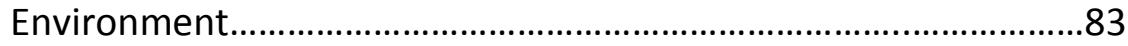

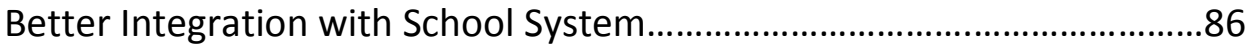

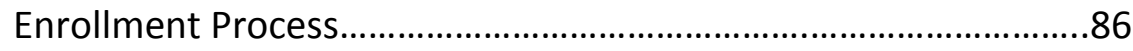

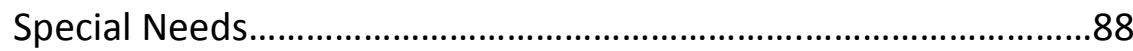

Program Awareness and Communication......................................89

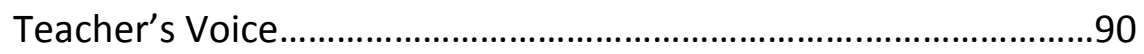

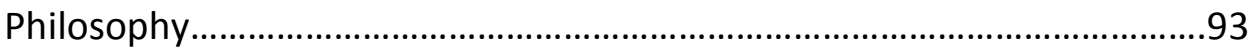

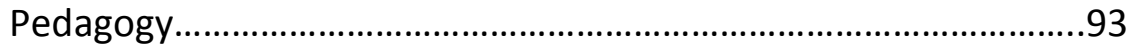

Classroom Communication..........................................................94

Guilt Factor 
(RQ4: What do parents and teachers perceive as successful elements of the WV universal pre-k program?)

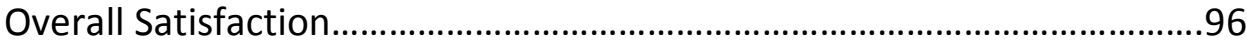

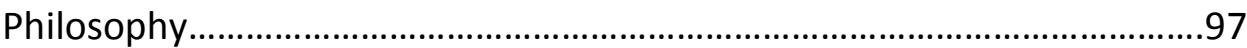

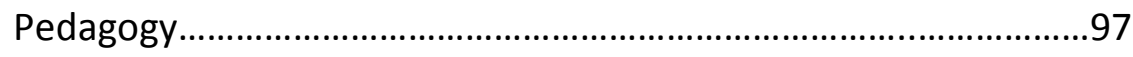

Classroom Communication...........................................................98

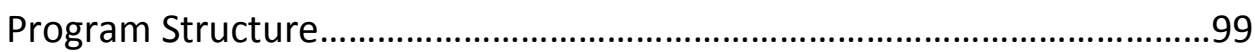

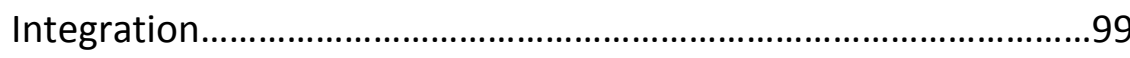

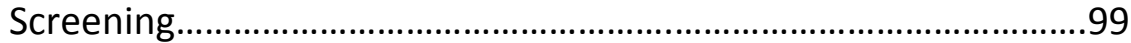

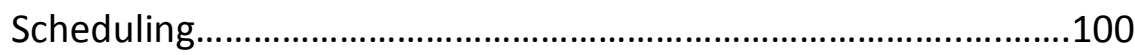

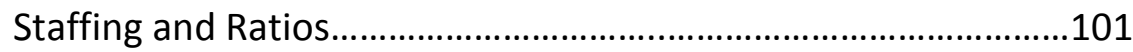

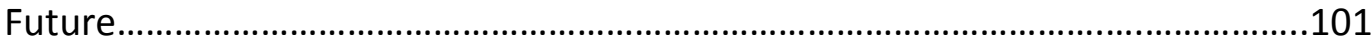

(RQ6: How do parents and teachers think that the WV universal pre-

kindergarten program should proceed in the future?)

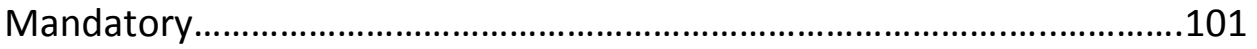

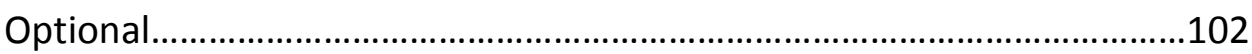

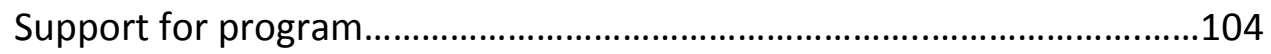

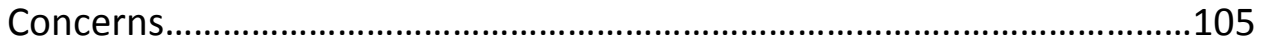

Three-Year-Old Program.......................................................................106

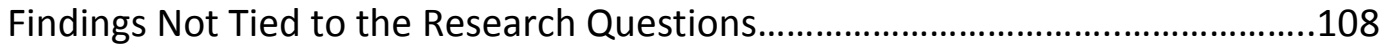

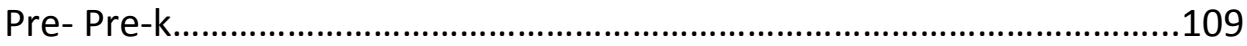

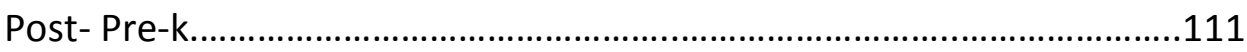

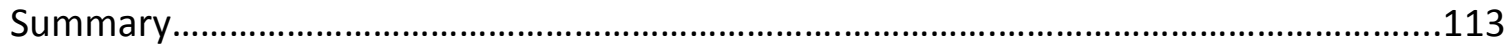

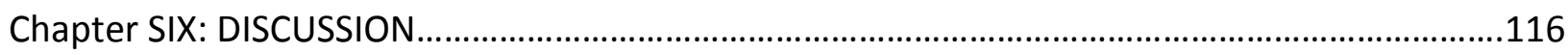

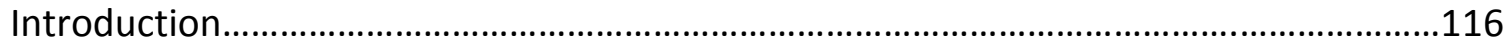

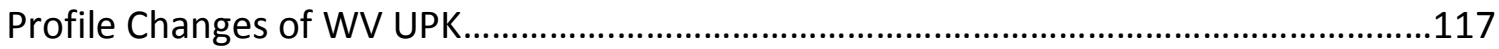

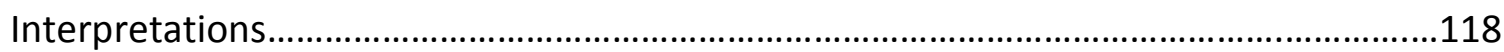

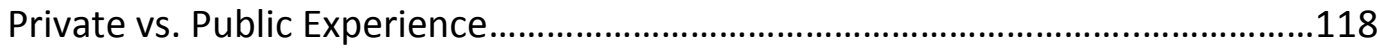

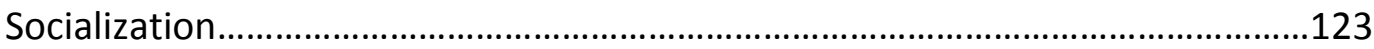

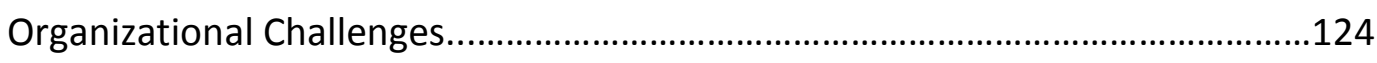

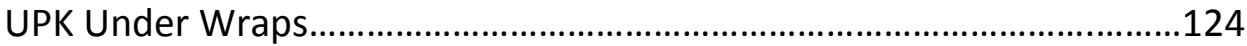

Enrollment Process and Transitions........................................................126

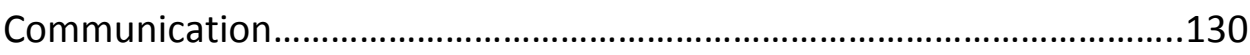

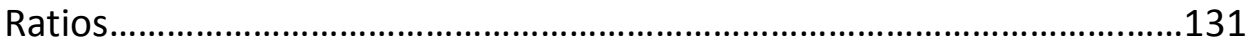

Collaborative/Inclusive Classrooms...............................................................132

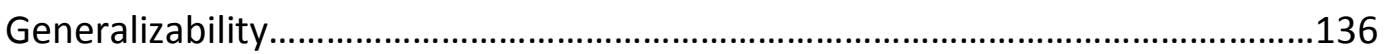

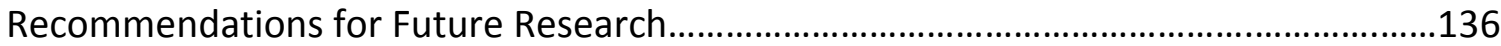

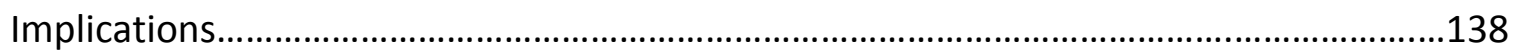

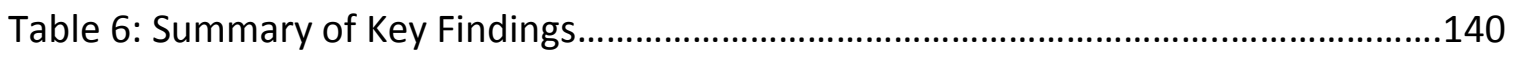

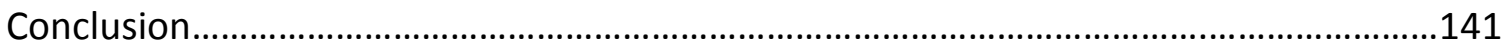




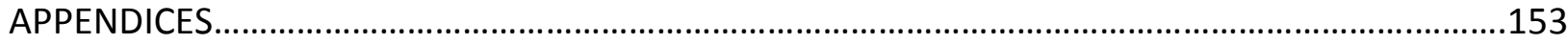

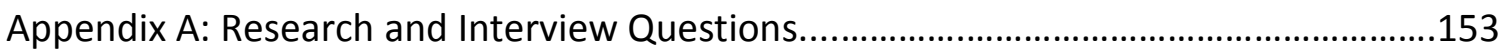

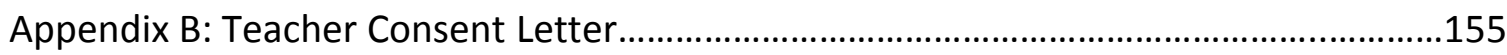

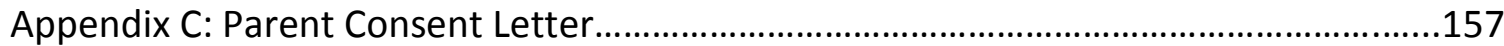

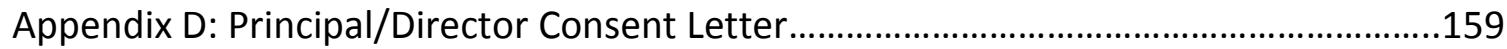

Appendix E: Participant Demographic Questionnaire.....................................................160 


\section{Chapter ONE}

\section{INTRODUCTION TO THE STUDY}

In the 235 years of this country's existence there have been great strides in educational policies and services, but new needs have arisen more quickly than solutions to the old problems. Those with an interest in education contemplate and debate what is versus what could be. Pre-kindergarten is a relatively new societal undertaking that is hitting the ground running. States are working towards the Obama platform to "provide every child with an education that will enable them to succeed." However, the United States struggles to academically perform as highly as other nations (Obama for America, 2011).

The social dynamic of childhood has evolved over the past few decades. The majority of children are now cared for and educated outside of their homes. This raises the question of what roles and responsibilities do the federal, state and local governments, communities and parents assume? Is quality care and education a private right or public responsibility? Historically, affluent families provided enrichment experiences for their youngsters. The advantages of these experiences were observed and pre-education programs were developed for low-income families to help offset the potential challenges for later school success (Bloch, Seward, \& Seidlinger, 1989; Grubb, 1989; Kagan, 1989; Winterer, 1992). Head Start reaches less than $50 \%$ of eligible children (RESULTS, n.d.). Some children benefit from social welfare reforms while others do not receive or are simply not eligible for any services. The current early education system segregates children on many levels. Is this an appropriate stance since research confirms children from disadvantaged backgrounds are more at risk for poor school success (Grubb, 1989; Bryant et al., 2005) or should society be focused on the motto that "the 
early years are the learning years (NAEYC)" and invest in introducing early childhood into the public school arena? Early childhood educators experience inequities in addition to the children. Salaries, educational and experience requirements, working conditions, and benefits of the teachers affect the quality of education and care that children receive (Kagan, 1989; The Trust for Early Education, 2004).

The need to accommodate children and families is undeniable. More families are dualincome earners or single parent-leaving their children to be cared for, raised, and educated in a wide array of accommodations. Only 27 percent of 4-year-olds in 2010 were being served by state-funded pre-kindergarten, Head Start or special education programs, leaving the other $73 \%$ of America's four-year-olds in the hands of costly childcare facilities, in family care, or a combination of arrangements (Children's Defense Fund, 2010). Nationally, pre-k enrollment was marginally above one-fourth of the four-year-old population, posing the questions of are these services not a) available to the extent of the demand, b) desired by parents that are capable of making alternative childcare arrangements, c) communicated effectively to the public about the availability of services, or d) other unknown reasons (Barnett et al., 2010). These dynamics will be explored to set the stage as parent and teacher perspectives being a missing link to inform universal pre-kindergarten. This research is going to get into the passenger seat with teachers and parents to ascertain what is valuable for children and families and what is challenging for children and families in public pre-kindergarten programs.

Married households with dual-working parents outnumbered single income families for the first time in US Census Bureau history in 1998. Fifty-one percent of the married couples with children were employed at least part-time, compared with 33 percent in 1976. Maternal 
employment has become the norm, instead of the exception for young children. In 2008, 61 percent of children under the age of five had both parents in the workforce (Laughlin, 2010). In 1991, there were 9.9 million children under the age of five who were in need of care while their mothers were at work; but less than one quarter were enrolled in a public or private early childhood center (Bureau of the Census, 1994). In 2005, the number rose to 12.7 million children with 23 percent served in an organized care facility. Forty-one percent were in relative care, 13 percent in non-relative care and 36 percent of children having no consistent child care arrangements. Three to four-year-olds in particular were cared for 20 percent by a family member, some even being sibling caregivers, 24 percent in a child care facility, and five percent by non-relatives. These children spent an average of 32 hours per week in their child care arrangements (Laughlin, 2010).

States are stepping up to the plate and delivering pre-kindergartens to four-year-olds and some three-year-olds. There is no federal regulation or guidance of these state initiated programs. As a result there are inequalities state-to-state and district-to-district. Quality and availability are at the forefront of the apprehension about incorporating another grade into the public school system. The concern about the public's role for the education and care of our youngest citizens has to be approached delicately. A legislative issuance of an early education platform is not sufficient unless it is grounded in theory and research specifically related to children less than five years of age.

Qualitative data offered by parents, teachers, and observational records are capable of imparting new wisdom to help the pre-kindergarten system to advance in developmentally appropriate approaches and policies that provides an optimal learning experience for children. 
Regardless of the valuable information that parents and teachers have to contribute regarding educational programs and outcomes, it is not always considered in the development of public programs. All of the conclusions of this research project can be translated into policy and program modification to help guide the future of state funded pre-kindergarten. Educators and parents will inform this research regarding these questions and concerns and the conversations with each will be used to help answer: Should we continue to tinker at the edges of public education? 


\section{Chapter TWO}

\section{PERSPECTIVES}

\section{Personal Biases}

As a qualitative researcher, I must be honest with my audience. I am the mother of a two-year-old son and have committed my life to early childhood education, but do not know if I am a proponent of state funded pre-kindergarten. I feel that this movement will contribute to the disappearance of childhood. There is a minimum to this "tinkering at the edges" and at some point there is an age in which the public has to declare, __ is too young to be cared for and educated by the public school system. I am apprehensive about the notion that I will have to "give up" my son when he turns four. Trusting the public education system with my fouryear-old is a scenario in which I am not comfortable. A child this young is tinkering on the edges of being a baby as it is being a public school pupil.

It is unsubstantiated, but my instinct makes me believe that the U.S. Department of Education is not as much concerned with making sure that our children are given a positive introduction to an educational setting in a developmentally appropriate manner as much as they are fixing the underachievement dilemma. The fact that the skills and knowledge that were once acquired in first-grade are being passed down to kindergarten is not a well-kept secret. Children are more responsible for knowing and doing at a higher level than ever before because the United States lacks in the educational achievements of other countries. School entry began at first grade a few decades ago. Half-day play-based kindergarten entered the arena, followed by mandatory full-day kindergarten that eventually lost the play-based approach. Upon entering elementary school, decisions are not made by parents on their child's 
behalf as much as for parents and children. Attendance is monitored and testing begins. These are not inherently bad, but not $100 \%$ properly applied. I question whether this benefits the child and their learning or the funding streams.

My fear is that pre-kindergarten will become mandatory. I know that I do not want this mandated for my children, and do not know if I support this for anyone else's children. As a mom, I want to protect childhood. As an early childhood education professional, I want to endorse a program that supports children in reaching their developmental optimums. As a mom who is an early childhood education professional, I want to see children being loved, cared for, socially prepared, and educated in developmentally appropriate approaches that also consider the needs of working households.

Mister Rogers believed, "Play is often talked about as if it were a relief from serious learning. But for children play is serious learning. Play is really the work of childhood." (Fred Rogers, n.d.). This is what I am a proponent of. If pre-kindergarten can exist in this frame of mind, then I will advocate, but still not support mandating.

\section{Professional Biases}

Going into this research I think that pre-kindergarten should be provided for socially related purposes, meaning that there is an absolute need for public funding for early childhood education and care services, and that pre-kindergarten is a possible resolution. As I will point out in the research, this need does not begin at four, but at birth. Pre-kindergarten should not be approached as a solution to help our youth get the upper advantage in comparison to the rest of the world. This is an inappropriate responsibility to place on their shoulders. The lack of 
performance should be solved from within, not creating an additional year in which we can identify other problems. Public support instead of public jurisdiction may be more appropriate in supporting the needs of young children and families. It is essential to consider, nevertheless, that between 35 and $45 \%$ of American children enter kindergarten poorly prepared for school success (Barnett \& Frede, 2010).

As much as I am personally concerned with the motive and future direction/implementation of universal pre-kindergartens, professionally I am excited. Research suggests that three and four-year-olds that have the greatest social and academic gains from preschool programs are supported in their development by well-paid teachers who have at least a bachelor's degree and small class sizes (Barnett \& Frede, 2010). On the contrary, research also indicates that few of the preschool programs that children attend are of high quality and provide little support for learning and development. It must also be widely spread that public programs that combine low reimbursement rates and low standards may be detrimental to a child's development. The daunting facet is that it can produce the opposite result than the goals if executed inadequately (Barnett \& Frede, 2010). The enlivening aspect of the public pre-kindergarten initiative is that we can build on what is superior about this field, and through public support correct what is deficient. The array of poor and mediocre care and education that many of our young children receive can be inclusive into a state's public education system, which will provide the governance and infrastructure for quality.

Pre-k is being made available and standards of quality are being tracked. Children can be better served, cared for, educated, and loved in public pre-k than the other choices for child care and education, but quality forever needs to be the guiding principle. The focus should not 
be the best bang for the buck or thrusting us forward in the educational market-these should be afterthoughts, not forethoughts. I maintain my "mommy brain" as a professional and remain apprehensive about the grey line between "school preparation" and childhood. On the whole, this movement seems to be headed in the right direction, but that "what if" remains in my mind. 


\section{Chapter THREE}

\section{REVIEW OF RELATED LITERATURE}

\section{Introduction}

The five-year-old has come into new national prominence. As the former stepchild of education programs and curricula, he now emerges as an important concern in the minds of many varied interest groups.

The cure for the ills of a host of educational, economic and social diseases is now being sought in this tiny personage.

What, actually, can be expected of this budding five-year-old? How does this school year, the kindergarten, fit into the scheme of things? Can it be and is it helpful in any way for the average five-year-old? Are any of the benefits lasting, and can they be traced in the later grades of the elementary school? (Widmer, 1967, p. 210) If kindergarten were replaced with pre-kindergarten and five-year-olds with four-yearolds in the above paragraphs, one might think that this is a modern day prose. Instead, this article was written almost forty-five years ago and today has the same implications displaced onto even tinier personages. Research is driving the public interest and investment in prekindergarten. State and federal policymakers, researchers, advocates, and funders are engaged in discussions and debates regarding the direction that this initiative should precede. The four questions posed by Widmer (what, how, can, and are) will guide the literature review. Research regarding a) exploration of four-year-olds in education, b) a view of public pre-k programs, c) how education affects four-year-old children d) outcomes of early childhood education initiatives, e) historical insights, f) divergent research outcomes, g) public poll and h) specifics of 
WV UPK of will be investigated in this chapter to guide supplementary research to the universal pre-kindergarten agenda.

\section{Research}

"What, actually, can be expected of this budding [four]-year-old?"

A four-year-old can be expected to be cared for and educated in a high-quality

environment. Styles of high quality can vary and can include home-like settings, private child care centers and preschools, and public preschools. Research shows that most early childhood programs are rated as mediocre and provide little support for learning and development (Barnett, 2008; Barnett \& Frede, 2010). Private centers are typically lower quality than public programs, which are a little better (Barnett \& Frede, 2010). High quality allows children to develop their knowledge and skills in language and literacy, math, science, social studies and the arts and well as facilitates their social, emotional, moral, and physical development. Children in high-quality programs are guided in enriching their attitudes, beliefs, dispositions, and habits (Barnett \& Frede, 2010). Other cornerstones of quality that a four-year-old should expect to receive are teachers with degrees, small class sizes, low teacher-to-child ratios, and age appropriate curriculum that is aligned with the upper levels (The Trust for Early Education, 2004). Children this young need a nurturing environment that is filled with age-appropriate learning that is guided by teachers with bachelor's degrees (plus) that are focused on early childhood education (The Trust for Early Education, 2004).

"By the year 2000, all children in American will start school ready to learn" (National Governors' Association, 1990, p. 16) was an unmet promise made to children, educators, 
parents, and society. No Child Left Behind called for state accountability of learning in K-12 and many states recognized that to perform well in kindergarten, children needed preparation. Focusing on improving the quality of a child's early childhood experiences became a way to control the source of accountability for performance at the early stages of public education (DHHS, 2003). Performance is correlated with success and children should be expected to experience success, not failure (Mitchell, 2001).

Research suggests that the best overall educational economic investment is a half-day, school-year program for four-year-olds. Doubling the hours of pre-kindergarten attendance per day from three to six leads to increased benefits, but does not double the benefits (Bartik, 2009). However, parents must be supported as participants in the workforce (Mitchell, 2001), and this structure is not always the most accommodating.

The expectations of a four-year-old have evolved. Throughout the early twentieth century, the effect of education on a child's health, personality and social development were the primary emphasis. Beginning in the late 1950's that attention shifted to education's effect on a child's cognitive and academic abilities (Bloch, Seward \& Seidlinger, 1989).

Public school based programs for four- and five-year-olds seem to gradually adopt more formal, academic curricula as they become more inclusive or unified with the primary school. In our opinion, while this is a danger, it need not prevent the development of good developmentally oriented public school based programs (Bloch, Seward \& Seidlinger, 1989, p. 17-18).

This slow evolution of what public education is accountable for has led to the current movement that children must be able to "start school ready to learn." Today, an alarming 
number of students fail to perform at grade level, disadvantaged children lack basic skills, and advantaged children lack motivation (Gormley, Jr., 2007). Children can be expected to arrive at the school doors ready to learn. Brain research demonstrates that children are capable and eager to learn, but their interactions and experiences in the first few years of life have a profound impact on their overall development (Perry \& Pollard, 1997). The truth is that a child is born learning and what should ultimately be expected is that they will be supported in this natural yearning.

How does this school year, the [pre]-kindergarten, fit into the scheme of things?

Pre-kindergarten gained its entry into the scheme in part because of the public dissatisfaction with public schools. If public schools were performing to their capacity, then universal pre-kindergartens would not be as popularly discussed, debated, and implemented (Gormley, Jr., 2007). The scope of public education is attempting to broaden its doors in the midst of the greatest economic downturn since the Great Depression. Budget cuts are plaguing our schools, but investment in early childhood is still seen as necessary (Barnett \& Frede, 2010). Sufficient funding, high standards and efficient management in a nurturing environment that provides instruction and school preparation are important elements to ensure the success of public pre-kindergarten (The Trust for Early Education, 2004).

State-funded pre-k programs enrollment exceeds Head Start annually (Gormley, Jr. 2005). Participation has exceeded a thirty-year-old program without any government supervision. Pre-kindergarten is certainly fitting itself into the scheme of public education; however, one should question if it is a forced fit or a puzzle-like fit. A shift towards providing 
public education for four-year-olds is sweeping the nation, but the services are not provided equitably, as they are in K-12 education. Thirty-two states have income requirements for their pre-kindergarten programs; twenty percent of the states do not offer a state funded pre-k program. This disparity in availability and funding ostracizes the notion that it is truly "public" or “universal” (Barnett et al., 2010).

Eighty percent of the children served attend pre-kindergarten in about a dozen states (Quality Counts, 2002). Two-thirds of pre-k dollars invested are absorbed by children in ten states (Education Commission of the States, 2003). By these accounts, the fit is not "universal" - availability and investment are not distributed equitably without limit or exception (Merriam-Webster.com, 2011), so the fit varies depending upon where the child resides. Many current programs target children for inclusion in public pre-kindergartens. Though there was a promise made that all children would be ready to enter kindergarten, lowincome, minority, or "at-risk" children are given priority at school readiness (Block, Seward \& Seidlinger, 1989; Children's Defense Fund, 2003; Gormley, Jr., 2007). In 2000, 77\% of children enrolled in public prekindergarten were low income and $23 \%$ were children above the poverty line (Children's Defense Fund, 2003). Programs targeting children at-risk for academic struggles are not always as successful as they are designed to be and oftentimes serve fewer children than are qualified and with lower quality (Gelback, \& Pritchett, 2002).

Trends are appearing as pre-kindergarten assimilates into the public arena. Actions are at state level; every legislation and program is different. Deciding where to seat the programs are one-public schools, child care centers, Head Start, nursery schools, or a combination of any or all. Approximately two-thirds of pre-k children in public programs are served in public 
schools (Isaacs, 2008). Another is the whether to provide public pre-kindergartens "universally" or to "target" populations (Mitchell, 2001). Presently, eight states provide universal programs and thirty-two provide targeted programs (Barnett et al., 2010). Providing funding and identifying the sources are also an action step of pre-kindergarten advocates. Addressing the reality that pre-k programs need to be designed to accommodate working families is gaining attention, as is the deepening commitment to quality. Enforcing pre-k standards as opposed to encouraging or recommending program standards, accreditation requirements, staff qualification and early childhood credentials are also on the rise (Mitchell, 2001). Quality or quantity is an ever-going challenge for pre-kindergarten proponents. Providing universal pre-k cheaply or subsidizing existing child care arrangements without quality control are temptations of politicians, but the incorporation of pre-kindergarten into the public sector could help to prevent a half-hearted effort to tackling early childhood education challenges (Barnett \& Frede, 2010).

Historically speaking, four-year-olds have been a partaker in public education longer than they have not been. When kindergartens made their appearance in the U.S., multiage classrooms of four-, five- and six-year-olds were the norm. In the 1920's the ages were separated and justification of the expenditures for kindergarten was through testing. By the late 1920's the movements of nursery schools and same age classrooms began removing fouryear-olds from kindergartens and by the late 1960s four-year-olds in public kindergartens had almost disappeared with few exceptions. 'History repeats itself' is not an exception in public education. Historic evidence reveals that four-year-olds fared well in these programs-when the programs were developed with sensitivity to the developmental needs of the children 
(Bloch, Seward \& Seidlinger, 1989). Interestingly, children across the United States are beginning their formal public education sometime between the ages of four and eight. There are some states in which kindergarten is not compulsory, and pre-kindergarten is also optional. Kindergarten attendance is mandatory for eleven states, including West Virginia, but in seven states it is not a state requirement to be provided. Eight states and the District of Columbia require five-year-olds to attend school, however, Pennsylvania and Washington age entrance requirement is eight. Full-day kindergarten is only required to be offered by school districts in 13 states (Children's Defense Fund, 2010). Should the decision of when to enroll a child in formal education remain in the hands' of parents or should there be a regulation that reduces that four-year gap in educational services? If there is a trend to initiate state-funded prekindergarten programs, one would not expect that mandatory age of attendance to be so variant between the fifty states.

In the international movement, the U.S. is lagging in policy development, but leading in research. The majority of European countries are granting access to universal pre-k programs. These policy-subsidized programs are serving $85-99 \%$ of three, four and five-year-olds and not all are free, nor do they target low-income families. The U.S. is recognized alongside Australia, Canada, Denmark, Sweden and the U.K. for conducting extensive longitudinal studies that assess child outcomes with characteristics of pre-k programs. The European Union states base their policy less on research findings; they also invest more per capita in early childhood, obtain better outcomes, and have less disparity in quality and access (Land, 2004). Perhaps they are heeding to Shriver's (1965) judiciousness, "If we study it, it will be studied to death, and it will never come to fruition," but only history will reveal which approach was more efficient. 
"Can it be and is it helpful in any way for the average [four]-year-old?"

Four-year-olds are walking into schoolhouses wearing a mask that reads, "I improve school readiness and decrease achievement gaps." Is this a truthful accomplishment or an agenda that is set before them that is unmet? Does it help the child or does it help everyone else-who benefits the most?

The achievement gap between social classes is a challenge of public education. It is well known and researched that children from disadvantaged families enter school "at risk" for lower performance. What is less well known is that the achievement gap between the middle and upper classes is as great as the gap of the former and just as serious. In fact, most of the children who perform very low on standardized tests and repeat a grade or drop out of school are middle-class. Lower class children are the furthest behind, but are a much smaller percentage of families (Barnett, 2007). Relating to the early years, almost fifty percent of children who do not know the alphabet at kindergarten entrance is middle class or above. Over one-fourth of children do not have the appropriate knowledge of letters, relative size, persistence, or the attention necessary for kindergarten (Quality pre-kindergarten for all: State legislative report, 2004).

Research concentrating the effects of pre-kindergarten for all socioeconomic groups found positive effects for all children (Gormley, Jr., 2007). The Tulsa Study and Abbott study found that gains for children advantaged backgrounds averaged at least $80 \%$ as large as children from low-income populations (Barnett \& Frede, 2010). Magnuson et al. (2004) determined that pre-kindergarten had significantly higher positive impacts on cognitive gains than private preschool or child care. 
Another factor to consider is where are the children if they are not in public programs? One million four-year-old children in forty states attend a state funded pre-kindergarten program. Seventy-three percent of four-year-old children are in child care arrangements other than a state funded pre-kindergarten program (Barnett et al., 2010). Sixty-one percent of children under the age of five all are a member of dual-working households (Laughlin, 2010). Quality child care is expensive; the average price of full-time care for an infant in a licensed center can be as high as $\$ 14,650$ a year and up to $\$ 10,920$ for a four-year-old child (NACCRRA, 2007). To send a four-year-old to school is more expensive than the annual in-state tuition at a public four-year college in 36 states and the District of Columbia. In 2008, fewer than 10 percent of all child care centers were accredited, meaning that they were nationally governed by quality standards. More than 20 percent of children under age five are poor despite the fact that more than $63 \%$ of mothers of young children are in the labor force. To receive child care financial assistance, a family must have an income that is below 175 percent of the poverty level in twenty states (Children's Defense Fund, 2010). Young children must be taken care of in some manner, but oftentimes parents are forced to sacrifice quality in the name of affordability.

"Are any of the benefits lasting, and can they be traced in the later grades of the elementary school?"

The quality of care and education a child receives in early childhood is largely indicative of future school success (DHHS, 2003; Campbell et al, 2001), graduation rates, educational attainment, employment rates, lifetime earnings (Bartik, 2009; Schweinhart, et al., 1993), 
reduction in grade repetition, achievement test scores, placement in special education services, and delayed parenthood (Campbell et al., 2001; Campbell et al., 2002; Adams et al., 2004). The U.S. ranks $21^{\text {st }}$ among 25 developed countries on overall educational achievement for 15 -yearolds. However, the U.S. invests nearly two-thirds less on their public school students than prisoners. In 2009-10, total state pre-k funding decreased by nearly $\$ 30$ million and was the first time in eight years of tracking pre-k funding that investments decreased from the previous year. If the American Recovery and Reinvestment Act funding of $\$ 49.3$ million had not been bestowed, the effects to public pre-k would have been problematic at the very least. The average spending per child enrolled is $\$ 4,831$ for pre-k, $\$ 9,198$ for Head Start, $\$ 12,404$ for K-12 (Children's Defense Fund, 2010).

Funding provides the means, but research is driving the direction of public prekindergartens; there is an immense body of research that demonstrates the absence and presence of short and long-term outcomes of such programs (Gormley, Jr., 2007; Ryan, 1998). Cognitive gains are the effects that are most widely replicated. In a five-state analysis of state pre-k programs large effects were reported for alphabet awareness and smaller gains for math and vocabulary (Wong et al., 2008). In a study in Oklahoma and a national Early Childhood Longitudinal Study of children entering kindergarten, these findings were similar (Gormley, Jr. 2005; Magnuson et al., 2007). These gains are subject to the "fade-out" effect for $70-80 \%$ of children by the spring of the first grade (Magnuson et al., 2007). In an analysis of ten states, Gilliam \& Zigler (2001) determined that children who attended state-funded pre-kindergartens consistently had higher scores on cognitive and language assessments. These outcomes were also subjected to fade-out and were nearly non-present by the time when the children were in 
the second and third grades. Florida followed children from pre-k through the fourth grade and with regards to achievement tests; attendance in state-funded programs only retained their effect through kindergarten (Gilliam \& Zigler, 2001). Positive impacts on cognitive development appear to last longer for low-income and at-risk children (Magnuson et al., 2007).

The effects of pre-kindergarten on behavioral and social-emotional outcomes are less favorable. Kindergarten teachers report higher rates of behavior problems in those children who attended a pre-k program (Magnuson et al., 2007) and small increases in aggression were also noted (McCabe \& Frede, 2007). In the ten state study, children in Kentucky had fewer behavior problems at the end of pre-k, but higher rates of behavior issues in the later grades; Washington revealed no differences (Gilliam \& Zigler, 2001). On the other hand, participation in pre-kindergarten was shown to improve a child's self-esteem and motivation and leads to a later reduction of criminal behavior and teen parenthood (McCabe \& Frede, 2007).

Grade retention rates were significantly lower in the six states that assessed this domain for children that attended public pre-k compared to those who did not (Gilliam \& Zigler, 2001; Adams et al., 2004). Attendance in later grades was better in all states in which it was evaluated and there were no significant outcomes regarding grades, special education referrals and placements and parent involvement (Gilliam \& Zigler, 2001).

Though there are no longitudinal studies of pre-k programs specifically, preliminary research suggests that public pre-kindergarten programs are effective at meeting their primary goal: school readiness (Isaacs, 2008; Adams et al., 2004). In the ten state study, nine states collected data on a child's overall development including cognitive, social, motor, academic, language, literacy, and self-help skills and found that children who attended a state-funded pre- 
kindergarten scored higher than those who did not (Gilliam \& Zigler, 2001). Studies have found that pre-k produces greater short-term outcomes than long-term, and have positive results (Gilliam \& Zigler, 2001; Magnuson et al., 2007). If pre-kindergartens are designed appropriately and are funded adequately to ensure availability, accessibility and quality, they are quite capable of producing impressive learning gains (Gormley, Jr. 2005).

\section{Historical Underpinnings}

\section{Public education}

The foundations of public education were during the colonial era when the Massachusetts Law of 1642 directed town officials to ascertain that parents were adequately training their children in labor skills and "to read and understand the principles of religion and the capital laws of the country" (Cubberley, 1919, p. 16). This was a reformist action; the state decreed that all children should learn to read. This directive was a new regulation, but school houses or instructors were not provided until five years later. The Law of 1647 asserted that towns with fifty or more households appoint and compensate a teacher for reading and grammar and towns with 100 or more households to provide a grammar school to prepare children for the university. A school system was established-elementary for all and secondary for larger towns. The state held the communities accountable for providing for the needs of the children. By 1725, settling populations were increasing in numbers and expanding in land area. Communities became more widespread, making it difficult to access the town schools and isolation and self-government lead to a decrease in the zeal for education (Cubberley, 1919). 
The Revolutionary War was ruinous for the early schooling efforts. The United States became an independent country in 1789 , but the revolution, reorganization as a nation, and establishment of the government perished the colonial schools, giving rise to a growing illiterate and impoverished population. The Constitution did not mention education, so the efforts were tabled until 1802 when the U.S. provided a section of land within every township for schools, which became the standard for every state admitted thereafter. The individual states retained local control to organize education (Cubberley, 1919).

The first Lancastrian free school was opened in New York in 1806. The system quickly spread among states and some went so far as to appoint a Superintendent of Public Instruction, but this outburst was a mere stage in the development of American schools, with most losing popularity by 1840 . Ultimately, the Lancastrian system (allowed the advanced students to teach the less advanced, which was inexpensive and effective) awakened public interest for free education and gained support for taxation to make them possible. This was the official precursor for American schools today (Cubberley, 1919).

At the rise of the Industrial Era in the first half of the 1800's children were increasingly used for child labor, were uneducated, or were delinquent street dwellers. Modern life and the manufacturing industry were deteriorating family life and education was looked to as a possible solution for all the newly arising societal problems. The first president of the Free School Society, De Witt Clinton, said, "If, then, the permanency of our Government depends on such knowledge, it is the duty of our Government to see that the means of this information be diffused to every citizen. That is a sufficient answer to those who deem education a private and not a public duty" (Cubberley, 1919, p. 117). 
The greatest educational awakening occurred after 1900. Educational legislations had been passed and state permission to provide education had changed to obligatory measures. Compulsory attendance and child-labor laws rehabilitated the course of the challenging past for public education. The original common school had three components, primary, intermediate and grammar. Agriculture, vocation, industry and home economics were replacing religion and faith as the topics covered and the American people deemed education as the best means for preservation and advancement of national welfare (Cubberley, 1919). After some Supreme Court decisions in the late 1800's segregated education was sustained. 1896 was the year that separate but equal was a new standard for public education in America. By the turn of the century education became something more appreciated than ever before and the U.S. offered the most schooling in the entire world. Throughout the early part of the 1900's American public education was impacted by immigration, the Depression and countless battles stemming from control over the curriculum. When the Depression hit, many students were pulled from schools and forced back into the work place (Mondale \& Patton, 2001).

The Progressive reform did call for more vocational skills being needed and boosted vocational education in school. In the mid 1950's The Space Race gave incentive to the National Education Defense Act of 1958 to give federal funds for high education with an emphasis on math and science. Throughout the 1950's education was changing right along with the civil rights movements. In 1954 Brown vs. Board of Education Supreme Court decision said that separate schooling is unequal and this marked the start of truly integrating schools. During the 60's and 70's many reform policies addressed challenges in schools. Some of these included students with English as Second Language (ESL), gender (Title IX) and special necessities for 
children with disabilities. Also with the growing population of Mexican American students the "English-only" approach to teaching became a thing of the past and bilingual learning and teaching was taking its place (Mondale \& Patton, 2001).

The year of 1983 became the year known for the Presidential Commission report "A Nation at Risk." Schools in the United States were falling apart, contributing to the failing economy. This ignited a drive for more corporate structure for a free market basis for public education. This is when standardized testing came into play in the large part which held students and teachers accountable for student learning (Mondale \& Patton, 2001).

\section{Kindergarten}

Kindergarten was originally started in Germany by Friedrich Froebel in 1839.

Kindergarten taught young children (ages three through five) basic social skills, and aimed at reforming preschool education and addressing family structures and child rearing practices. He drew on the philosophies of Pestalozzi and Fichte to conceive that kindergartens would synthesize the public and private sectors of education, citizenship, nurturing, and familial involvement. Froebel's programs were designed to operate three to four hours a day and supplement, not replace the family's role in the life of a child. Toys ("gifts"), songs, and games guided kindergarten, translated to mean "children's garden", and was intended to be led by women to build on the maternal needs of young children. This was also one of the first movements that allowed women to extradite their skills from the home-based sphere to public application and begin the adoption of a new social role (Allen, 1988; Montes, 1997). 
The first kindergarten opened in the U.S. in Watertown, Wisconsin in 1855 by one of Froebel's former pupils, Margarethe Schurz, but for several years was only accepted and attended by German-speaking communities. Elizabeth Peabody was the main figure in the American kindergarten movement, gaining widespread acceptance and support. This was despite the skepticism of the earliest kindergartens in the U.S. In 1867 Peabody traveled to Germany to study the methods and implementation and met Maria Boelte and Susan Blow, who would respectively start a training program for kindergarten teachers in New York and set up the first public school kindergarten program in St. Louis (1871). Blow approached the kindergarten movement under the philosophy that the most important product of the kindergarten was the happiness that was rendered to the child. Peabody declared that kindergartens were a perfect synthesis of individualism and community responsibility and went on to found the American Froebel Union and the Kindergarten Messenger. The National Education Association was newly formed in 1873 and made a recommendation to adapt kindergarten into the American culture (Allen, 1988; Montes, 1997).

Private and free kindergartens responded to the urbanization and industrialization in America throughout the 1870 s and 1880 s and female kindergarten training institutes were in demand. In 1911, Indianapolis petitioned for the establishment of free public kindergartens to assist with the influx of immigrants from Europe. Though the U.S. adoption differed from the German roots some, the pedagogy remained the same and the movement gained more acceptance than it did in Germany. Kindergartens intended to reform children of the unchurched poor, but attracted children from less needy backgrounds. Recognizing this attraction of kindergarten accessibility for all children and that it helped to create better 
citizens, Peabody was instrumental on securing funding for the assimilation into the public school system. Kindergarten was recognized as a successful social reform movement in the United States when kindergarten was incorporated into most urban American public school systems on a noncompulsory basis in 1914. By 1925, forty-four states allocated funding for high-quality kindergartens and only Arkansas, Georgia, Maryland, and Mississippi had no such laws (Allen, 1988; Montes, 1997).

Kindergarten enrollment has increased since 1940. State laws have been passed to limit the class size and adjust age requirements for entrance. Kindergarten shifted roots by the 1980 's to be a primary means for school readiness as opposed to child-centered education. As of 2008, over three million children attend a public kindergarten, although there are still no national parameters regarding the provision and attendance requirements for kindergarten (Children's Defense Fund, 2010; Encyclopedia of Children and Childhood in History and Society Kindergarten, 2008).

\section{Public early childhood education}

Infant-Schools made their way to America in the early 1800 's because children had no schooling to attend before they could read and write, typically at age eight. Boston was the first to initiate endorsement of these Infant or Primary Schools and provided funding to organize the public school systems. Children were admitted at four years of age, were schooled year-round by female teachers, and were prepared for the early grammar public schools. They were housed and managed separately from older children until they were combined in 1854 . The 
philosophy was built on Pestalozzi and centered on small group work (Cubberley, 1919; Zigler \& Muenchow, 1992).

As part of the War on Poverty, Johnson launched the Economic Opportunity Act in 1964, which funded the Community Action Program aimed at employing poor adults. As a result of futile use of funds, there was a federal budget surplus. Sargent Shriver challenged the Office of Economic Opportunity to address the surplus and deliver a recommendation for use of the funds. Upon learning that half of the nation's population that was living in poverty was under the age of 12 , Shriver's forward thinking and the budget surplus were utilized to create Head Start (Guzetti, 2003; Zigler \& Muenchow, 1992).

Underprivileged children were the target of this new federal program aimed at improving the intellectual capacity and school performance, and reducing the anxiety of entering a school building prior to first grade. Evidence from Susan Gray's Early Training Project in Tennessee, personal experience with special needs individuals, and consultations with preschool programs, child psychologists, a pediatrician, and the Kennedy Foundation science adviser validated the potential efficacy of what would become the Head Start program. Dr. Robert Cooke (the Kennedy Foundation science adviser and friend of Shriver, the chief investigator behind the creation of the National Institute of Child Health and Human Development, and the Chairman of the Department of Pediatrics at Johns Hopkins) undertook the obligation to incorporate a health services component alongside the educational services (Guzetti, 2003; Zigler \& Muenchow, 1992).

October 1964 was the first meeting of the senior advisors to create a blueprint from scratch and in December 1964 a memo was issued stating that Head Start shall encompass 
medical and nutrition components and one-fourth of the staff should be paraprofessionals, primarily parents of the children. Also in December 1964, at the age of thirty-four, Cooke was asked to chair the Head Start planning committee. On this committee served two early childhood educators, four physicians, a nursing professor, an associate dean of social work, a nun who was a college president, and two research psychologists, one of whom was Cooke. Cooke selected Bronfenbrenner as another member of the committee and his theory known as the ecological approach to child development determined the overarching philosophy of Head Start. Bronfenbrenner acknowledged that a child is influenced by all of their environments and experiences. One could not expect a child's outcome to be changed based on a few hours of intervention in Head Start and suggested that neighborhoods and communities, and most notably parents, needed to be key elements in this model (Guzetti, 2003; Zigler \& Muenchow, 1992).

"Recommendations for a Head Start Program by a Panel of Experts" was delivered in February 1965. Improving a child's physical health and mental processes, success experiences for the child and the parents, and screening for special problems and strengths were at the center of the discussion. Without being tested, the first Head Start program launched an immediate nationwide eight-week summer program to serve 100,000 children-“Cooke remembers Shriver's telling him 'Look, you academicians are purists here. If the nation is ever going to have any program, it has to be done right away. If we study it, it will be studied to death, and it will never come to fruition (p. 76)." Lady Bird Johnson quickly came aboard to spread favorable public light on this new federal program and become the honorary chairperson of project Head Start. Head Start continues to be a successful model today, but the 
limited number of eligible and served children is the most deliberated downfall (Guzetti, 2003; Zigler \& Muenchow, 1992).

The Comprehensive Child Development Act of 1971 was passed to lay the groundwork for universally available child care services, but was vetoed at the presidential level. In summer 1971, Secretary Richardson was successful under the Nixon administration for supporting the Revised Federal Interagency Day Care Requirements that would govern child care by consolidating and coordinating federal day care and child development programs and assist in the development and delivery of these services. Public and political outcry opposing this bill was greater than the support, so this effort was again presidentially vetoed. These efforts were used to improve Head Start, but were never successful in the child care field in general. Under Carter's administration, Head Start was transferred to the federal Department of Education. The Perry Preschool program research revealed the return on investment dollars for early childhood education for disadvantaged children during the Reagan administration, but the toll of this office forced quantity over quality and budget cuts in Head Starts (Guzetti, 2003; Zigler \& Muenchow, 1992).

President Bush supported the efforts of Head Start and increased funding so that by 2000, every child would enter school ready to learn (Zigler \& Muenchow, 1992). The Clinton administration supported early childhood by hosting the first-ever White House Conference on Child Care. The need for safe, affordable, quality child care gained national attention and funding for child care subsidies was increased. Head Start quality, participation, and services were increased and Early Head Start was commenced. This administration also recognized the need to focus on providing child care services in rural and urban areas (The Clinton 
Administration and Child Care, 1997). President Bush hosted the Summit on Early Childhood

Cognitive Development in the summer of 2001. This administration recognized that the first five years were a tremendous window for learning and development and increased funding for early education programs and services administered through the department of Health and Human Services and the Department of Education as well as to states for local initiatives. Newly adopted were assessments of learning in Head Start as was training for teachers and educating parents and caregivers about supporting development was also a focus (The White House President George W. Bush, n.d.). Obama's Zero to Five plan invests in young children and their parents by funding Head Start, grants, and tax credits for personal child care expenses. Paramount to this research, universal pre-school is a current emphasis of the Obama administration, which provides funding and encouragement to states to adopt voluntary, universal pre-school available to all (The White House Barack Obama, n.d.).

\section{Public pre-kindergarten}

There has been a paradigm shift in what denotes a state-funded pre-kindergarten program throughout the $20^{\text {th }}$ century. Prior to the 1990 's, state funding for public early childhood programs either supported existing Head Start programs or developed programs modeled after Head Start. Historically, pre-kindergarten programs were targeted to three-and four-year-old children whose backgrounds caused concerns for a delayed start when entering school; families with low incomes, English as a second language homes, or children with special needs. Even with restricted eligibility, all eligible children were not served (Hinkle, 2000; Mitchell 2001). 
In 1993, Georgia became the first state to offer universal pre-kindergarten for four-yearolds, providing voluntary programs for all four-year-olds. New York followed suit in 1997 and began phasing in their pre-kindergarten program, with the goal of offering universal prekindergarten for four-year-olds by 2003. In 1998, Oklahoma began paying for all four-year-olds who are enrolled in public school pre-kindergarten. Georgia, New York, and Oklahoma were the frontier states for universal pre-kindergarten and 18 years after Georgia introduced a truly universal public education system for all four-year-olds, a total of forty states now offer pre-k to four year olds. Although the target audience has expanded, in the fiscal year 2011, thirty-two states still use family income to determine eligibility for pre-kindergarten; ten states do not have state pre-k programs (Barnett et al., 2010; Wong et al., 2008; Hinkle, 2000).

Modern Pre-k programs are operated in public schools and in partnership with community-based early childhood programs like child care centers, nursery schools and Head Start programs. National Institute for Early Education and Research collects and disseminates data about pre-kindergarten, including quality standards, which allow all states execution of pre-kindergarten programs to be analyzed. Decisions about the development and organization of pre-k programs are at the state and local levels and there is great variance between the operational schedule, funding, standards of quality, and access (Hinkle, 2000).

\section{Historical Evidence from Kindergarten}

Comparing the drive of publicly funding pre-kindergarten programs is analogous with the entrance of kindergarten into the public sector. Important lessons can be taken by proponents and critics alike with regard to assimilating pre-k into the public schools. General 
public school followed the same course of history, allowing researchers to draw on the past of one to predict the next. Public schools, kindergartens, and pre-kindergartens have their historical roots as charity reform schools, but attracted a broader population that what was intended. There was a tremendous growth in the first twenty to thirty years of implementation of public education and kindergarten. Eventually, funding and attendance were not guided by willingness of participation by contributors and consumers, but by the power of the law (Montes, 1997).

Modifications that occurred to kindergarten as a result of transferring ownership to a public system are something to consider. Nonprofit kindergartens were focused on the child's general development, concern for the common good, curriculum focused on socialization and religious and moral training, it was regulated by peers, and there was poor regulation of quality. Public kindergartens are focused on academic outcomes, concern for school outcomes, focus on manual dexterity, obedience, and academic outcomes, is regulated by superiors, and has standardization of quality across kindergartens. Pedagogical approaches were alteredteachers were required to work in a manner similar to their peer educators. Child schedules changed, home visits disappeared, and they were pressured to prepare the children for the rote learning methods that preside in elementary education (Montes, 1997).

Advocates of public pre-kindergartens must take these historical lessons and proceed by erring on the side of caution. If pre-kindergartens are going to continue stepping into the public education footprint, these lessons from the past should provide some valuable considerations. The definitive characteristics of early childhood education that have been researched and cultivated should be a priority while utilizing public funds. Universal pre-kindergartens need to 
be introduced as a leader in child-directed education, not be destroyed to purely academically driven test-directed education.

\section{Divergent Research}

The research reviewed above indicates that the positive outcomes of state-funded universal pre-kindergartens outweigh the negative possibilities. Low-income children benefit the most, but it appears to be a win-win situation for all. It is a valuable return on investment, increases jobs, provides care and education during working hours that is not at parent's expense, and promotes school readiness. So, is there anything not to love? "Yes" cautions the other side of early childhood researchers and practitioners.

The question returns - whom benefits the most? The child, the parents, or the public? While it can not be refuted that they all do to an extent, due to the expense of private child care some parents are forced to decide whether to pay for quality (or even mediocre) preschools or to save for college education. Sixty-four percent of children attend preschool prior to kindergarten; less than half of low-income children attend, half of middle-income, and three-fourths are from high-income families.

These years of a child's life are the formative years and what should be concentrated on is their need for love and attention. Incorporating pre-kindergarten into the public sector makes childhood at risk for over institutionalization. Public funds are allocated because of accountability, which is determined through testing. Preparation for testing is by way of a standardized curriculum, which does not most appropriately consider the child. Kindergarten was adopted in its infancy as a school readiness movement, but is now considered a "grade" by 
most states (Lester \& Russell, 2010). Parents of young children have been encouraged to hold their children out of school for an additional year (Bracey, 1989; Elkind, 1987). Studies have found a positive correlation between older entrance age and school performance (Bisanz, Dunn \& Morrison, 1995; Uphoff \& Gilmore, 1985). Datar (2004) determined that delaying kindergarten entrance is associated with positive effect on test scores, but differ when poverty, special needs, and gender are controlled. In a study conducted on four groups of kindergarten students with different pre-kindergarten experiences, it was revealed that children who had attended a private pre-kindergarten program scored higher on a readiness test than students from the comparison groups (Carthum, 1987).

The original preschool was a socialization experience and currently it is to meet the needs of working parents (Lester, 2007). Historically looking, socialization took a back seat to academics along the way of the development of modern early childhood programs. What traits are really desired for four-year-old? Would one rather be in company of a child that was capable of having an intelligent conversation or one that had respectable social skills and morals? David Elkind, professor of child development, child psychologist, and author of Miseducation argues that our youngsters need to be equipped with three things before entering kindergarten: listen to adults and follow instructions, complete simple tasks independently, work cooperatively with others (Elkind, 1987). With these foundations, the other life skills and knowledges can be established, but it is necessary to build correctly for stability. 


\section{Poll of the public}

Edutopia posed the question "Should preschool be a part of public school?" in 2007. 935 registered members of this site that is designed to offer "practical, hands-on advice, real-world examples, lively contributions from practitioners, and invaluable tips and tools" contributed to this blog topic over a period of two and a half years. Fifty-six percent of the respondents answered, "Yes. Preschool has been shown to have positive effects on future school performance, and all children, regardless of income, should have access to high-quality preschool programs." Forty percent voted, "No. Adding preschool to the regular grades could quash early creative impulses, and ultimately, the choice of preschool should be left to the discretion of parents or guardians." Four percent responded, "Neither." The results of the qualitative feedback from this poll were organized into a tag cloud to provide a representation of the key terminology voiced by members of this educational resource site (Bernard, 2007). 


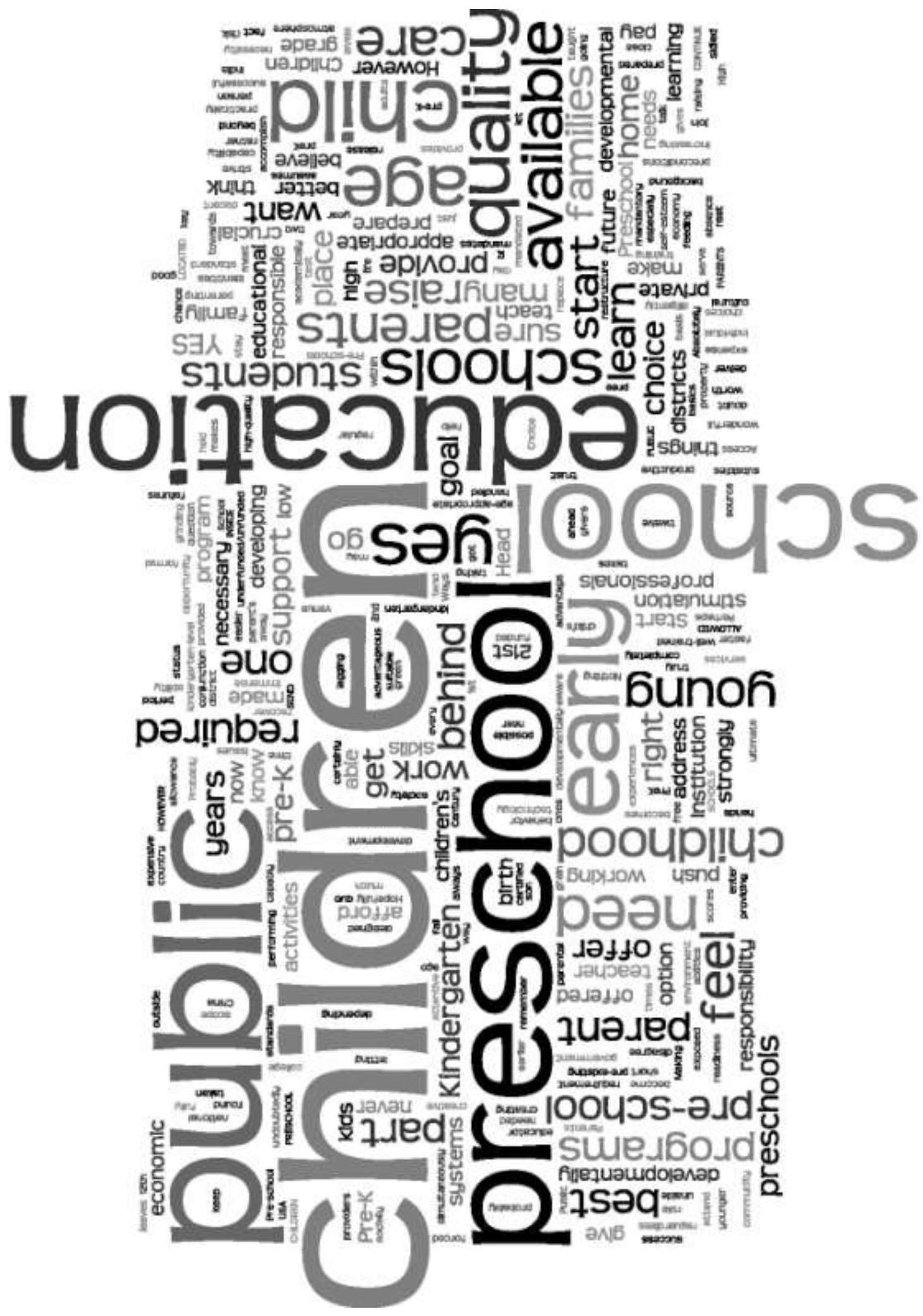




\section{West Virginia Universal Pre-k}

The goals of universal pre-kindergarten in West Virginia are to provide enriched environments for young children, design developmentally appropriate and natural environments that are based on what preschool children should know and learn, and offer high quality early education environments that are responsive to individual children and maximize their learning and skill development. It was implemented to promote school readiness skills for all children, including children with disabilities and to connect resources of the community with the school system to create a community that supports early learning and families (WVDE, 2011). The West Virginia Pre-k system is defined as pre-k classrooms operated by county school systems or community programs which have contracts with these schools (Templeton, Dozier \& Boswell, 2009). Unlike earlier models of publicly funded early childhood programs, WV UPK dispels segregation based on developmental and economical needs; all children have access to pre-k services.

West Virginia will provide access to a publicly funded high quality pre-kindergarten program to all four-year-olds and three-year-olds with special needs by $2012-13$. Prekindergarten in West Virginia was realized at an opportune time-the state was faced with declining enrollments that translated as teacher surpluses and vacant buildings (Gormley Jr., 2007; Ackerman et al., 2009). This was a creative and effective solution to the aforementioned problems in districts with declining enrollments, but for counties with steady or increasing enrollments, there were budget deficits. Legislation for this remedy was first passed in 2002 as W.Va. Code §18-5-44 when state senator Lloyd Jackson proposed UPK on the last day of the legislative session. Jackson was a proponent for free pre-kindergarten programs based the 
personal experiences of the deficiency of high quality early childhood programs, especially in rural areas in WV (Gormley, Jr., 2005). Policy 2525, which ensures continued revisions and strengthening of quality requirements, collaborations to provide pre-k, and county plans for implementation went into effect February 12, 2003 (WVDE, 2003).

UPK programs run the same as the WV academic school year. Placement of children enrolled in pre-kindergarten programs can occur in public school preschool programs, public school preschool special needs programs, licensed child care programs, or head starts. Seventy percent of the pre-kindergarten classrooms were collaborations with community partners in 2010-11. This is significant to maintain the quality and vitality of privately owned centers as well as government funded and operated programs and to provide adequate physical space to house classrooms. Quality is measured by national benchmarks and WV met eight out of ten of the NIEER quality standards in 2010. Areas that were not met were teachers do not have to have a bachelor's degree in collaborative classrooms and assistant teachers do not have to be credentialed. Quality measurements that are met include teacher trainings, class sizes, ratios, services, monitoring, and learning standards supported by a curriculum (WVDE, 2011). In addition to national measures of quality, all classrooms must also meet WV childcare licensing requirements (WVDE, 2003).

By 2012-13, every four-year-old will have access to this optional pre-k program. Full participation is estimated to be between $75-80 \%$ of the eligible children when fully implemented in 2012. In the 2010-11 school year, enrollment was 14,606 children and accommodated over $80 \%$ of the state goal for anticipated participation when it is fully implemented. Flexibility in the implementation of pre-kindergarten is afforded to each county 
so that well-informed decisions can be determined locally. One variation is the number of days and that services are provided, $13 \%$ of children attend pre-kindergarten five days a week and the remaining $87 \%$ participate in four-day programs. Hours of instruction vary from $70 \%$ of children attending $24+$ hours weekly to $25 \%$ attending $12-16$ hours. In 2010-11 there were a total of 988 pre-k classrooms and an average of 55\% of four-year-olds participating in UPK, with $70 \%$ of children having access. Since the inception of WV universal pre-kindergarten until the 2009-10 school year, there has been over a $100 \%$ growth in enrollment. All of the counties in the state offer pre-k (WVDE, 2011; Barnett et al., 2010).

Fifty-seven percent of children under age six in WV have all parents in the labor force. The annual cost for four-year-old child care in a private center is $\$ 4,560$ and the average annual income is $\$ 37,423$. Residents spend upwards of $8 \%$ of their income on child care expenses for one child. The state serves $73.3 \%$ of four-year-olds in state funded pre-k, Head Start, or special education programs (Children's Defense Fund, 2010). State spending has been reduced every year since 2004 and enrollment has been increasing (Barnett et al., 2010).

A study to assess the status of universal pre-kindergarten in WV was conducted by Marshall University. Obstacles to successful implementation were reported as nondevelopmentally appropriate physical spaces (restrooms and playgrounds), adult to children ratio (due to inadequate physical spaces), inequities in salary, and lack of resources (specifically consumables). Transportation (not developmentally appropriate and large land area of rural counties and time in which children must be transported) was deemed as a huge barrier to successful implementation and inhibited access to children in most need of the program. The notable areas of success perceived by teachers, teacher assistants, and administrators were 
community collaborations to house the classrooms and the curricula that were approved for program use (Templeton et al., 2009).

West Virginia is recognized for its efforts to design and implement a universal prekindergarten. According to NIEER (National Institute for Early Education Research): The State of Preschool 2010 Yearbook, WV pre-k ranked third in the country for enrollment of four-year-olds enrolled in pre-k, tenth for state spending per child $(\$ 5,521)$, and fourth nationally for overall spending $(\$ 9,413)$.

\section{Definition of Key Terms}

Childcare. Meets the needs of providing for a child's development during the hours of parental employment. (Scarr, 1988).

Developmentally appropriate practice. "(DAP) is a framework of principles and guidelines for best practice in the care and education of young children, birth through age eight. It is grounded both in the research on how young children develop and learn and in what is known about education effectiveness. The principles and guidelines outline practice that promotes young children's optimal learning and development. (NAEYC, 2009)"

Head Start. A comprehensive services program launched in 1965 by the Johnson administration that serves low-income children from birth to age five and their families. The goal is to foster the healthy development of the whole child and services provided include education, medical, dental, and mental health, and nutrition. A safe, nurturing, stimulating, 
enjoyable and secure environment is provided and Head Start partners with parents to enhance a child's development (Guzzetti, 2002).

Private preschools. An early childhood program run by professionally trained adults. Preschool is a general term that includes different types of early care and education settings. Children are engaged in learning through play and are most commonly enrolled in preschool between the ages of three and five. Preschools are different from traditional day care in that their emphasis is learning and development rather than enabling parents to work or pursue other activities. Tuition is charged and is the parent's personal expense or is subsidized through state or federal programs. (Swartout-Corbeil, 2002).

Public education. "Any educational institution operated by publicly elected or appointed school officials and supported by public funds." (Office of Education, 1966)

Public pre-kindergarten (Universal Preschool/Pre-kindergarten, UPK, pre-k). Preschool education initiative that serves three and/or four-year-old children. A program that is funded, controlled, and directed by the state and early childhood education is the primary focus. A group learning experience must be offered at least two days per week and it must be distinct from state subsidized child care initiatives, but they can be coordinated and inclusive. Not primarily designed to served children with disabilities only, but they may be offered to children with special needs and can be coordinated and inclusive with Head Start initiatives (Barnett, et al., 2010).

High-quality. Efforts that enhance the nature of services provided to young children and their families. Develops the whole child to help facilitate their developmental domains and 
content areas as well as provides positive guidance to their attitudes, beliefs, dispositions, and habits. Factors such as teacher education, salaries, child activities, professional development, regulation, and class sizes are determinants (Barnett \& Frede, 2010; Kagan, 1989).

\section{Call for Further Research}

As an area of such public concern, state-funded pre-kindergarten programs are still in their early stages. The initiative to extend public education downward is not a new social campaign; it is one that keeps reappearing, but never getting successfully resolved. As with many research agendas there is data-driven evidence that can allow one to jump on either side of the fence. The focus of this research is not to support or oppose the forward direction of publicly educating four-year-old children. Instead, it is to understand what is valuable and what is challenging for children and families in public pre-k. It will also focus on discerning if there should be comprehensive strategies to govern the education and care of young children. Specifically, parents and educators will answer the questions:

RQ1: Why are children participating in public pre-kindergarten programs in WV?

RQ2: How would parents and teachers adapt the structure of the WV universal prekindergarten program?

RQ3: What do parents and teachers perceive as the outcomes of WV UPK?

RQ4: What do parents and teachers perceive as successful elements of the WV universal preschool program?

RQ5: What is perceived as challenging elements of the WV universal pre-k program? 
RQ6: How do parents and teachers think that the WV universal pre-kindergarten program should proceed in the future?

Qualitative assessments will allow daily key participants in WV's universal prekindergarten programs to be informants of how children and families are being served. The idea of four-year-olds being educated by public school systems is a reality, as it was multiple times in the past. Decades of research focusing on early childhood development and education is available at our fingertips to design the world's best early childhood education system. Opportunity is knocking, but are we adequately responding to this responsibility? The days of trial and error and give and take back should be far removed. As a nation (not state-by-state) there should be a commitment to support all children in their education-we are capable. What age does a child's learning begin? At birth. At what age should public support of education begin? Controversial. At what age should children be "prepared" for school, also controversial. What is not controversial is that society is changing, as are the needs of society.

As early childhood advocates we must be forward thinkers and design programs that meet the needs of tomorrow, not of today. We must also remember that we advocate for the child above all else. History verifies that the age of accountability is widening and childhood is diminishing. What is going to be done to stop this trend while supporting the needs of working families and the developmental needs of children? Parents and educators will provide personal insights to enrich this unsettled air of whether we should continue tinker at the edges of public education to consider what is best for children and families. 


\section{Chapter FOUR}

\section{RESEARCH DESIGN AND METHODOLOGY}

\section{Introduction}

An extensive literature review was conducted to cognize the history and current situation of preschool education in America, and specifically in West Virginia. The purpose of this study was to gain a qualitative perspective of parents' and teachers' regarding the WV universal pre-kindergarten program.

This research is yielding at a significant moment in the timeline of WV UPK. The 2002 law calls for counties to offer a publicly funded pre-k program to every four-year-old by 20122013. This is determined by being able to accommodate $80 \%$ of the four-year-old population without a waiting list (Cavalluzzo, et al., 2009). Participation is voluntary, but availability is required. The research questions posed in this study determined how the individuals most intimately (e.g. children, parents, and teachers) involved with and affected by WV universal prekindergarten program deem its significance.

\section{Problem and Purposes Overview}

There are 105,393 residents of West Virginia that are age four and under. 67,000 (approximately 64\%) of the children are members of families with both parents in the labor force or are members of a single parent family in which the parent works. The total number of children that all child care centers or family child care homes combined can accommodate is 26,546 , but only a marginal percent of these accommodations are nationally recognized for quality. Full-time childcare tuition for a four-year-old in West Virginia averages at $\$ 5,800$ 
annually. College tuition for undergraduates in West Virginia averages at \$5,049 annually (NACCRRA, 2011).

There is a dire need to address childcare access, quality, and affordability in West Virginia. The West Virginia State Board of Education addressed this need with Policy 2525. The supporting bills mandate that four-year-olds have access to a high quality, free prekindergarten program by the year 2012. WV has risen to the task to support working families with childcare matters in the arena of the public school system. This research examined parents' and teachers' perspectives on specific issues relating to the WV universal prekindergarten program.

\section{Research Questions}

RQ1. Why are children participating in public pre-kindergarten programs in WV?

RQ2. How would parents and teachers adapt the structure of the WV universal prekindergarten program?

RQ3. What do parents and teachers perceive as the outcomes of WV UPK?

RQ4. What do parents and teachers perceive as successful elements of the WV universal preschool program?

RQ5. What do parents and teachers perceive as challenging elements of the WV universal preschool program?

RQ6. How do parents and teachers think that the WV universal pre-kindergarten program should proceed in the future? 


\section{Study Procedure}

\section{Research Framework}

A phenomenological approach was the research framework used for this study. Phenomenological research explores, describes and analyzes the meaning of an individual's lived experience. Participants were engaged in a phenomenological framework research because they were asked to share with the researcher how they perceived, described, felt about and judged their personal experiences with UPK. In-depth interviews were at the heart of this approach and this research project, which allowed the phenomenology to be a complementary framework (Marshall \& Rossman, 2011).

\section{$\underline{\text { Research Sites }}$}

Forty-eight percent of children participating in pre-kindergarten in West Virginia in 2006-07 qualified for free or reduced lunch. Seventeen percent received special education services (Cavalluzzo, et al., 2009). These two conditions are limiters for qualification of pre-k services in many states, but not in WV.

In WV, the average participation for rural counties is $48 \%$ and $35 \%$ for non-rural counties. (Cavalluzzo, et al., 2009). This research focused on two public schools and two collaborative-based classrooms in a child care setting. Two rural sites (West End Elementary and Happy Hands Child Care) and two non-rural sites (Novell Elementary and Cottage Child Care) served as the research sites. The public sites each had two pre-k classrooms, but only one from each participated in the study. The demographics of these schools were more dissimilar than similar allowing the researcher to generate potentially differing viewpoints based on 
family lifestyle and school composition. The following table illustrates the similarities and differences amongst the research sites.

Table 1: Demographics of Pre-k Research Sites

\begin{tabular}{|c|c|c|c|c|}
\hline & $\begin{array}{l}\text { West End } \\
\text { Elementary }\end{array}$ & Novell Elementary & Cottage Child Care & $\begin{array}{l}\text { Happy Hands Child } \\
\text { Care }\end{array}$ \\
\hline Composition & $\begin{array}{l}\text { Public school } \\
\text { classroom }\end{array}$ & $\begin{array}{l}\text { Public school } \\
\text { classroom }\end{array}$ & $\begin{array}{l}\text { Child care center } \\
\text { collaborative site }\end{array}$ & $\begin{array}{l}\text { Child care center } \\
\text { collaborative site }\end{array}$ \\
\hline Locale & rural area & mid-size city & mid-size city & rural area \\
\hline Title I & Yes & No & $\mathrm{n} / \mathrm{a}$ & $\mathrm{n} / \mathrm{a}$ \\
\hline Total Enrollment & 370 & 750 & 33 & 100 \\
\hline Pre-k Enrollment & $18 / 15$ & $18 / 12$ & 10 & 13 \\
\hline $\begin{array}{l}\text { Pre-k } \\
\text { Classrooms }\end{array}$ & 2 & 2 & 1 & 1 \\
\hline $\begin{array}{l}\text { Pre-k First } \\
\text { Offered }\end{array}$ & 2005 & 2007 & 2006 & 2008 \\
\hline Income Statistics & $\begin{array}{l}\text { Free lunch: } \\
41.6 \% \\
\text { Reduced lunch: } \\
13.2 \%\end{array}$ & $\begin{array}{l}\text { Free lunch: } 25.6 \% \\
\text { Reduced lunch: } \\
6.7 \%\end{array}$ & $\begin{array}{l}\text { Free lunch: } 3 \% \\
\text { Reduced lunch: } 6 \%\end{array}$ & $\begin{array}{l}\text { Free lunch: } 55 \% \\
\text { Reduced lunch: } 8 \%\end{array}$ \\
\hline $\begin{array}{l}\text { Ethnicity } \\
\text { Distribution }\end{array}$ & $\begin{array}{l}\text { Non-Hispanic } \\
\text { White: } 99 \% \\
\text { Other: } 1 \%\end{array}$ & $\begin{array}{l}\text { Non-Hispanic } \\
\text { White: } 73 \% \\
\text { Asian or Asian } \\
\text { American: } 14 \% \\
\text { African American or } \\
\text { Black: } 10 \%\end{array}$ & $\begin{array}{l}\text { Non-Hispanic } \\
\text { White: } 70 \% \\
\text { Asian or Asian } \\
\text { American: } 30 \%\end{array}$ & $\begin{array}{l}\text { Non-Hispanic } \\
\text { White: } 89 \% \\
\text { African American or } \\
\text { Black: } 10 \% \\
\text { Asian or Asian } \\
\text { American: } 1 \%\end{array}$ \\
\hline
\end{tabular}

(Data provided by each school, July, 2012)

\section{Ethical Assurances}

The research received approval from West Virginia University's Institutional Review Board prior to the start of the research project. This study sought to evaluate the perceptions of parents and educators and did not directly involve research on any of the pre-kindergarten 
children. Research participants were asked to reflect on how West Virginia's UPK programs influenced the children; this study did not examine student performance.

Permission for this study was granted based on the assurance that the confidentiality and condition of the participants and pre-k sites was protected. The school names, locations, and names of participants mentioned in this study are pseudonyms.

\section{Participants}

The perceptions of the parents and teachers were evaluated qualitatively using openended interview questions. The study sample consisted of three parents from each prekindergarten classroom, for a total of twelve parent participants. Each of the classroom teachers were interviewed as well, for a total of four educator participants. There were sixteen participant perspectives analyzed in this study.

The parents were chosen for the study by random sampling and then contacted phone or email by the researcher. The researcher selected the participants by the assignment of the child's rank based on the children's last names. Children who were alphabetically assigned to numbers three, six, and nine were initially selected and the alternate numbers were one, five, and eleven. When additional participants were needed because of lack of response or refusal from the first six parents, guidance was sought from the teachers.

Parent participants who were selected for inclusion in the study were invited to participate by a consent letter that was sent home directly with the parent or the child from the child's teacher. The interview questions were included with the consent letter as well as a return envelope. A reminder postcard was sent home the day before the return date for the 
form. If the parent did not return the signed consent form by the designated date to the child's teacher, alternate parent participants were contacted. Teachers were initially contacted prior to the study to indicate if they were interested in the study and to give verbal permission for participation. A written consent was obtained at the formal start of the research by means of the consent letter and enclosed interview questions.

\section{Data Collection and Analysis}

In developing the research questions, the researcher considered the topics of personal and professional concern that have been scarcely addressed in research, but identified as central questions (Zaslow, M., 2011). The questions were organized into three distinct themes: the children, the composition, and the future. Each matter was guided by open-ended questions to initiate the response to the specific query. The interviews were audio recorded for reliability and accuracy.

The purpose of this study was to analyze parental and educator insights concerning the execution of West Virginia's universal pre-kindergarten programs. They were asked to discuss the needs of pre-kindergarten aged children, the needs of parents, their feelings about UPK participation, and the future of state-funded pre-k.

One of the best and most effective ways to assess consumer stakeholder's perceptions is via qualitative analysis (Gibbs, 2007; Lindlof \& Taylor, 2002). The interview style was semistructured and had a pre-determined and limited set of questions; the research method was open-ended. The researcher had the same open-ended questions that were asked to all interviewees, but accommodated other matters that resulted from during the interviewee 
responses to gain the most meaningful human communication (Gibbs, 2007; Lindlof \& Taylor, 2002). The technique used for theming data was open coding and the research attempted to have no preconceptions so to allow the themes to naturally arise from the human meaningful communication that was collected during the interviews. Grounded theory was utilized to allow the themes to emerge and be supported by the data (Gibbs, 2007).

The main goal of this study was to seek and achieve a deep understanding of the human feelings pertaining to universal pre-k in WV; a phenomenological approach. The researcher anticipated revealing the story behind the parent and educator experience. Understanding was developed inductively; as interviews were conducted exploratory knowledge was tested against the knowledge that was being gained from current interviews. The types of topics in questions that were explored were: opinions/values (what the participant thought about the topic), feelings (what a participant felt about the topic), and knowledge (to get facts about topic) (Lindlof \& Taylor, 2002).

The sixteen participants had the right to decide if they wanted the interview to be conducted as a phone interview or personal, face-to-face interview. Parents and educators were informed that their participation was voluntary and they were asked to make a contribution of approximately one hour of their time for the interview. All interviews were administered at the convenience of the interviewee. Personal interviews were administered at a public location that was mutually agreed upon, but had minimal distraction, or the participant's home upon their invitation.

A blind participant demographic questionnaire was completed by each participant at the start of interview to provide background information that may influence the data. Participants 
had the choice of completing all, some, or none of the questions (i.e. all participants: age, sex, race/ethnicity, marital status, employment status, education completed, family size, household income; parent participants only: parent occupation(s), specifics about their pre-k aged child; teacher participants only: teaching experience and certification) then inserted the questionnaire into an envelope and a folder so that the demographic profile was not matched with participants. Prior to the interview, the participant was briefed on the purpose of the interview, the terms of confidentiality, the format and expected length of the interview, and contact information for the researcher. The researcher clarified any doubts, questions, or concerns of the participant prior to starting the interview. Interviews were audio recorded and the researcher took notes as a precautionary to media failure. Participants were identified by their pseudonym school and as Parent 1, Parent 2, Parent 3, or Teacher in the documentation process. Parents and educators were asked the same interview questions, which were semistructured, open-ended. The researcher interviewed the participants individually, allowing for unique situations and responses to arise. The interview questions served as probe questions, but were not all-inclusive in order to accommodate firsthand material. At the completion of the interview, each participant was given a fifteen dollar gift card incentive to Wal-Mart, which was disclosed in the consent letter.

The interviews were transcribed by a hired transcriptionist and verified by the researcher. The interviews were coded and analyzed to allow for understanding of the universal pre-kindergarten phenomenological data from the perspectives of parents and teachers. The researcher identified the themes that emerged by identifying critical elements that recurred in the conversations - giving meaning to the data through the analysis. The analysis of the 
interview data allowed the researcher to identify parents' and teachers' points of views and feelings relating to WV universal pre-kindergarten programs. Biases of analysis were minimized by an inductive approach to analyzing and organizing the transcribed data (Straus \& Corbin, 1990).

Responses were transcribed and themed to facilitate data. Three tiers of analyses were performed to allow the researcher to categorize, understand, and clarify the data. In the first tier of analysis, key words were separated from the conversation to allow for the themes to begin emerging naturally. In the second tier, these keywords were put back into context and isolated to the research question that they addressed. The theming in the second tier analysis was divided according to the corresponding participant and school. In the third tier, the key words were separated from the context and assigned to the theme in which they represented. These key words became the defining elements of the categories that emerged from the data. A doctoral student with a research interest and experience in early childhood education and qualitative studies analyzed the themes and categories found in three interviews-one teacher and two parental. The perspectives of the checker matched $100 \%$ with the themes and categories identified by the researcher.

\section{Limitations}

Although this research was limited to four pre-kindergarten programs in two neighboring counties, the findings, conclusions and recommendations may be applicable throughout the state of West Virginia and possibly across the nation regarding state-funded pre-k programs. Evaluations of the perspectives of parents and teachers involved in these 
public universal pre-kindergartens may be helpful in steering the direction of forthcoming decisions statewide and possibly nationwide.

\section{Summary}

Preschool programs, including state-funded pre-kindergartens, have been proven in literature to positively impact a child's short and long-term outcomes. Therefore, it is of great importance to guide the profession in making informed decisions regarding the future goals and expectations of public pre-kindergarten. This research will challenge key decision makers in considering what the needs of children and parents are and how they are best met through public funding.

It is anticipated that the findings of this data will guide certain aspects of Policy 2525 in the years beyond full implementation, which is occurring within the next year. Seeking the qualitative input from parents and educators are perspectives that are not often collected, but are important viewpoints to consider. Understanding the needs, challenges, and sentiments of these research participants are critical as states continue to implement and expand their public pre-kindergarten programs. 


\section{Chapter FIVE}

\section{RESULTS}

\section{Demographic Results}

Twelve parents and four teachers completed a pen and paper participant demographic questionnaire form prior to the interview $(n=16)$. Anonymity was assured and demographic data is not linked to interview data. Four participants were male (one teacher, three parents), 12 were female (three teachers, nine parents). Participants reported an average age of 34 years for parents and 38 years for teachers, with a range of $24-38$ and a mode of 36 and 38 for parents, and a range of 27-47 for teachers. Fifteen of the respondents self-identified as NonHispanic White and one parent as Black or African American. More respondents described themselves as having a relationship status of married (parent $n=11$, teacher $n=3$ ) than never been married (parent $n=1$, teacher $n=1$ ). Parental employment status consisted of primarily employed for wages $(n=9)$, as well as homemaker $(n=2)$, and student $(n=1)$. Respondent education level ranged from $67 \%$ of parents identifying as having a bachelor's degree or higher (bachelor's $n=3$, master's $n=4$, doctorate $n=1$ ), $17 \%$ as having an associate degree $(n=2)$, a high school degree $(n=1)$, and prefer not to answer $(n=1)$. Seventy-five percent $(n=3)$ of teachers held a bachelor's degree and one held a master's degree. The participants reported total household incomes of $\$ 10,000-\$ 19,999$ (parent $n=2$, teacher $n=1$ ), $\$ 20,000-29,000$ (parent $n=2$ ), $\$ 40,000-49,000$ (parent $n=1), \$ 90,000-99,000$ (parent $n=2$, teacher $n=2$ ), $\$ 100,000-\$ 149,000$ (parent $\mathrm{n}=3$, teacher $n=1)$, and $\$ 150,000$ or more (parent $n=2$ ).

Parents spoke on the experiences of fourteen children because there were two sets of twins represented in the study. Forty-three percent $(n=6)$ of children represented had one 
sibling, 29\% ( $n=4)$ was an only child, $7 \%(n=1, n=1)$ had two or three siblings respectively, and $17 \%(n=2)$ had four siblings. Roughly equal numbers of children were male $(n=8)$ and female $(n=6)$. The most frequently occurring age of the pre-k child participant was four-andone-half ( $n=9$ ) with a range of three-and-one-half to five-and-one-quarter. The majority of children were cared for a parent at home $(n=4)$ or by a childcare/daycare center $(n=4)$ prior to enrollment in WV's UPK program. Other children were cared for equally by a relative caregiver $(n=2)$, non-relative caregiver $(n=2)$, or a combination of parent at home and childcare/daycare center $(n=2)$. Zero children were cared for by an in-home provider. Parent participant occupations included the following: senior sales manager, career counselor, human resources professional, adjunct professor, director of educational office, homemaker $(n=2)$, customer service representative, data processing $(n=2)$, finance and student. Non-participant parent occupations included the following: foreman for coal/natural gas company, corporate trainer, student, accounting, IT manager, medical sales manager, and senior manager of global travel.

The average overall years of teaching experience for teacher participants was sevenand-one-quarter (three, five, six, and 15 years). Two teachers only had experience teaching in a private setting, and two teachers only had experience in a public setting. The years of experience in a WV UPK program were two, three, four, and five. All self-reported teaching certifications were different (early childhood, preschool special needs/autism b-0k, pre-k and elementary, K-6). One teacher had zero experience working with other ages or grades, one worked with children birth to three, one taught kindergarten, second, and forth, and one had experience as a substitute teacher. 
Table 2: Demographics of Parent Interviewees

\begin{tabular}{|c|c|c|c|c|c|c|c|c|c|c|}
\hline Sex & Age & $\begin{array}{l}\text { Race/ } \\
\text { Ethnicity }\end{array}$ & Marital Status & Education & $\begin{array}{l}\text { Number of } \\
\text { Children }\end{array}$ & $\begin{array}{l}\text { Household } \\
\text { Income }\end{array}$ & Occupations & $\begin{array}{l}\text { Child's prior } \\
\text { Care Arrangement }\end{array}$ & $\begin{array}{l}\text { Child's Birthdate } \\
\text { \& Sex }\end{array}$ & $\begin{array}{c}\text { Child's } \\
\text { Classroom Type }\end{array}$ \\
\hline $\mathrm{F}$ & 29 & $\begin{array}{l}\text { Non-Hispanic } \\
\quad \text { White }\end{array}$ & Married & $\begin{array}{l}\text { Grade } 12 \\
\text { or GED }\end{array}$ & 3 (ages 5-12) & $\begin{array}{c}100,000- \\
149,999\end{array}$ & $\begin{array}{c}\text { Homemaker/ } \\
\text { Foreman for Coal/Natural Gas Co. }\end{array}$ & Parent at home & $\begin{array}{l}\text { Sep-06 } \\
\text { M }\end{array}$ & Elementary \\
\hline \multirow[t]{2}{*}{$\mathrm{F}$} & 35 & Black or & Married & Associate's & $1(<5)$ & $10,000-$ & Student/ & Parent at home & May-08 & Elementary \\
\hline & & African American & & & 1 (ages 5-12) & 19,000 & Student & & $\mathrm{F}$ & \\
\hline $\mathrm{F}$ & 24 & $\begin{array}{l}\text { Non-Hispanic } \\
\text { White }\end{array}$ & $\begin{array}{l}\text { Never been } \\
\text { married }\end{array}$ & Associate's & $2(<5)$ & $\begin{array}{l}10,000- \\
19,000\end{array}$ & Customer Service Rep. & Parent at home & $\begin{array}{c}\text { Jul-07 } \\
\mathrm{F}\end{array}$ & Elementary \\
\hline \multirow[t]{2}{*}{ M } & 36 & Non-Hispanic & Married & Master's & $1(<5)$ & $150,000+$ & Human Resources/ & Relative caregiver & na & Elementary \\
\hline & & White & & & 1 (ages 5-12) & & Accounting & & $\mathrm{F}$ & \\
\hline M & 36 & $\begin{array}{l}\text { Non-Hispanic } \\
\text { White }\end{array}$ & Married & Master's & 1 (ages 5-12) & $\begin{array}{l}90,000- \\
99,999\end{array}$ & $\begin{array}{l}\text { Career Counselor/ } \\
\text { Director }\end{array}$ & $\begin{array}{c}\text { Childcare/ } \\
\text { Daycare center }\end{array}$ & $\begin{array}{l}\text { Aug-06 } \\
\text { M }\end{array}$ & $\begin{array}{c}\text { Childcare/ } \\
\text { Daycare center }\end{array}$ \\
\hline \multirow[t]{2}{*}{$\mathrm{F}$} & 38 & Non-Hispanic & Married & Bachelor's & $2(<5)$ & $150,000+$ & Homemaker/ & Parent at home & Sep-06 & Elementary \\
\hline & & White & & & 2 (ages 5-12) & & Medical Sales Manager & & M & \\
\hline $\mathrm{F}$ & 29 & $\begin{array}{l}\text { Non-Hispanic } \\
\text { White }\end{array}$ & Married & Bachelor's & $1(<5)$ & $\begin{array}{l}20,000- \\
29,999\end{array}$ & $\begin{array}{l}\text { Data processing/ } \\
\text { Data processing }\end{array}$ & Non-relative caregiver & $\begin{array}{l}\text { Jun-07 } \\
\text { M }\end{array}$ & $\begin{array}{c}\text { Childcare/ } \\
\text { Daycare center }\end{array}$ \\
\hline \multirow[t]{2}{*}{$\mathrm{F}$} & 36 & Non-Hispanic & Married & Doctorate & $3(<5)$ & $40,000-$ & Adjunct Professor/ & Parent at home \& & Jul-07 & Childcare/ \\
\hline & & White & & & 2 (ages 5-12) & 49,000 & IT Manager & Childcare/Daycare center & F (twins) & Daycare center \\
\hline $\mathrm{F}$ & 38 & $\begin{array}{l}\text { Non-Hispanic } \\
\quad \text { White }\end{array}$ & Married & Bachelor's & $2(<5)$ & $\begin{array}{l}100,000- \\
149,999\end{array}$ & $\begin{array}{c}\text { Sr. Sales Manager/ } \\
\text { Sr. Manager Global Travel }\end{array}$ & $\begin{array}{c}\text { Childcare/ } \\
\text { Daycare center }\end{array}$ & $\begin{array}{l}\text { Jun- } 07 \\
M \text { (twins) }\end{array}$ & $\begin{array}{c}\text { Childcare/ } \\
\text { Daycare center }\end{array}$ \\
\hline \multirow[t]{2}{*}{$M$} & 31 & Non-Hispanic & Married & Prefer not & $1(<5)$ & $20,000-$ & Data Processing/ & Non-relative caregiver & Jun-07 & Childcare/ \\
\hline & & White & & to answer & & 29,999 & Data Processing & & M & Daycare center \\
\hline $\mathrm{F}$ & 38 & $\begin{array}{l}\text { Non-Hispanic } \\
\text { White }\end{array}$ & Married & Master's & 1 (ages 5-12) & $\begin{array}{l}90-000- \\
99,999\end{array}$ & $\begin{array}{l}\text { Director of Educational Office/ } \\
\text { Career Counselor }\end{array}$ & $\begin{array}{l}\text { Childcare/ } \\
\text { Daycare center }\end{array}$ & $\begin{array}{l}\text { Aug-06 } \\
\text { M }\end{array}$ & $\begin{array}{l}\text { Childcare/ } \\
\text { Daycare center }\end{array}$ \\
\hline \multirow[t]{2}{*}{$\mathrm{F}$} & 35 & Non-Hispanic & Married & Master's & $1(<5)$ & 100,000 & Finance/ & Relative caregiver & May-07 & Elementary \\
\hline & & White & & & 1 (ages 5-12) & 149,999 & Corporate Training & & $\mathrm{F}$ & \\
\hline
\end{tabular}

Table 3: Demographics of Teacher Interviewees

\begin{tabular}{|c|c|c|c|c|c|c|c|c|c|c|c|}
\hline Sex & Age & $\begin{array}{l}\text { Race/ } \\
\text { Ethnicity }\end{array}$ & Marital Status & Education & $\begin{array}{l}\text { Number } \\
\text { of Children }\end{array}$ & $\begin{array}{l}\text { Household } \\
\text { Income }\end{array}$ & $\begin{array}{l}\text { Overall Years } \\
\text { of Experience }\end{array}$ & $\begin{array}{c}\text { Years of Experience } \\
\text { Private - Public }\end{array}$ & $\begin{array}{c}\text { Years of Experience } \\
\text { WV UPK }\end{array}$ & $\begin{array}{l}\text { Teaching } \\
\text { Certification }\end{array}$ & $\begin{array}{l}\text { Teaching } \\
\text { Experience }\end{array}$ \\
\hline $\mathrm{F}$ & 27 & $\begin{array}{c}\text { Non-Hispanic } \\
\text { White }\end{array}$ & Married & Bachelor's & $1(<5)$ & $\begin{array}{l}100,000- \\
149,999\end{array}$ & $6+$ & $0-6$ & 2 & $K-6$ & K-6 sub. \\
\hline$F$ & 40 & Non-Hispanic & Married & Master's & 2(ages 5-12) & $90-000-$ & 5 & $0-5$ & 5 & Preschool Special Needs/ & birth-3 \\
\hline & & White & & & & 99,999 & & & & Autism B-OK & \\
\hline$F$ & 47 & $\begin{array}{c}\text { Non-Hispanic } \\
\text { White }\end{array}$ & Married & Bachelor's & 0 & $\begin{array}{l}90-000- \\
99,999\end{array}$ & $3+$ & $3-0$ & $3+$ & Early Childhood & n/a \\
\hline M & 37 & Non-Hispanic & Never been & Bachelor's & 0 & 10,000 & 15 & $15-0$ & 4 & Pre-K\& Elementary & $K, 2,4$ \\
\hline & & White & married & & & 19,000 & & & & & \\
\hline
\end{tabular}




\section{Preface to the Interview Results}

Permission to access parents and teachers for interviews was granted by the county superintendents and each program's principal or director. Once administrative approval was gained, teachers assisted in attaining parent participants. Consent letters were mailed to the teachers and teachers disseminated letters to the appropriate families either by direct hand delivery to the parents or sent home with the child. At two sites, Novell and Happy Hands, three participants were acquired through the original six letters (three for the first selection and three alternates). West End and Cottage required much more follow-up to obtain three participants. The teachers assisted with verbal and email reminders for the six selected families, but eventually they recommended families that they felt would be willing participants due to high refusal and non-response rates.

When consent letters were returned, the teachers were phoned and they provided the parents' names and contact information so that I could proceed with scheduling interviews. The consent forms were acquired at the site locations; three while interviewing the teachers and one visit to specifically acquire the forms. Three teachers were interviewed at their schoolstwo on Fridays during planning time (public school sites) and one on a Wednesday during nap time (private center). One teacher met me at a public place after hours. Fifty-eight percent of parents $(n=7)$ preferred for me to interview them in their homes. Six of the seven participants had their pre-k-aged children at home with them during the interview (three evening interviews, two Saturday interviews, one Friday interview) and the other participant had a younger child at home during the interview. The pre-k children either played in a separate area or were tended to by the other parent during the interviews. One parent was interviewed over 
the phone due to scheduling conflicts on the interviewee's end. Four parents selected to be interviewed in a public location. All interviews were conducted at a time and location that was convenient for the participant and occurred from the first week of December 2011 through the third week of January 2012.

I probed extensively during the interviews to capture the full-range of the parents' and teachers' experiences. All participants were assured that their responses would be kept in strict confidence so that they would be comfortable revealing their authentic positive and negative experiences. Overall, participants were not reluctant to provide their feedback. They seemed passionate to share about the children's early childhood education experiences and appeared to reveal heart-felt attitudes and insights. For some parents, it was an opportunity for their voice to be heard about difficulties they had experienced and those happenings became their primary focus, which they related to many of the interview topic and questions that were not specifically related to their concerns.

\section{Interview Results}

Semi-formal, recorded, and transcribed interviews were conducted with twelve parent participants and four teacher participants, equally representing four research sites. The qualitative dialogue occurred over a period of one-and-a-half months. The average interview

length was 39 minutes, with a range of 21 to 64 minutes. Using the research themes-children, composition, and future-as an organizational method for this chapter, the following results emerge. 


\begin{tabular}{|c|c|c|c|c|c|}
\hline $\mathrm{RQ}$ & Theme & Subtheme & Sample Quote & $n$ & $\%$ \\
\hline \multirow[t]{6}{*}{$R Q 1$} & Children & & & & \\
\hline & Socialization & & $\begin{array}{l}\text { "Mine personally, was he needed to learn how to interact with other } \\
\text { kids his age and other adults. He ended up having a really bad case of } \\
\text { stranger anxiety to the point where we would go to church and scream } \\
\text { and be scared. He never dealt with kids his age because he has two } \\
\text { older brothers. I wanted him to meet kids he would be going on through } \\
\text { his school years with" (West End, Parent 3). }\end{array}$ & 13 & $81 \%$ \\
\hline & $\begin{array}{l}\text { Kindergarten } \\
\text { Preparation }\end{array}$ & & $\begin{array}{l}\text { "I would say the regimen of getting into habits such as going to school. } \\
\text { Getting them to enjoy school rather than just throwing them in like with } \\
\text { kindergarten. With pre-K it gives them a heads up with what to expect } \\
\text { in the years to come" (Novell, Parent 1). }\end{array}$ & 16 & $100 \%$ \\
\hline & $\begin{array}{l}\text { Working } \\
\text { Parents }\end{array}$ & & $\begin{array}{l}\text { "I wanted to go back to school for some time but haven't been able to } \\
\text { do that. Daycare is so expensive and my husband is a student as well. } \\
\text { Rather than daycare, we decided for me to stay at home and once they } \\
\text { got to school age I would go back to school" (Novell, Parent 2). }\end{array}$ & 14 & $88 \%$ \\
\hline & Environment & & $\begin{array}{l}\text { "The need for us is we need to have a secure environment for the kids } \\
\text { during the day. We want the continuous learning, we want the } \\
\text { structure, and we want the discipline" (Cottage, Parent 1). }\end{array}$ & 12 & $75 \%$ \\
\hline & $\begin{array}{l}\text { Lack of } \\
\text { Confidence in } \\
\text { Own Ability }\end{array}$ & & $\begin{array}{l}\text { "I do not feel equipped to teach them what they need to know. I have } \\
\text { the skills, but I don't know how to teach the skills to them" (Happy } \\
\text { Hands, Parent 1). }\end{array}$ & 7 & $44 \%$ \\
\hline
\end{tabular}

Children

Socialization

\begin{tabular}{|l|l|}
\hline Skills & $\begin{array}{l}\text { "Probably the social and emotional development. They learn how to get } \\
\text { along with others and to express themselves in other ways; they might } \\
\text { not get the opportunity to otherwise." " (West End, Teacher). }\end{array}$ \\
\hline "Without the program I don't think that they will know all that stuff, I \\
know that I couldn't teach that that anymore. With the teachers they \\
know that is the time for learning and they are little sponges. They \\
absorb and absorb" (Cottage, Parent 1).
\end{tabular}




\begin{tabular}{|c|c|c|c|c|c|}
\hline $\begin{array}{c}\mathrm{RQ} \\
R Q 2 / R Q 5\end{array}$ & Theme & Subtheme & Sample Quote & $n$ & $\%$ \\
\hline \multirow[t]{8}{*}{$R Q 2 / R Q 5$} & Composition & & & & \\
\hline & Program & & & & \\
\hline & Structure & & & & \\
\hline & & $\begin{array}{l}\text { Staffing and } \\
\text { Ratios }\end{array}$ & $\begin{array}{l}\text { "Maybe number of students in the class. With more students there } \\
\text { should be more assistants. The teachers try their best to manage but it } \\
\text { isn't easy" (Novell, Parent 2). }\end{array}$ & 9 & $56 \%$ \\
\hline & & Scheduling & $\begin{array}{l}\text { "If it weren't having grandparents out this way to get them to school } \\
\text { and off the bus, I don't know how people do it with the times that are } \\
\text { available and the Fridays off" (West End, Parent 2). }\end{array}$ & 9 & $56 \%$ \\
\hline & & $\begin{array}{l}\text { Inclusive } \\
\text { Classrooms }\end{array}$ & $\begin{array}{l}\text { "In a lot of classes generalizations are being made that it is just ok to } \\
\text { have the two [teachers]. When they go to kindergarten, they have and } \\
\text { aid and the teacher. If they have a child with special needs, there is } \\
\text { going to be a special needs aid or a special needs teacher pull him out, } \\
\text { so why can't that be the case with preschool?...If you could have those } \\
\text { supports in place in higher grades why can't you have those supports in } \\
\text { place here?" (Novell, Teacher) }\end{array}$ & 6 & $38 \%$ \\
\hline & & $\begin{array}{l}\text { Concerns about } \\
\text { Availability and } \\
\text { Equality }\end{array}$ & $\begin{array}{l}\text { "That would be a concern to me as a parent that there are people out } \\
\text { there that aren't as fortunate as us that aren't able to afford [Cottage's] } \\
\text { extra charges. That would be my concern, it doesn't really affect us, that } \\
\text { there isn't enough space out there for the pre-K aged kids. That there } \\
\text { might not be enough room in the school system for the kids who need } \\
\text { it, in the public school setting" (Cottage, Parent 3). }\end{array}$ & 9 & $56 \%$ \\
\hline & & Environment & $\begin{array}{l}\text { "The location is difficult because the pre-K room is right off of an infant } \\
\text { room, so the environment could be a little less distracting" (Happy } \\
\text { Hands, Teacher). }\end{array}$ & 7 & $44 \%$ \\
\hline
\end{tabular}

Better

Integration

with School

System

Enrollment

Process

Special Needs

Program

Awareness and

Communication

Teacher's Voice
"When we went to the pre-K round up and with [that public school] the atmosphere and the size of that school was very intimidating for [my daughter]. If we lived in town I would have a few more reservations about having the pre- $K$ inclusive with the rest of the school with those being much larger" (West End, Parent 2).

"I don't think it's anything wrong with [Happy Hands] per say, I'm just saying the integration of the services with the system I don't feel is adequate" (Happy Hands, Parent 3).

"I don't think people fully know that UPK even exists. I just happened upon it by talking to people" (Novell, Parent 3).

"My only interaction with that is when I go to trainings off property. I don't have someone else there to bounce ideas off of or have and aid or someone else to work together on things. A lot of times the information comes last minute and now there's a training session of Friday, if it wasn't already on our calendar the public schools are closed to children on Friday, it's teacher planning day, well it's not a big deal for them to go if it's a planning day. But if it's for us, the collaborative sites, you're all of a sudden scrambling to find a substitute, and you're trying to set things up in your classroom" (Cottage, Teacher). 


\begin{tabular}{|c|c|c|c|c|c|}
\hline $\mathrm{RQ}$ & Theme & Subtheme & Sample Quote & $n$ & $\%$ \\
\hline & Philosophy & & & & \\
\hline & & Pedagogy & $\begin{array}{l}\text { "Start teaching them languages; have it learning based and not really } \\
\text { play based. Children learn at an earlier age, but if it is play based-I } \\
\text { don't know if earlier would have any benefits" (West End, Parent 3). }\end{array}$ & 7 & $44 \%$ \\
\hline & & $\begin{array}{l}\text { Classroom } \\
\text { Communication }\end{array}$ & $\begin{array}{l}\text { "I'm just always working and then on Thursdays and Fridays I just have } \\
\text { to take care of everything. I had a parent teacher conference and I } \\
\text { missed it twice, I felt horrible. I just haven't had a chance to go in, sit } \\
\text { down, and watch them" (Novell, Parent 1). }\end{array}$ & 5 & $31 \%$ \\
\hline & Guilt Factor & & $\begin{array}{l}\text { "The only thing I can say as a parent, I look at me and say 'I'm not there } \\
\text { three days a week for my child.' I want to know if morals and good } \\
\text { values are being instilled upon them. Am I being a good parent or are } \\
\text { they someday going to be upset that they spent five days a week at } \\
\text { daycare? Sometimes I have to think, 'Am I doing the right thing?' My } \\
\text { husband and I look at ourselves and we think we are. The kids are really } \\
\text { happy and they seem to have adjusted...But you can't help but wonder } \\
\text { twenty years from now when they are young adults, did we make the } \\
\text { best decision and are they are doing the best they can with their family } \\
\text { situation in the future. It's more on our end saying, 'Did we do the right } \\
\text { thing?'” (Cottage, Parent 1). }\end{array}$ & 4 & $25 \%$ \\
\hline \multirow[t]{2}{*}{$R Q 4$} & Composition & & & & \\
\hline & $\begin{array}{l}\text { Overall } \\
\text { Satisfaction }\end{array}$ & & $\begin{array}{l}\text { "I would have to think pretty hard to come up with a complaint. We are } \\
\text { among the luckiest parents around; [my son] has had two years with } \\
\text { [his teacher] and the other kids there. I don't think I would have any } \\
\text { complaints, at least not now" (Cottage, Parent 3). }\end{array}$ & 13 & $81 \%$ \\
\hline
\end{tabular}

Philosophy

Pedagogy

Classroom

Communication

Program

Structure
"I really like the flexibility. You're not stuck to a curriculum. You might go in thinking you are going to do something, but there is always a different route. It's an adventure and you never know what is going to happen" (Happy Hands, Teacher).

"As far as our situation, I have daily contact with the parents and I don't

know how it happens in the public school system. But we see the parents on a daily basis so we are able to give them feedback on what's going on, we have a meeting with them in the fall and the spring to give them feedback and in between contact if it's necessary" (Cottage,

Teacher).

\begin{tabular}{|l|l|} 
Integration & "We are a Head Start family and other kids don't know that so there is \\
& never that depiction of bullying. Things like that and the fact that they \\
are not [in the same building] with the [older] kids, if they were in the \\
rest of kids I think that would be very overwhelming. I'm comfortable \\
with how they do things on their own, yet they still are part of the \\
school (Novell, Parent 1). \\
"I like how they bring all the kids in at the beginning and they do the \\
hearing, eyes, and speech. I learned a lot just by sitting in those settings \\
with [my son]. Just making sure your child is developmentally in the \\
right place. I think that it is good that they do them for every child. I like \\
the standards across the board. I think that it is good to get an early \\
start because you're going to be going to kindergarten the next year and \\
it's all day kindergarten. That's a lot for a five year old to start straight \\
into kindergarten" (Cottage, Parent 2).
\end{tabular}




\begin{tabular}{|c|c|c|c|c|c|}
\hline $\mathrm{RQ}$ & Theme & Subtheme & Sample Quote & $n$ & $\%$ \\
\hline & & Scheduling & $\begin{array}{l}\text { "No, I think it is good. I like the four full days and Fridays off" (West End, } \\
\text { Parent 3). }\end{array}$ & 9 & $56 \%$ \\
\hline & & $\begin{array}{l}\text { Staffing and } \\
\text { Ratios }\end{array}$ & $\begin{array}{l}\text { "That is one thing that I do like about [Novell] is that they have the aides } \\
\text { in pre-K, so they do get the individual attention and it's a smaller class } \\
\text { size" (Parent 1). }\end{array}$ & 7 & $44 \%$ \\
\hline
\end{tabular}

\section{Future \\ Mandatory}

Optional

Support for

Program

Concerns

Three-Year-Old

Program
"Seeing the benefits that it has made for [my son], I would be a proponent for mandatory. Just by seeing the development that it has given him. I'm sure there are reasons for it being optional, but I feel mandatory" (Cottage, Parent 3).

"Optional, definitely. Some kids and families just aren't ready. It's a personal decision. Like you said, they are young. I think while it's a good thing and all children need some type of experience before kindergarten because of what is expected of them. But whether it is a parent or child issue, some people have big issues and to tell them they have to go to school at the age of four is just crazy" (Novell, Teacher).

"They say that most of a child's development comes from three to five, or something like that, when they absorb the most information. So why not start earlier so they can use what they learned in early stages of life throughout their whole life? (Novell, Parent 1)"

"What are they going to do, keep lowering the age where it is mandatory for them to start going to school when they are one? We can pull back the learning as early as we need to...I can understand it as our country is falling behind. But, I don't know if pulling the mandatory age back is the solution" (Parent 2, West End).

I think the thing about targeted programs, it's the parents that come in and enroll the child. You miss the children that really need it, when the parent decides not to enroll their child...And I just think of the child at home not getting as much help as he needs because she is too embarrassed. But if there was a universal program that everyone would have to go to, that would be really great for that child. Part of me says yeah, there should be a universal program that every child goes to when they are three, but it must meet the needs of everyone not just the people who are able to get in or are fortunate. But it's going to be hard to convince everybody of that (Cottage, Parent 2).

\section{Findings Not \\ Tied to the \\ Research \\ Questions}

Pre- Pre-k

Post- Pre-k
"I think whenever you get younger kids you start blurring the lines with the school in terms of parenting and education. They can't do everything, their job is to prepare students but there is still the parental role there. I think parents need more support but I don't know if the school is the right place for that" (Cottage, Parent 2).

"The problem with kindergarten now is the expectations are so high, now you go in and you have to fight to survive. There's a lot of pressure on the children" (Happy Hands, Teacher).

\section{$4 \quad 25 \%$}




\section{Children}

(RQ1: Why are children participating in public pre-kindergarten programs in WV?; RQ3: What do parents and teachers perceive as the outcomes of WV UPK?)

Why are children participating in public pre-kindergarten programs in WV? Socialization

Parents identified the need to provide their children socialization experiences and outlets; therefore they electively enrolled them in the WV UPK program. Some parents expressed the desire to introduce their children to same age peers, "And we also knew that we needed to work on socialization skills with others because they were familiar with just seeing us all the time and our immediate family, so they didn't play with a lot of other kids and they twin talked" (Cottage, Parent 1). Connecting children with future classmates and adults was also identified as important, "Mine personally, was he needed to learn how to interact with other kids his age and other adults. He ended up having a really bad case of stranger anxiety to the point where we would go to church and scream and be scared. He never dealt with kids his age because he has two older brothers. I wanted him to meet kids he would be going on through his school years with" (West End, Parent 3). Other parents wanted their children to have exposure to adult figures other than themselves or family members, “...socialization skills and being outside of parents and grandparents trying to get her interested in learning things" (West End, Parent 2). One parent relented that prior socialization experiences were not adequate, resulting in a perceived disadvantage they felt could have been avoided. She shared, 
We don't qualify for any type of assistance. We were barely scraping by just to pay a sitter. It would have been a lot more money and we would have found a way to pay the money but we had heard all these terrible things. All these are stupid and ridiculous stories. We should have known better than to listen and he wouldn't have as many problems and would be better socialized. (Happy Hands, Parent 2)

All teachers shared these beliefs, one feeling more strongly that the parents were the ones being socialized to the educational experience, Generally we are here for support, we have special education come in and they can ask questions. I have resources I can ask to answer parent's questions. For example one parent was concerned about how his child was crying and having a breakdown when he was dropped off. I told him that is was really all for show, once the parent leaves the child will be playing and having fun with friends, he will be alright. Now the child knows the routine. I help prep the children for kindergarten and help qualm parent's fears. (Happy Hands, Teacher)

The parents' desires to seek out socialization for their child were echoed by teachers as a need for the children to acquire these skills:

Social emotional help. Seriously, whether they have special needs or not they come in here to get their social skills underway. I've had a variety of classes the five years I've been here, but every single class has needed assistance with social skills. Of course they all are learning letters, numbers, and all those academics things but they all need to learn social skills, hands down. (Novell, Teacher) 


\section{Kindergarten preparation}

Preparing children for the expectations of kindergarten was another primary theme expressed by parents and teachers. Exposing children to the school hours, providing the basic skills, learning to focus and be independent, understanding classroom expectations, and listening to others were identified as reasons that children were enrolled in a pre-k program as well as outcomes of their participation.

A teacher from a private center (Cottage) stated, To be able to pick up the basic skills that they will need later on for kindergarten, but in a different sort of way: they are exploring their environment; you're setting up things and activities for them to be able to come to their own conclusion, to make their own predictions, see what happens, and to follow through. Also, to give them the basis to start working on their fine motor skills for writing, for cutting, and basic skills they will need later on in kindergarten. It does seem to me as if it keeps getting pushed down that they are expecting more of them once they hit kindergarten. But it is also trying to prepare them for that.

A parent said the decision was based upon "Again, I needed daycare. I was working full time and I saw that as an advantage. Something that made me feel better about them being in daycare all day is that they were sponsored by the board of education and had a specific curriculum. That they were going to be preparing for kindergarten, not just being watched while I was at work" (Happy Hands, Parent 1). Another parent agreed that the earlier start to formal education would be beneficial for her child, "He missed the cutoff for school by one day and I was think that it was really time for him. I could see that he wasn't really progressing like 
my other two did. I've always heard that the babies usually are. I just thought it was time for him to go and listen to other people and authority and be made to go into a routine" (West End, Parent 3).

Participants also thought that pre-k offered a more gradual transition to school, "I would say the regimen of getting into habits such as going to school. Getting them to enjoy school rather than just throwing them in like with kindergarten. With pre-k it gives them a heads up with what to expect in the years to come" (Novell, Parent 1). Furthermore, “Depending on their home environment, you don't know what kind of basic skills or basic instruction, socializing, even being with other kids in a structured environment. To throw them into a public setting without prior experience would be rather traumatic for the kids" (Cottage, Teacher).

For one family they were concerned at addressing delays prior to kindergarten entrance, "Really we know that he was lacking developmentally for his age and was definitely having problems socially; I think it was the lack of being in social situations. This was the only thing we could do to get him what he need so he would be prepared for school when kindergarten came around" (Happy Hands, Parent 3). For another it was because she wanted to take the most advantage of the school system offerings, "It's because she needs that early start in school. She is a very smart child and has a lot of imagination and creativity. I think to put her in school early will give her the chance to grow and succeed in the future" (Novell, Parent 1).

Again speaking on the comfort level of the parents' first school experience for their child, the teacher from Happy Hands said, 
They are there to learn but also the parent feels better for their child to enter kindergarten, to set a foundation for them, and get them use to being away from mom and dad while being in an environment that is fun while learning. Teaching them problem solving skills, "what do you do when someone is mean to you?" Teach them to use their words.

Receiving support in addressing developmental skills was identified as an additional reason why children were attending pre-k.

At the time she would not sit down and do anything for very long. [My] mom would try and work with her, but only for ten minutes at a time. We wanted her to be more outside of us and my mom and try to get her interested. She knew lots of the stuff we were doing, but she just wouldn't respond to us when we would ask questions; she just didn't want to. The other part with her staying with mom she wasn't around children. (West End, Parent 2)

The teacher from Novell summed up why she feels children are attending her public school program,

When they come in we ask, "What do you expect from your child and for them to gain this year?" I've heard a variety of answers from parents, some say socially interact, and others have never been in a daycare. Some parents say specifically some academic skills. I would say those are the two biggest things. Some of them do need daycare. This is a way for them, if they do have some flexibility, they would send them to our preschool and then send them to regular daycare rather than all day because of the cost. 
Establishing habits, attentiveness, basic skills, supporting acquisition of child development milestones, and an understanding of school culture were the primary themes articulated as defining characteristics of kindergarten preparation. As the Novell teacher answered above, there is also the need for "daycare."

\section{$\underline{\text { Working Parents }}$}

Parent participants sought pre-k experiences for their children so that they could return to work or school or as a means of childcare during these hours. A previous stay-at-home mom stated "I wanted to go back to school for some time but haven't been able to do that. Daycare is so expensive and my husband is a student as well. Rather than daycare, we decided for me to stay at home and once they got to school age I would go back to school" (Novell, Parent 2). Other parents were frank in sharing that is used as childcare, "It acts as a daycare service but that wasn't our intent, we can pay for daycare if we needed to" (West End, Parent 1). Additionally, "Yes, a lot of that is because I work during the day. I work from 9:30 to 5. So she'll go to daycare afterwards, but as a parent it is good for me and my work schedule" (Novell, Parent 1). Teachers also agreed that pre-k was utilized to supplement childcare needs, "A majority of the parents in my classroom either work or go to school. I probably only have three or four stay at home moms, the rest are either at school or working" (Novell, Teacher). The teacher from the rural public school agreed, "I feel, especially in our area, that it is for child care services. If you have several working parents, this is an easy way to get them child care services four days a week. Then we have parents who just like to have their child out of the house four days a week" (West End). 
Convenience also played a role for many parents. "It's more convenient than dealing with a private sitter. There were constant schedule changes and they're really not dependable; it's hard to find a backup. Since we have been taking him to [Happy Hands] we've been like, 'Wow, it was this easy the whole time?'” shared a parent from Happy Hands (Parent 3). Also speaking on the convenience of a state pre-k in a private setting, a mother conveyed, I think it is the one that we have chosen because the public ones finish early and then we would have to service at the end of the week, it didn't work with our schedules. It really didn't. I think the problem for [our town] and how we are doing the whole structure with it is there isn't enough places that provide five days a week... Truthfully, we looked at a couple other places here in town and we actually looked before I delivered the boys and we got in. We went to the open house and decided not to go there we were unpleased with the way things were and it was supposed to be one of the top ones. We choose one of the smaller facilities and with it the kids seem kind of happy so we will stick with what we are with because it is convenient for us. (Cottage, Parent 1).

\section{Environment}

Another recognizable reason why parents wanted their children to participate in a pre-k program was for the social and physical environment, "The need for us is we need to have a secure environment for the kids during the day. We want the continuous learning, we want the structure, and we want the discipline" (Cottage, Parent 1). Parents expressed the desire for their children to be safe, secure, loved, and engaged in learning during the school day. Another 
parent from Cottage said, "I want what's best for our child so it really provides the sense of security for us wanting the best for him and wanting to be safe and having a good jumpstart on school. I would say the biggest need is having the trust in the people you put your child with" (Parent 3). Parents expressed the desire to be selective of the environment in which their child was enrolled in pre-k, "We knew the pre-k teacher and we both worked, so it would have to be in a daycare setting or one of the pre-k programs. One of the biggest reasons I think is preparation for kindergarten. We like the teacher and the daycare, so we felt really comfortable with that" (Cottage, Parent 2).

Comparing the environment of the care arrangement before enrollment in pre-k, one father stated, "Before he started the pre-k program I think it was more...they are watching the kids and playing with the kids, but they weren't doing much to help the kids. Basically it was like being spoiled by grandma all day when [he] was with the sitter" (Happy Hands, Parent 3). Furthermore considering prior experiences, "She seems as if she is definitely taking a step towards actually learning more rather than being at home. With the structure and activities, I think that is great" (Novell, Parent 1). A mother also spoke on the perceived advantages of being in a public program compared to a private setting, "By volunteering in the schools, which I have, seeing the children that have come from a private caregiver...it is so much easier for them compared to those that came from a private setting. I think it's those academic and social needs that the setting is providing" (Novell, Parent 3). 
Lack of confidence in own ability

Not feeling adequately capable of providing their child what they deem as necessary was a sentiment expressed by parents. A mother from Happy Hands said, "I do not feel equipped to teach them what they need to know. I have the skills, but I don't know how to teach the skills to them" (Parent 1). "You think you can do a lot for them at home, but it isn't easy. At school she is around professionals that can give her the skills needed" articulated a parent from Novell (Parent 2). Speaking on behalf on her own family's experience as well as empathizing with other families' challenges, a mother said, "Like I said, I had trouble working with [my child], she is better at working with someone outside of the house. I think especially this end of the county there are a lot of children who do not get the parents working with them like they should and the only way to get that is through public programs" (West End, Parent 2).

What do parents and teachers perceive as the outcomes of WV UPK?

\section{Socialization}

The outcomes of a child's participation in a universal pre-kindergarten program were weighed in on by parents and educators. The Encyclopedia of Identity (2010) defines socialization as "the process through which people learn skills, knowledge, values, motives, and roles appropriate to their position(s) in a social group or society, resulting in a particular identity or identities relevant to that social group or society." These properties of socialization are appropriate descriptors of the outcomes that parents and teachers identified. 
Skills

Social skill acquisition was a result of a child's participation in pre-k programs. One parent relayed, "My view is they are learning socialization skills as well, that goes far beyond school and any sort of scholastic basis" (Happy Hands, Parent 1). The teacher at West End also said the most significant outcomes were "Probably the social and emotional development. They learn how to get along with others and to express themselves in other ways; they might not get the opportunity to otherwise."

Many of these relationships are sustained outside of the classroom, He made a friend that he will be going to kindergarten with; they live up the road actually. He called and asked for a play date since he had never been to another house other than family. He went and played, he didn't stay as long as I wanted him to. He played for an hour and a half before he said he was ready to go home. We just have to take it in small doses and work out way up to it. He definitely came out from the backward awkward thing with people. (West End, Parent 3)

One parent admitted that they gained socially in addition to their children, It's been good because the kids now have other friends to play with; we have people to social and talk to too. Because my husband and I are older, a lot of our friend's children are thirteen fourteen and in that stage. So we don't have a lot of people our age having young children, so it's been good that we met other people through the daycare. (Cottage, Parent 1) 


\section{Knowledge}

Knowledge was a prominent outcome that surfaced through the interviews too. The knowledge that was identified was specific to the child's social situation, being educational outcomes and general preparation for schooling. One mother gave ownership of her children's knowledge of some matters to the pre-k: "Without the program I don't think that they will know all that stuff, I know that I couldn't teach that that anymore. With the teachers they know that is the time for learning and they are little sponges. They absorb and absorb" (Cottage, Parent 1). Another parent from Cottage expanded on the knowledge that his child acquired, "Just being able to learn the social skills, working with others, the motor skills, his ABC's, colors, numbers, and all those other things. We work with him the best we can with the time we have, but having him in that structured environment since he was two, he made a lot of progress from 3 to 4 years old" (Cottage, Parent 3). Some spoke of skills more specific of kindergarten readiness - "She is definitely exploring and how to write her letters. We do that stuff at home, but I think being in school has helped her a lot. The structure of actually sitting down to do stuff has been good as well" (Novell, Parent 1). One mother disagreed with the outcomes of pre-k providing to its full potential for her child, "I don't really feel that it gets them ready for kindergarten other than the basic routines of the day. When I was in kindergarten that is where we learned $A B C^{\prime}$ s and math. These days they are already breaking kids into groups that can or cannot read. I don't feel that pre-k gets them as much prepared for kindergarten as it could" (West End, Parent 3). 


\section{Values}

Values, or rules for behaviors, are also an end product of pre-k participation according to parents and teachers. Parent 2 from Cottage shared, "I think he has picked up a lot of skills that can help him throughout his life. Just think of the diversity aspect and having friends from other countries that speak other languages and have other religions. I mean that he will carry with him his whole life. So those are things that he is picking up now that will help him with the person he will become." Being valued as a person and learning to value learning is something that is also experienced in some classrooms, "A love of learning and a willingness to try. Being excited to explore and being able to learn through play and not to be intimidated/discouraged. Also, to know that they are loved and important, that the world is theirs" (Happy Hands, Teacher). Sometimes the outcomes extend beyond the child to influence the family, "Sometimes families are very guarded with school and authority, if we can get them in and have a positive experience that would be one of those things that would go beyond kindergarten readiness and benefit the child, family, and the school. If the child can have a positive experience that will continually be positive experiences towards school" (Novell, Teacher).

\section{Motives and Roles}

Lastly, social roles that children learn while attending pre-k were identified as an outcome. Children acquire awareness of behaviors that are allowable and unacceptable. Parent 1 from Cottage shared, "there was a lot of talking and words were sometimes being said that sometimes weren't the nicest of words. And we saw personality changes with ours." Another 
parent spoke of the unfavorable outcomes, "The only adverse outcome is having the other younger kids and the older kids having to deal with it. Kids are different, I'm sure there are some that it doesn't faze. [My son] having high anxiety, it doesn't mix with him. He didn't go to school for a while and I had a rough time getting him to go to school today; he had gotten used to being home" (West End, Parent 3). Another mother from the same school said, "She had her little group of friends and didn't want to work with girls that were not in her clique. We didn't realize things like that happened that early. Talking to the teachers and getting her to work with other children, we had progress" (Parent 2).

Other parents shared of the favorable outcomes that pre-k had on their child's maturing social roles. Parent 2 from Cottage explained how her son has grown throughout the year, "just cooperation and following rules. Following a schedule is kind of important, if I had him at home he would understand that there is meal time and bed time, the schedule would have been less formal. I think the structured environment as well as the learning to get along with kids with all backgrounds and ways about them, I think that is important." A parent from a public setting agreed, "Now she is on routine, she knows when to do things and when it is important to do things. She is becoming independent and wanting to do things on her own" (Novell Parent 2). Children developed in the context of peer relationships, classroom expectations, and personal identity; "Self-esteem, his self-worth has definitely increased. For example he came in here and played around where you are. Before he would have just totally avoided you and been really upset that you are here. Now he is curious" (Happy Hands Parent 2). Norms and roles were depicted by parents as learned behaviors such as taking turns, cooperating, self-help skills, and 
desire to learn; negative outcomes such as talking back, rude and bad language, and creating isolated friendships; and personal identity included independence and self-expression.

\section{Composition}

(RQ2: How would parents and teachers adapt the structure of the WV universal pre-

kindergarten program?; RQ4: What do parents and teachers perceive as successful elements of the WV universal preschool program?; RQ5: What do parents and teachers perceive as challenging elements of the WV universal preschool program?)

Each participant was asked to rate the child's pre-k experience on a scale of one to five. They were asked to consider the program as a whole as well as specific classroom experiences and to provide a rating based on those involvements. Results were as follows:

\section{Table 5: Participant Pre-k Ratings}

\begin{tabular}{|c|c|c|c|c|c|c|c|c|c|c|c|c|c|c|c|}
\hline 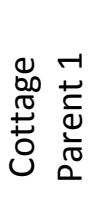 & 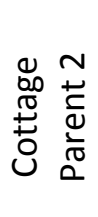 & 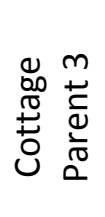 & 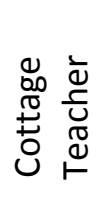 & 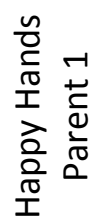 & 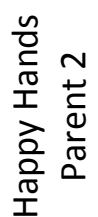 & 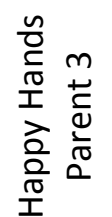 & 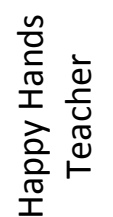 & 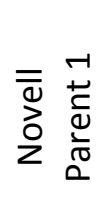 & 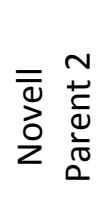 & 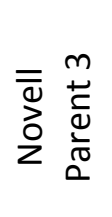 & 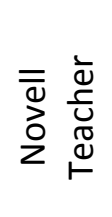 & 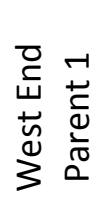 & 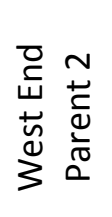 & 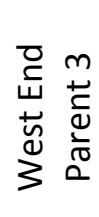 & 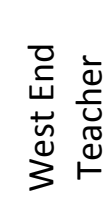 \\
\hline 5 & 5 & 4.8 & 5 & 5 & 5 & 5 & 3 & 4 & 3.5 & 5 & $3.5-4$ & 3 & 3 & 4 & 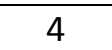 \\
\hline
\end{tabular}

The average overall rating was 4.2, with programs in public settings having an average rating of 3.8 and programs in private settings having an average rating of 4.7. The data below provides some personal accounts to offer insight to the ratings. 
How would parents and teachers adapt the structure of the WV universal pre-kindergarten program?

What is perceived as challenging elements of the WV universal pre-k program?

\section{Program structure}

\section{Staffing and ratios}

Staffing and ratios was commonly referred to as a challenging element or something that would be adapted. Parents expressed concerns about the teachers not receiving enough support, "Maybe number of students in the class. With more students there should be more assistants. The teachers try their best to manage but it isn't easy" (Novell, Parent 2). Some offered specific suggestions: "I would say probably a part-time assistant, maybe be there for half the day each day...or for Monday, Wednesday, Friday. Some type of set up. I don't know if ten four-year-olds need two people all the time, although that would be great. From [the teacher's] standpoint I would like to see her have some type of help, at least part time" (Cottage, Parent 3). Teachers also expressed the need for additional support and were also explicitly clear in what would be helpful:

Teacher: "Probably the numbers. I feel like the kids don't get all the attention they should to make it an optimal experience."

Interviewer: "You said you would rather have an additional person than reduce the class size?"

Teacher: "I'm thinking 20 with two supports." (Novell) 
The other public site teacher said, "I would really encourage them to make the class sizes smaller than what they are so the children can really get one-on-one interaction more often. My optimal class size would be 15" (West End).

\section{Scheduling}

Scheduling was vocalized as another area that was problematic. Parents in private centers were forward in saying they selected that program in part due to scheduling:

We didn't look closely, but we were going to. Because the program is closed on Fridays, that poses as a problem for us logistically; we would have had no caring. We would have looked at it more if there was some other program that we would have put him in on a Friday. I talked to other parents and they couldn't do it either. They were going to try and do pre-k Monday through Thursday and get them into a daycare on Friday... but no daycare is going to take them just for Friday. That poses as a big problem, I don't know what you would do if you don't have family. (Cottage, Parent 2)

Another parent from a private center expressed the desire to only send her children four days a week, "I don't like that it is five days a week. Because I was using it for daycare when we started, I liked it in that sense. But now that I am home again... four seems so young to be in school all day" (Happy Hands, Parent 1).

Parent 3 from Novell said it was not the number of days, but the length of day: "The only reservations I had was the all-day four days a week. That was difficult for me, but being familiar with the school system and the teachers I had no reservations with that. What made it difficult was the timing, the day length." Some parents expressed concerns for families that 
were not able to solve the Fridays like themselves, "If it weren't having grandparents out this way to get them to school and off the bus, I don't know how people do it with the times that are available and the Fridays off" (West End, Parent 2).

The teacher at Novell offered a suggestion:

Teacher: "I think it's a long day for them; ideally it would be a half day program. Really what are they doing? We eat lunch, they go to bed, and then they go home. Really they aren't doing much after a point."

Interviewer: "What would it look like ideally?"

Teacher "I think half day would be better, 8:30-11:30 somewhere around there. Five days, depending on the kid. Most kids can handle five days based on my kids this year. It's a lot for them. Some kids... but that is a nightmare logistically. It's funky scheduling with the Friday off, but I think it is nice to have the three day weekend."

From the private center perspective, the teacher shared why the parents of her children were served well in her program,

They make the choice of before and after care that isn't necessarily offered at school as early or late as it is there for a daycare center. For some of them to go to a public school wouldn't meet their timeline needs with work. They would have to find some kind of care prior to and after school. I know that there are programs available, still we are open on snow days and other holidays when things are close. For some parents that really factors in, they'll have to deal with that when they go to public school, but right now that is a lot of reason. (Cottage) 
Inclusive classrooms

Inclusive classrooms were a source of contention for some parents and teachers. One mother from West End expressed her dissatisfaction with an occurrence:

Parent: After school started, there was a new child that had severe behavioral problems. He kicked scratched, bit the teachers, and at that time he hated going to school. I called the principal about it because I felt that child was in such need of special care that he shouldn't be in a classroom setting like that. The teachers are great and [my son] has gained a lot, but I feel that there are things that I feel he shouldn't have to be exposed to.

Interviewer: How did administration respond to your concerns?

Parent: He listened to me and said other parents had called. But he kind of blamed it on the teacher and the aid, that they weren't doing their job. I said they were doing the best that they can, but it takes two of them to deal with one child. Kids are kids and they are going to do what they do. He said pre-k and Head Start was made for children to learn how to act and not to act. I agreed by said that when children are constantly hurting other kids and teachers then I don't think it is the right time for him to be in the situation.

Interviewer: Has that situation gotten any better?

Parent: There hasn't been anything else. We went to schools where seventh graders were mixed in with eighth graders, there are always going to unfavorable situations. As he gets older there are going to be kids that act out, in middle and high school they have separate environments for them. They get equal opportunities to learn but just not 
taking away from other kids in the classroom. I don't understand why pre-k maybe can't be setup like that. (Parent 3)

A teacher expressed the same concern,

In a lot of classes generalizations are being made that it is just ok to have the two [teachers]. When they go to kindergarten, they have and aid and the teacher. If they have a child with special needs, there is going to be a special needs aid or a special needs teacher pull him out, so why can't that be the case with preschool? I understand that they are younger, but sometimes they have more needs because they might not be potty trained or they aren't communicating as much. If you could have those supports in place in higher grades why can't you have those supports in place here? (Novell)

\section{Concerns about availability and equality}

Concerns about availability and equality were relayed with three specific challenges coming to the forefront. The first was having access to facilities that provide care and education five days a week, second was accommodating all children who wished to participate, and thirdly was being served equally. A father from Cottage covered all three of these challenges in one of his responses, "That would be a concern to me as a parent that there are people out there that aren't as fortunate as us that aren't able to afford [Cottage's] extra charges. That would be my concern, it doesn't really affect us, that there isn't enough space out there for the pre-k aged kids. That there might not be enough room in the school system for the kids who need it, in the public school setting" (Cottage, Parent 3). The West End teacher believed there were un-served children in her area, 
Teacher: We are allowing more children in, which I don't know is such a good idea with such the small number of classes we have out here.

Interviewer: What is the class size?

Teacher: 17 each and the maximum is 20 (with the one to 10 ).

Interviewer: Do you think that there is a greater need than what you guys are able to accommodate?

Teacher: I think so and in the coming years, there is going to be more. A parent from West End expressed a common concern,

Parent: ...there are a lot of three and four year olds in the pre-k. My sister has a little girl that was premature; she is very smart and has no developmental delays. When my sister tried to get her in Head Start they got denied because her husband makes too much and she didn't have any needs. She did Birth-to-Three because she was premature, but I don't think everybody is entitled to a fair chance to get their kids started in an early education.

Interviewer: So she entered the lottery system, but wasn't selected? Parent: Right. (Parent 3) Speaking on equality of programs, parents from public and private programs both weighed in. Parent 1 from Novell said:

Parent: I guess the particular school would have been a deciding factor. I strongly agree with [my child's school] and if she wasn't allowed to go there, I don't know. Interviewer: Give me the scenario if she hadn't been able to go there. You live in the school district so she was automatically able to go there? 
Parent: [No]. I actually don't live in that district; I live in [another school district] and I am very against it because they haven't passed their testing for the last two years in the development of their children. That really bothers me. I want my daughter to have the full benefit from the schools available. If I could pay for private school, she most likely would be in a private school.

Interviewer: Even with the free program, you would still choose private school? Parent: Yes.

Interviewer: When would you stop private school?

Parent: Probably in high school so that way she still has the feel for public school and can experience everything. But I still feel that private schools have more one-on-one feel with the children. That is one thing that I do like about [my daughter's school] is that they have the aides in pre-k, so they do get the individual attention and it's a smaller class size.

A parent from Cottage also indicated that she felt her child was served better than other children because of smaller class size and setting:

I would say that size really does matter. I like the fact that he is in a smaller group, he gets more individualized attention. The thing is if I were to put him in a pre-k program at school I think that I would have liked to gone and observed that class room first. I don't know if there are opportunities to do that, but I would have liked to gotten to know the teacher. I kind of like the idea of universal pre-k, but it's hard on parents. Depending on schedules, how many kids they have. I feel really fortunate where we are at. (Parent 2) 


\section{Environment}

Parents and teachers communicated discontentment with the environment in terms of technology, materials, facilities, and had solid opinions on their preference of private or public pre-k settings. Parents wanted more computer use, "In this day and age, I do feel that it is important for kids to get used to computers" (West End Parent 2). A mother from Cottage agreed, "Not every kid has a computer and I'm ok with that, but to some degree I wish they did more little work stations to it. She does more building blocks using your hand coordination using your hand type of things and some motor skills and stuff like that. I think that computers are important, they know how to use iPad...but in the same token I don't know if it would hinder or hurt their knowledge. That may be bad, but that's still a good thing" (Cottage, Parent 1).

One teacher spoke on the need to have additional to funding to provide specific materials that her classroom is lacking, "Toys and developmental games, new computers for the children (we only have one right now), and more multicultural things because children around here don't have as much experience as other areas" (West End).

Facilities were an adversity for some programs - some dealing with space and some with location of classrooms. The teacher at Cottage shared her contentions with space and regulations that are soon to prohibit them from being connected within the community:

In general, I think my classroom is too small. My classroom itself, we have what we need; we have the standards. We've been rated quite high with ECERS. We've done very well with that evaluation. But on a day when we can't get outside, we don't have a gym or somewhere larger to go to for movement activities, and that physical activity and 
daily exercise is so important. We have a wonderful playground that is better than any other place in town, but that is if we can get outside onto the playground. If we are stuck inside, it is a challenge. Our children get the opportunity to go to [community program] once a week and we take them off the property to [community building], but next year because of the mandate that they have to be transported in a school bus as opposed to a van, no more. Our children have a wonderful experience because we do all kinds of different field trips we can just take off and go. The parents have to sign a blanket. We don't go without the parents being notified. It is safe, the children are placed in a car seat, and it is much safer than putting them on a large school bus. It really doesn't make sense; the law is saying that they have to be transported on an actual school bus.

A parent (2) at Novell believes, "Space wise, with so many kids there should be more space" while the teacher at Happy Hands struggles with location, "The location is difficult because the pre-k room is right off of an infant room, so the environment could be a little less distracting."

At West End, children and teachers are faced with a unique challenge, Teacher: Some kids have trouble going to the lunch room with two other classes, it is much more noisy and there are many more kids. Interviewer: You guys don't do family style here? Teacher: No. Interviewer: Even with Head Start? Teacher: Nope. 
Interviewer: Have you requested that?

Teacher: [Yes], the cooks don't want to provide it. We are actually going to a thing on the $27^{\text {th }}$ about family style.

As far as parents having the choice of public or private pre-k settings for their child, parents and teachers expressed concerns about each. One mother at Happy Hands was unaware of the opportunity to participate in a free program, "I did not realize that there were options that allowed you to participate in a board certified pre-k program that did not include a fee" (Parent 1). A Novell parent (2) commented "I don't know about the structure here-your location determines where your child should attend...maybe so the school isn't too populated? I think the parents should be allowed to decide where your child goes." She followed up with: Parent: I prefer private. I'm looking at the private sector and a lot of the values have been wiped away from the public centers. I don't think it's making the environment safe or good for my child. The private settings, which up holds moral values. Interviewer: Would you do that through early childhood till kindergarten? Parent: If I had the money I would prefer through elementary up to eight grade. By then they have learned a lot from a good moral background and can make decisions for themselves. A lot of the things I hear about public schools scares me and I even want to go back home in Ghana. (Parent 2)

Another public school participant spoke out with concerns about private programs, not desires to be a part of,

Interviewer: How do you feel it should be incorporated into the public school system? And what form of pre-k is best for your family? 
Parent: I would be open to any of the above, only some of the private settings I would not be comfortable with.

Interviewer: For what reason?

Parent: The facilities.

Interviewer: Do you think the state should be a little bit more selective?

Parent: I do.

Interviewer: What about the facilities were you hesitant about?

Parent: The upkeep of them and the state of disrepair they are in. The staffing issues I

can't say they were $100 \%$ true, it wasn't confirmed nor denied. (Parent 3)

\section{Better integration with school system}

\section{Enrollment process}

The enrollment process for pre-k was a source of stress and confusion for some families. Communication about what the screening entailed caused concern for one family at Cottage, We were disappointed when we did the pre-k screening. They didn't tell us anywhere in the paperwork to bring our child. We thought we were supposed to fill out the paperwork. We didn't know that they did a hearing test, and the sight, the reading vocabulary. We had to go to the doctors, get their dental records, have their teeth checked. We did all that stuff and we had to sit in a big auditorium with all these people. This information wasn't dispersed well enough for us. We ended up calling a friend that was picking up their child after I called and said "when you get your child, how about you get mine?" I had to send along the permission for him to take mine type of thing. 
That was done through the state and through the county. I made a comment here later to the board in [this county] that I don't think some of the crazy things they assume you know, you don't know. They sent you the paper work and said please go to the doctor's office and do all this. We did all this. We had everything up to date and the records, it didn't say to bring your kid. We didn't know what we were going for. We thought we were going to bring in the paperwork and they would give us information as to what to expect in your children as the advance. (Parent 1)

The site that hosted the enrollment day was alarming for a parent, whose child would be attending a different program, "when we went to the pre-k round up and with [that public school] the atmosphere and the size of that school was very intimidating for [my daughter]. If we lived in town I would have a few more reservations about having the pre-k inclusive with the rest of the school with those being much larger" (West End, Parent 2).

A family from a private center recalled the county misunderstanding their paperwork, but also empathized with other families whose waitlist letters were accurate,

When we originally filled out the paper work for the county, this didn't really affect us because we knew that [our son] was going to [Cottage] and was going to be in [the prek] class, they sent us information back telling us that he was waitlisted at other elementary sites. That would be a concern to me as a parent that there are people out there that aren't as fortunate as us that aren't able to afford [Cottage's] extra charges. That would be my concern, it doesn't really affect us, that there isn't enough space out there for the pre-k aged kids. That there might not be enough room in the school system for the kids who need it, in the public school setting. (Parent 3) 
Preference to meet the child's upcoming teacher and knowing their qualifications was expressed as a desire,

"A deficiency on the centers part is they really don't let you know the credentials of the folks who are teaching. I don't know if that is a lack on my part for asking or whether that is something that they need to make a little more known. For example, you don't really get one-on-one meetings with the teachers prior to enrolling. It's just this is who teachers that class, you don't know if they are accredited, if they graduated from a program, or if they are just doing it because they like children. I did know that [the teacher] was a certified board of education teacher, so that reassured me" (Happy Hands, Parent 1).

This mother also expressed the desire to better understand the program prior to enrollment, I think knowing what the expectations of the school system are, it is important to know if I could meet those needs at home. If I could meet them at home, I would rather be doing that. A lot of that sort of information sharing in that time. There is that pre-k meeting in the middle of summer, but that is not enough time to see that child's needs. If there was some way to connect parents with the board of education or prekindergarten teachers in your area. (Happy Hands, Parent 1).

\section{Special needs}

Receiving special needs services through the public school system was desired by one family to be more streamlined to meet her son's needs. She shared, 
I think the staff and the services that they provide are the best, overall there could be more integration for kids with special needs. Trying to get [my son] screened for autism and what not has been extremely difficult. I remember at one point we felt like we were taking the correct course of action and was expecting certain results but didn't exactly obtain those. But I think that was more to do with the school board, I don't think that was any fault of [Happy Hands] or the staff there. I think we've had to do a lot more independent leg work and led to places that could've been cleared up by some straight forward yes or no answers. (Parent 3)

Later in the interview, she reiterated, "I don't think it's anything wrong with [Happy Hands] per say, I'm just saying the integration of the services with the system I don't feel is adequate."

\section{Program Awareness and Communication}

A common thread in the way that the school system needed to be inclusive with the pre-k programs was better communication. One mother felt that the program was not exposed well enough for the general public,

Parent: Some PR!

Interviewer: How would they communicate with the public?

Parent: Let people know the benefits.

Interviewer: How do you share that?

Parent: Maybe send out representatives to where people are employed. Interviewer: Do you really think there are parents who don't know that pre-k is offered? 
Parent: They may be like, "there is nothing wrong with letting family watch the kids all day," but the family is not teaching them how to sit still and be quite and other things like that that they are getting in pre-k. It could be presented to parents in that light. They probably know that it is there but haven't seen why it is so much more beneficial. (Happy Hands, Parent 2)

Another parent agreed, “I don't think people fully know that UPK even exists. I just happened upon it by talking to people" (Novell, Parent 3). This mother also spoke about a specific instance, in which their family could have benefited from better communication with the county school system,

Parent: The lottery system to get in. It seems like there is no rhyme or reasons to what happens. There is no good communication either.

Interviewer: When did you know he was getting in?

Parent: Maybe a week before school started.

Interviewer: Does that mean he was put on the wait list?

Parent: No, I had asked for him to be put on the wait list but he was assigned a different place that I didn't want. So then he did get on the wait list, but I didn't know that at the time.

\section{Teacher's voice}

Teachers addressed professional concerns regarding professional development and mentoring, pay, and assessment systems. The teacher at Cottage shared her challenges with being at a private site regarding professional development and mentoring, 
I think it's well-meaning but being in a collaborative site, I don't think they set up trainings well. But it maybe I say that more because there's not any another classroom other than mine so there's not a peer on property that I can bounce ideas off of. My only interaction with that is when I go to trainings off property. I don't have someone else there to bounce ideas off of or have and aid or someone else to work together on things. A lot of times the information comes last minute and now there's a training session of Friday, if it wasn't already on our calendar the public schools are closed to children on Friday, it's teacher planning day, well it's not a big deal for them to go if it's a planning day. But if it's for us, the collaborative sites, you're all of a sudden scrambling to find a substitute, and you're trying to set things up in your classroom. I mean that's a real challenge that's when they set them up, for the majority of people that is the day that makes sense. For us we were not closed, we are open five days a week as opposed to having that as a planning and recording day. (Cottage)

Whereas the teacher at the other private site, Happy Hands, had concerns about the rate of pay compared to the credentials necessary to be a pre-k teacher:

The finances, the only thing I would say is the silent wage. I have been teaching for fifteen years now and this is my fourth year here. I used to teach in Pennsylvania and back then I was making two or three dollars more an hour and I am much more experienced now. I'm not here to make money... I'm here to make a difference. But some people don't share that opinion. They are trying to attract people with four year degrees and it is going to be hard for them to take it financially. Special education teachers come in, the trainings that we go to, the equipment that we can use, is much 
more sophisticated than Pennsylvania was when I was there. I feel like everything here is better except for the hourly wage. (Happy Hands)

The assessment system instigated a response from teachers as well. One teacher shared her experience,

In general, that the assessment system has changed three times and you're learning that while school is starting at the beginning of the year and that is the most critical time to be establishing a routine. I hope the system that we have now stays in place. It's been a lot for the people that have been in the program to have to learn something new each year while you are trying to get to know your children, set up your room, establish routines, and evaluate what is going on with the kids. While you are trying to figure out what they need, you're learning something new at the same time. This is the third year I have been a teacher and the third year that I am learning a new system as the school year goes along. They have wonderful ideas about what's going to happen and dates, but it is never ready and pushed back. That has been a major issue that I have dealt with and other teachers at trainings have said as well, that we would like to know in advance. (Cottage)

This teacher was not the only one who mentioned this as a challenge, "...I'm not sure who is doing the changing but I know that I am using different assessment tools. It takes me a while to adapt; if you are used to them it's no problem" (Happy Hands). The changes caused difficulties at the public sites as well, "Last year I had to learn something new and this year I had to learn something new, so I don't have a feel for either one of them yet" (West End). 


\section{Philosophy}

\section{Pedagogy}

Pedagogy was an area of conversation that emerged as parents shared the styles of teaching and upbringing they preferred for their children. Some parents mentioned a specific model, Montessori, which they would like to see their child's classroom emulate. One mother compared the experiences of an older child who attended Montessori with her child that was attending public pre-k, “Optimally Montessori is my type of experience. Since [her older sister] has been through that and started out so much above where the other children were by the time she hit kindergarten, that is probably my optimal experience. As far as it being a public school, I definitely feel that it has provided what [my daughter] has needed" (West End, Parent 2). Another said, “Ideally, which hasn't been in our realm of possibility, I would love for my children to go to a Montessori preschool" (Happy Hands, Parent 1).

Instead of specific models, some parents expressed the desire for the programs to adopt different techniques. One mother desired for her child to experience a different disciplinary structure, "I know that they don't do a lot of disciplinary acts, they do stars. For instance, this week she got in trouble twice for talking at naptime to the same little girl. In my mind if I was that teacher, why wouldn't you move her away from that situation?" A mother from West End spoke about the manner in which her child learned, "I wish that the pre-k program could teach a little more. They are not really allowed to have teaching criteria. This is basically like sending them to daycare every day. I think it would be nice they could really focus on some of the basics that they need to know going into kindergarten" (Parent 3). A father from the same school wants the pre-k to "start teaching them languages, have it learning based and not really play 
based. Children learn at an earlier age, but if it is play based-I don't know if earlier would have any benefits" (Parent 3). A teacher disagreed with the parents' desire to make the classroom less play based,

How our curriculum is set up, even for some kids now, it is a challenge. They don't get the chance to be kids and experience their environment without some kind of structure. Society is so different and pushed for what is coming next that they don't get to enjoy where they are. It's nice that they are learning these skills earlier, but they are so pushed they don't know how to do other basic things. They are not necessarily being taught social skills. They may be able to read, but not able to understand what they are reading or have the comprehension for that. I think it pushes them too hard. (Cottage)

\section{Classroom Communication}

Communication between the home and classroom proved difficult for some. The teacher from Cottage felt the disconnect, "With so many parents working, they drop them off and pick them up, I don't know if they are really as involved as they can or should be with their kids' education." One mother compared the difference between private and public settings, each of her children having a different experience, "At Montessori, he picked her up and I dropped her off so we both had communication with the teacher on a daily basis. That did make a big difference, we could ask questions in person and that would make them more inclined to fill us in" (West End, Parent 2). Another public site mom discussed the difficulty of maintaining communication and working, "I'm just always working, and then on Thursdays and Fridays I just have to take care of everything. I had a parent teacher conference and I missed it 
twice, I felt horrible. I just haven't had a chance to go in, sit down, and watch them" (Novell, Parent 1).

\section{$\underline{\text { Guilt factor }}$}

One of the challenges that parents disclosed that they had to deal with was the guilt of sending their child to pre-k. One mother had self-inflicted guilt as well as pressure from her mother about the decision. She shared,

The only thing I can say as a parent, I look at me and say "I'm not there three days a week for my child." I want to know if morals and good values are being instilled upon them. Am I being a good parent or are they someday going to be upset that they spent five days a week at daycare? Sometimes I have to think, "Am I doing the right thing?" My husband and I look at ourselves and we think we are. The kids are really happy and they seem to have adjusted...But you can't help but wonder twenty years from now when they are young adults, did we make the best decision and are they are doing the best they can with their family situation in the future. It's more on our end saying, "Did we do the right thing?" (Cottage, Parent 1)

She also provided a vision of how the previous generation responds to this style of childrearing,

My mom was thirteen years in special ed. and fifteen years in pre-k as a teaching assistant and you know in the old days she was like "oh man" - she wasn't crazy about pre-k. She was like "kids need to be kids at some point" and the same thing is you have to make accessibility for the parents to work and be able to afford a child and 
everything. So, the inevitable thing is to go to daycare and she still gets mad at me and my husband sometimes about how long they are there and stuff like that. But it's like we all have to work full time jobs. There are different demands (Cottage, Parent 1). One mom felt guilty after observing her son in the setting, We went to the school for a school function and when I came home I felt bad that I sent him because there was a group of kids that were acting like toddlers. The kids his age were waiting for the other kids to be taken care of so that they could do what they were there to do. Tucker is kind of mature for his age because of his older brothers, plus he is a big kid and looks like a giant, I almost cried about it wondering if I did the wrong thing by sending him (West End, Parent 3).

What do parents and teachers perceive as successful elements of the WV universal preschool program?

\section{Overall satisfaction}

When asked about successful elements, many participants responded with a general sense of satisfaction with the program. A mother from Cottage said, "I don't know if there is necessarily something that I like least with it....I don't necessarily find something that I'm disappointed with. With my mom in the school system, so she is surprised by how they respond to the kids. They are more of an extension of the family now and able to help the kids more" (Parent 1). Another family concurred, "I would have to think pretty hard to come up with a complaint. We are among the luckiest parents around; [my son] has had two years with [his teacher] and the other kids there. I don't think I would have any complaints, at least not now" 
(Cottage, Parent 3). A Happy Hands participant shared “I don't think there is very much that I would change about the services that we are receiving. I mean [my son] seems really happy, I am more than satisfied with the results. Generically speak I think we get what we are paying out of the services" (Parent 3).

\section{Philosophy}

\section{Pedagogy}

Participants supported the curriculum and teaching style of the pre-k classrooms in some instances. The teacher at Happy Hands said, "I really like the flexibility. You're not stuck to a curriculum. You might go in thinking you are going to do something, but there is always a different route. It's an adventure and you never know what is going to happen." The curriculum was appreciated by the teacher at West End too, "I think the open ended curriculum is the best thing we have going. We are not required to teach specific things, this is what we are supposed to follow but we are not teaching something specific." One father liked "The fact that they embrace the diversity is really great. How they include that in the curriculum is really great as well" (Cottage, Parent 3). Learning through play was also revealed as successful elements, "I think pre-k is part play. I think learning can be fun and if you have the right structure it should be. Learning shouldn't just be all academics, it should be fun and there should be games" (Cottage, Parent 2). Speaking on tending to the needs of her children, a mom shared, "I know that there is a curriculum, there are guidelines, but it doesn't seem to be set in stone. I have talked to some other parents who have children in other centers. I like that part about it. It 
seems they are flexible and meetings the needs of your child at whatever point they are at" (Happy Hands, Parent 1).

\section{Classroom Communication}

Establishing a symbiotic relationship between the child at school and the child at home was mentioned by some respondents as an attained element. One teacher is very conscientious about these relationships, "I talk to parents and they are generally very pleased. If they have concerns, we talk it out and discuss it. It is a give and take process. We ask each other if there are things that we can do to help in the classroom or at home" (Happy Hands). He continues, "The parent teacher relationship is very important. I think parents can be the greatest asset or the greatest pain in the neck and hold you down. If the parent trusts you, they will try almost anything and work with you." Parents also realize the importance of this rapport, "I think having on going communication with the teacher is important. If there's a problem you can go in and talk to them even if your child is having a good time, I think feedback is really important"

(Cottage, Parent 2). The teacher at Cottage also works to establish this relationship, "As far as our situation, I have daily contact with the parents and I don't know how it happens in the public school system. But we see the parents on a daily basis so we are able to give them feedback on what's going on, we have a meeting with them in the fall and the spring to give them feedback and in between contact if it's necessary." 


\section{Program structure}

Integration

Participants were grateful for the integration of pre-k between Head Start, private centers, and the public school system. One mother spoke of the convenience of having all children in the public schools, "I like it in the public setting at the school because I have everybody at one place. That is one thing that I like the most" (Novell, Parent 3). Having Head Start children in the same classroom as pre-k children was beneficial for one family because,

“We are a Head Start family and other kids don't know that, so there is never that depiction of bullying. Things like that and the fact that they are not [in the same building] with the [older] kids, if they were in the rest of kids I think that would be very overwhelming. I'm comfortable with how they do things on their own, yet they still are part of the school (Novell, Parent 1). Parents from private pre-k sites expressed their gratitude of being in a public school pre-k site for different reasons, "Overall the center and the state, I think they are providing a lot of the tools. One of the reliefs to us was the daycare cost went down a little bit which was great. When you look at the price of daycare, it's the cost of a mortgage" (Cottage, Parent 1).

\section{Screening}

The pre-enrollment screenings were considered advantageous by parents and teachers alike. Screenings were specifically mentioned when asked what they liked the most about the program, "I like how they bring all the kids in at the beginning and they do the hearing, eyes, and speech. I learned a lot just by sitting in those settings with [my son]. Just making sure your child is developmentally in the right place. I think that it is good that they do them for every 
child. I like the standards across the board. I think that it is good to get an early start because you're going to be going to kindergarten the next year and it's all day kindergarten. That's a lot for a five year old to start straight into kindergarten" (Cottage, Parent 2). The teacher from Cottage concurred about the value of the screening, "They go through the screening in advance to going to pre-k. They offered it in the summer this year before they started school to be prescreened for any issues be it speech, hearing, etc. so they did have that if they were signed up for the pre-k program. I think the pre-k screenings are helpful to the families and the teacher to provide them with the services that they need."

\section{Scheduling}

Scheduling was viewed as a positive aspect of the program by some respondents despite it being a challenging aspect for other families. After being questioned if a different schedule would be best for their family, one mother said, "No, I think it is good. I like the four full days and Fridays off" (West End, Parent 3) and another replied

Interviewer: And you are comfortable with the hours that they are there?

Parent: [Yes] because they are there for the whole school day which I think is good, but also having the day off is beneficial to them.

Interviewer: Do you think it would be better if it was a half day program?

Parent: I think that it is good that it is a full day so that way it doesn't set up the expectation of having that half day when they do have to switch over to the full day schedule. (Novell, Parent 1) 
One mother related the scheduling satisfaction to the fact that it was housed in a child care setting, "The boys are allowed to stay there, they don't have to be transported anywhere else; they can stay there until 5:30" (Cottage, Parent 1).

\section{Staffing and Ratios}

Parents of pre-k children in public schools commented on the staffing as successful elements, "That is one thing that I do like about [Novell] is that they have the aides in pre-k, so they do get the individual attention and it's a smaller class size" (Parent 1). A parent at West End shared the same thoughts, "I like the small numbers and that there is a teacher and teachers aid" (Parent 1).

\section{Future}

(RQ6: How do parents and teachers think the WV universal pre-kindergarten program should proceed in the future?)

How do parents and teachers think the WV universal pre-kindergarten program should proceed in the future?

\section{Mandatory}

Three parents and one teacher were supporters of making UPK participation mandatory, constituting $25 \%$ of the participants in favor of mandatory attendance. One father shared his thoughts on being a proponent of mandated participation, "Seeing the benefits that it has made for [my son], I would be a proponent for mandatory. Just by seeing the development that 
it has given him. I'm sure there are reasons for it being optional, but I feel mandatory" (Cottage, Parent 3). A mother from Cottage justified her opinion "Four is a good mandated age because they are ready to be educated. They are ready to be social. Their minds are ready to absorb. They are ready for socialization, they thrive" (Cottage, Parent 1). Another mother said, "I would like to look at studies between the kids that have gone and haven't. If there are differences educationally, I think it should be mandatory. I'm sure there are parents who have arguments against that. I would like to see it become mandatory to cover everybody" (Cottage, Parent 2). When asked if participation should be optional or mandatory, the teacher responded, "I see how beneficial it is. I know some parents feel sad sending their child away and normally they would have them for four or five years before having to send them away. When the teacher is with it, it is really important. I say yeah, it is so helpful. They learn so many skills. I think it is a great experience for a child" (Happy Hands). When prompted further and asked:

Interviewer: How would you feel if they announced tomorrow that it would be mandatory starting next year?

Teacher: I think it would be a great idea. It would be great for their child; it is a great way for their educational life to get started.

\section{Optional}

Optional attendance, as the program is designed currently, was preferred by nine parents and three teachers. This represented $75 \%$ of the participants in favor of optional participation. Parents and teachers weighed with reasons as to why they were opposed at all four-year-olds attending a pre-k program. One mother was very adamant in her viewpoint, 
Parent: I don't think it should be mandatory because it should be the parents' choice to decide. I don't want the state parenting me or my children. Some parents who feel that their children would benefit from those services, absolutely. But those who are perfectly comfortable with their child being at home with them or have some other option, they have the right to do that too.

Interviewer: Will your opinion change in the future and how?

Parent: I don't think my opinion will change regarding the mandatory part of it. Interviewer: Do you think that there will be an evolution of needs in society where it will be necessary or appropriate?

Parent: I think at some point parents need to say, "Enough is enough." I understand the goal of public education and the importance of it, but you do not need to take my child straight from the womb and start teaching them. (Happy Hands, Parent 1)

One father saw the value in providing the mandate for some families, but was challenged in declaring it should be mandatory for all to attend, "unless there is evidence that there are kids being neglected...you have to be very careful how they make it mandatory. Unless you say every four-year-old has to go to school, no absolutely not. You only have a select amount of time with your kids. If [my wife] was staying home, I feel very confident that [my daughter] would get the same if not more than she gets down there" (West End, Parent 1). The teacher at Novell also realized the worth but said, “Optional, definitely. Some kids and families just aren't ready. It's a personal decision. Like you said, they are young. I think while it's a good thing and all children need some type of experience before kindergarten because of what is expected of 
them. But whether it is a parent or child issue, some people have big issues and to tell them they have to go to school at the age of four is just crazy."

\section{Support for program}

Regardless of the participant's personal points of view regarding whether pre-k should be mandatory or optional, many offered words of support for the state's effort. One father was forward thinking in what would be required on the next generation, "Things have obviously changed a lot since when I started school. We're seeing more of a phasing out of labor as a job that can support a family. I'm starting to think that more of an intellectual pursuit is being thrust on this generation" (Happy Hands, Parent 3). Another mom, "They say that most of a child's development comes from three to five, or something like that, when they absorb the most information. So why not start earlier so they can use what they learned in early stages of life throughout their whole life?" (Novell, Parent 1) she said, moments before saying that she favored optional participation. The teacher at Happy Hands commended the early childhood profession for its positive role in the life of a child,

I think it is kind of exciting that they know so much more than I knew in kindergarten. When I was in kindergarten the expectations were not the same. What I am doing now is preparing them for kindergarten. What I'm all for is challenging children, not overwhelming children; this is where you're at, and this is where I think you can go. I wouldn't be concerned. I see stuff about how the country is behind, but I don't know, I think the ball has been dropped in upper grades. What is happening down here is point on. I think the challenge is at the high school level, there aren't shootings in elementary 
school. If you can make a difference now, it might set them on the right path. You never know who you impact, so do what you can.

A father also was more hesitant about his son attending school as an older child as opposed to attending when he is four,

You grasp kids more when you start them at four. You lose kids as they grow up. It would be interesting to cross study with middle and high school teachers coming to prek and say "wow these kids are so excited to learn!" Then have the pre-k teacher go to the high school and middle school and maybe there can be some learning on when we really lose kids. I wouldn't worry so much about sending my kid to pre-k; I worry more if they are still interested in middle school. I think it can be a good thing, kids can still be kids, it's just a different setting. (Cottage, Parent 2)

\section{Concerns}

Although parents offered their words of support, they were equally ready to offer their expressions of concern-"What are they going to do, keep lowering the age where it is mandatory for them to start going to school when they are one? We can pull back the learning as early as we need to...I can understand it as our country is falling behind. But, I don't know if pulling the mandatory age back is the solution" said Parent 2 from West End. Another mom was weary of the same outcome, "I don't want the state to take over the job of parenting. That is a really big concern of mine. There are some families that if you offer than option, they are going to take it. For me, I want them to have their base from us, our values and our culture. Not from 
public school necessarily" (Happy Hands, Parent 1). When asked how she would feel if the program were made mandatory, one mother commented, I don't know if it is just me, or also the general public, but I think a lot of the times we can perceive the private schools as having better teachers and staff while the public education system is really lazy. I can't help but feel a little bit biased there myself. I would hope that since it would be made mandatory and we would be trusting the system with the care of our children that are that young, that they would be extremely strict on who they employ to take care of our kids (Happy Hands Parent 2).

Teachers were asked the same question, and the response from Novell was,

I guess I would just go with it. Here's the thing, if the school based one is the only free one, maybe a family doesn't want their kid to come to the school based because it is four days a week. Maybe they want the preschool experience that is two days a week, I'm thinking that that is probably just as good as the four day a week we have. They just need exposure before they come. To tell a family they have to pay for their child to come to a two day a week daycare because they don't want to come to this one, I think is just too much of a nightmare.

\section{Three-year-old program}

The participants were asked the following question: "How would you feel if three year olds were encouraged to participate in the school system?" Responses were wide-ranged by both teachers and parents. One mother doubted that the state could provide enough funding or support to be effective and "I think they need that time to be a kid and to figure out who 
they are and what they are at that point. To some degree we are interfering too much with growth and development. At the same time I think back and I didn't have to take kindergarten as a kid, but the reality is people have to work eight hours a day, typically. You don't have those luxuries anymore" (Cottage, Parents 1). One mother was aware of current programs available for three-year-olds that meet inclusion criteria and commented,

I think the thing about targeted programs, it's the parents that come in and enroll the child. You miss the children that really need it, when the parent decides not to enroll their child. I'm thinking of a student that I have now, I wanted her to enroll him into early head start, but the parent won't do it. And I just think of the child at home not getting as much help as he needs because she is too embarrassed. But if there was a universal program that everyone would have to go to, that would be really great for that child. Part of me says yeah, there should be a universal program that every child goes to when they are three but it must meet the needs of everyone not just the people who are able to get in or are fortunate. But it's going to be hard to convince everybody of that (Cottage, Parent 2).

A father was supportive of the idea under certain conditions "All we have known for the last three years is a small classroom setting. If it's designed as it currently is, I don't think I would have a reservation for a three year old to go in and be in a daycare setting. My thing would be, putting three year old in a public school where there are older kids" (Cottage, Parent 3). Seeing the value for parents, one mother stated, "It depends on the choice of the parent. It should be left to the parent because three is so young, but some kids are so smart. It really should be 
optional starting at two" and she followed up with "I think parents would love that. Parents have to work, but it is hard to pay for daycare" (Novell, Parent 2).

Teachers offered their educated viewpoints,

Teacher: I think they would need separate classrooms.

Interviewer: Would it still be appropriate for it to be housed under the public school system?

Teacher: I would say private for the three-year-olds.

Interviewer: Not publically funded in any way?

Teacher: Right. (West End)

The teacher at Novell agreed about separating the children, and possibly keeping it as a private responsibility,

I used to work for Birth-to-Three, and you could tell going into their home that they were ready. Even though I said before that three and four-year-olds need to be separated, you could still tell that a three year old needs something even though they are not going to be the most social animal. They still need something, whether it is a half day program or something like that. I feel like they do the structure and routine. I'm not saying that we need to make that happen for three year olds at all, but I'm just saying things like that need to be available through the community, church, or whatever. I don't think they need something big, I just think that they need something "more."

\section{Findings not tied to the research questions}

Two major themes emerged from the interviews that were not tied to the research questions. Firstly, there was an expressed desire to have social support services more accessible 
to parents of young children. Secondly, participants spoke about life after pre-k including kindergarten, transitions, and trepidation about the next stage.

\section{Pre- Pre-k}

Participants spoke vividly about the children's experiences in pre-k, but could not dismiss the years prior to pre-k entrance and the year after pre-k completion. One mother relayed that she would like for a parenting component to be assumed by the board of education, “Sometimes I think parents need some sort of basic parenting class and I don't know if the school system can do some of those informational things, those would be helpful" (Cottage, Parent 1). She further explains, I don't think that there is enough education for the parents when they have kids. You don't necessarily know what to do; that can even mean in the hospital you can get the called to action kind of thing and know what to look for and so forth. The down side for us, and we may be against the norm, we didn't get any prenatal classes. I was hospital bound and I could not deliver naturally, I was going to be an automatic C-section regardless. In the hospital, people weren't there to be like “hey, do you want to talk to somebody?" I would've said "Sure!" They give you baby food, even if you're nursing, you still get that, and you get the blanket, you get the little bulb that they use and they send you on your way. There's no hand out to say this is what your get. Birth-to-Three gave us a little book What if your child gets sick...things to do and what to look for. I thought that was helpful, it was a very basic, inexpensive, little book on what to do. What temperatures are dangerous, they tell you that in the beginning, but it's a lot of 
information. Anybody if they got those types of things would be more helpful. Even at daycare now they put together an information thing explaining the rules of the county. "This, this, and this" has to be done before your child comes to school and things like that.

Another mother from Cottage had a different perspective, "I think whenever you get younger kids you start blurring the lines with the school in terms of parenting and education. They can't do everything, their job is to prepare students but there is still the parental role there. I think parents need more support but I don't know if the school is the right place for that" (Parent 2).

One family that had to seek out their own social services for their son shared, "Every agency you go to has something like that but there is a song and dance to get to it. If there was a public institution that made it easier, just tell me where the door is and I will open it. By the age of one you know if there will be problem for the most part. A public institution would be very helpful. It benefits everyone because if that individual is helped to be their best, they can contribute back to society" (Happy Hands, Parent 2).

The teacher at Novell knows the benefits of social services for families, but does not believe that it should be the responsibility of the schools. Speaking to the benefits, she said, I think both the pre-k parents and Head Start parents, even the children with special needs...that extra support we get from Head Start meets the additional needs that the families might have, more so than when they are in kindergarten or the upper level grades; because we have more connection to the community. Having worked in this environment and prior having working in the community service, I think that school is not quite closed off, but not as included in the community. 
However, this was her recommendation on meeting the needs of families better, "I don't feel like there should be something that is school based, but if there is it should be a home visiting program. If the state wanted to take on a parent teachers program, like in the state of Missouri, I think that would be a very beneficial program."

\section{$\underline{\text { Post- Pre-k }}$}

Secondly, parents were concerned about the next stage after pre-k-the expectations, the process, the school day, and the connection to the teacher. One father was apprehensive about the transition,

I don't know how kindergarten works; I know we visit the schools, but at [Cottage] that's one of the things would do. We could go in one day and observe and get to know the teacher beforehand. Some of that would be nice. I guess they do parent teacher conferences. If they did those things up front, it would make a difference. You're sending your child there every day, and you'd like to know what they are doing when your mind wanders, "Oh, I wonder what they are doing today." At [Cottage] I have an idea, with kindergarten; I don't know. (Parent 2)

One mother talked about how the transition from private care to public kindergarten was going to affect her family, "when they get in the kindergarten program next year, we are going to need to have a nanny for two - two and a half hours a day. They have an after school program, but we don't know if there is a cost for that yet. They haven't told us, we just don't know" (Cottage, Parent 1). 
There was a comparison between two cultures in education style by one mother. She shares about her experiences in Ghana,

Back home we do it until they meet a certain level. You don't want to push a child that isn't doing well. We have extra classes for children that are not doing well rather than push to the next grade. There are grade guidelines rather than age guidelines. This is for every place along the school path, except for very early ages. Rather than pushing, there is competition in the class and keeps the students on their toes. Here they just leave the child to do their own thing. (Novell, Parent 2)

The pre-entrance expectations of kindergarten are alarming to some participants and they identified the disadvantages that some children are faced with upon entering into their formal education. Speaking of a child's readiness, the teacher from Cottage said, "I think it depends on the classroom and the teacher. If they haven't had any kind of pre-k exposure, I think it would be a really big challenge to go straight into kindergarten the way that it is set up for them. I think it would be very much of a challenge if they haven't had any pre-exposure to school." The teacher at Happy Hands concurred, "The problem with kindergarten now is the expectations are so high, now you go in and you have to fight to survive. There's a lot of pressure on the children." Another teacher cautioned of the kindergarten structure and appropriateness,

Do I think that what is happening is appropriate? No. I feel kindergarten should be more like pre-k and maybe have some more...I understand having ridged standards, but I feel like it could be done in a better or more play based structure like we have. I think it would be very easy to do in our structure, and kids learn in this structure. I feel like it 
would be more appropriate for five year olds, they still need to be kids and sitting at a table four hours of a day isn't doing that. (Novell)

Having other children who attended public kindergarten, one mother relived her experiences of the pre-entrance expectations, “I think it's absolutely ridiculous. I don't know if the children feel the stress, but I know the parents do" (Happy Hands, Parent 1).

\section{Summary}

The purpose of this study was to explore experiences of WV Universal Pre-kindergarten as shared by parents and teachers. Participants spoke on many topics including themes related to the children (why they are participating and what are the outcomes), the composition (how the structure would be adapted, what are challenging elements, and what are successful elements), and the future (how should UPK proceed). Two other themes emerged as participants spoke about the time immediately before pre-k and immediately after pre-k. The sixteen participants each had distinct happenings, but the data merged to centralize some key findings.

The core category emerging from the data analysis was the idea that the reasons that children were participating in pre-k also became the outcomes of their participation. These included socialization, kindergarten preparation and exposure to the environment. Additionally, parents identified reasons for participation as the need to seek child care services while working or attending school and because they were not confident in their own abilities to prepare them for kindergarten entrance. 
As the data were analyzed it became evident that there were ample aspects that participants would change, but also those in which they were satisfied. Staffing and ratios, scheduling, inclusive classrooms, concerns about availability and equality, environment, integration with the school system, teaching philosophy, and the guilt factor came to the forefront of what they would change or what was challenging. Successful elements were revealed as being overall satisfied with the program as well as specifically pleased with the teaching philosophy, environment, integration with the school system, pre-k screening process, scheduling and staffing. There are some overlaps due to personal experiences - what was challenging for some was identified as a positive element for others.

Participants were split in how the future of pre-k should proceed. The majority of respondents reported that they desired for pre-k to remain optional, while some called for mandatory participation. Parents and teachers alike shared reasons why they support pre-k, but also concerns. The sixteen were also not in consensus about whether the state should provide education, care, or other services to children less than four years of age and their families. While some identified it as an option that is universally unavailable, different participations cautioned could overcome the role of parents. Participants were forward thinking despite being interviewed just one-half of the way through the school year. Parents and teachers shared their perspectives on pre-k's role in the school system and how seamlessly it did or did not shift into kindergarten.

One mother's personal experience sheds some light on this research, "my mom drank so school was an escape for me and that is why I liked school. I didn't have any concerns or worries at school. At the same time I had to go home to it and live my life, but it made me who I 
am today, and I think school is awesome." There will always be children in these home situations. Regardless of the decisions that parent's make for their children regarding their education and home life, it is our responsibility as educators to assure that all children's schooling experiences are "awesome." The next chapter will explore the meanings behind these findings so that as a state and country we can improve and enhance all educational experiences. 


\section{Chapter SIX}

\section{DISCUSSION}

\section{Introduction}

A child's first school experience occurs during preschool rather than kindergarten for a majority of children in the United States. State-funded pre-k has distinctively revolutionized the first schooling experience because more states are investing in early childhood education initiatives (Hustedt \& Barnett, 2011). Specific elements of West Virginia Universal Prekindergarten were explored through the perspectives of parents and teachers of four-year-olds in this study. The qualitative data was explored by their voices in the previous chapter and in this chapter results will be interpreted. The data that emerged will be highlighted as wider sets of issues and questions to help initiate discussion as to what elements should be modified and what should remain invariable. The 2012-13 school year is slated to provide availability of a prek program to all four-year-olds statewide, so this discussion could impart insights at a critical moment for WV UPK. Our perceptions of childhood are developed within our social context and represented within our society according to the images and expectations that we have developed and directed towards children. There is a common consideration of the competency of a child (ability to learn, love, be moved, and lived); then again, very little has been done to take this image genuinely (Rinaldi, 2006). Capturing this opportunity to appropriately and marvelously create early childhood programs is the on brink of our modern society. 


\section{Profile changes of WV UPK}

The State of Preschool Yearbook 2011 was released at the time of the writing of this chapter and provided statistics regarding the changes in the WV UPK program in the 2010-2011 school year. West Virginia served nearly three percent more four-year-old children in 2010-11 (58.2\%) than in $2009-10$ (55.3\%), but the access rank decreased from three to five; two states increased percentage served more rapidly putting Florida, Oklahoma, Vermont, and Georgia ahead of WV for the number of four-year-olds served. The total number of three and four-yearolds served was $33.6 \%$, the fourth highest percentage of children enrolled in the nation. WV UPK remained unchanged in the total number of benchmarks met (eight out of ten), state spending per child increased by approximately 80 dollars (\$5605), and overall investment per child decreased by nearly 300 dollars $(\$ 9136)$. The resource rankings increased for state spending from $10^{\text {th }}$ in the nation to $8^{\text {th }}$ and all reported spending remained constant at $4^{\text {th }}$. The two benchmarks that were unmet were the same as in years past, teacher degree and assistant teacher degree. WV planned to revise and strengthen the assistant teacher requirements during the 2011-12 school year. As discussed by the teachers in their interviews, the child assessment system was revised in 2011 and now includes an assessment system that encompasses the Early Learning Scale, health data, and additional information from the WV Early Learning Standards Framework (Zigler, et al., 2011). 


\section{Interpretations}

\section{Private vs. public experiences}

Results describe pre-k experiences in a private setting to be more favored when compared to experiences in a public setting. The average rating of the eight private center participants was a $4.7 / 5$ compared to a $3.8 / 5$ rating for programs situated in a public school setting. Of all sixteen participants - private center was preferred by eleven, two for public, and three did not express a deep-seated preference. This inclination is worthy of note because research shows that in some states standards vary depending on whether a program is housed in a public or private setting. Some state-funded, private pre-k programs have lower quality baselines and are sometimes perceived by parents to be lower-quality as well, even if standards are the same. In many cases teacher compensation is lower resulting in higher rates of staff turnover compared to programs in public settings (Hustedt \& Barnett, 2011). Interestingly, two out of four teachers (one public, one private) prefer the classroom

environment for children opposite than what they are teaching in. Two teachers didn't specify a personal point of view and had similar responses, "so much depends on the child. They all have such individual needs" (Cottage). Furthermore, both public setting teachers would not send their child to their program. One teacher reported, "If I had pre-k aged children now, I would not send them here. Not because of bad quality, just that the other place is a higher quality" (Novell). However, she contradicted herself at a later point and said "I would rather send my child to a public setting over a private setting. I feel like we have more standards. I also feel like there are better classrooms than others." The other teacher is not planning to send her toddler 
to pre-k in her community because she "feel[s] that is another year of school that she might not need" and she "feel[s] that I can offer her the same stuff at home" (West End).

Teachers have the ability to scrutinize aspects of the program that may be specific to early childhood professionals. They have received an education in understanding and evaluating both types of programs. Teacher participants shared their unique opinions when asked about their perspective. All teachers only have prior experience in the settings in which they currently teach; the teachers at Cottage and Happy Hands have only taught in private settings and the teachers at Novell and West End have only taught in public settings. One private teacher (Happy Hands) thought pre-k in the school would make for an easier transition to kindergarten and the public teachers thought that the public school setting was too overwhelming and the other thought the experience was completely dependent upon the child's teacher. This ability to discern differences in programs without experiencing them both may play a role in their assessments or it may be an occurrence of "the grass is always greener on the other side" idiom. Each of the teachers have familiarity with WV UPK solely in the situations in which they are currently teaching; therefore it is unexpected that the majority selected the opposite classroom type from that which they are most accustomed.

Also supporting the preference for private programs that emerged from this research, five out of six parents of children in public school programs would select private programs if available and affordable. "I want my daughter to have the full benefit from the schools available. If I could pay for private school, she most likely would be in a private school" (Novell, Parent 1). Evidence from another parent was "I think that if there were definitely private programs that were out this way, we would have taken that opportunity" (West End, Parent 2). 
One parent supported the statements above by saying, "private schools have more one-on-one feel with the children" and followed up with "I prefer private. I look at the private sector and a lot of the values have been wiped away from the public centers. I don't think it's making the environment safe or good for my child. The private settings which up holds moral values" (Novell, Parent 2). This parent was the only to mention this specific and isolated reason why she preferred a private education for her children. She was raised in another country and her children are the first generation to be educated in America. This mother was the single participant that was foreign born and educated and it raises the question of how character education is delivered in other countries compared to the U.S. in early childhood. Further exploration of this specific dynamic would delve into if private education focuses more heavily on morals and values in her country and if her judgment that private is superior in America for this sensed reason is valid.

Parents made remarks on criteria that they perceived to be different or better, but did not actually experience the private center UPK programs to know if these sensed distinctions were actualized. It is attention-grabbing to establish that the preference of private programs was more numerous than for public programs, but there is not substantial evidence or recurring rationalizations to draw conclusions.

All Cottage parents thought it should be "mandatory," accounting for three out of three of the parent participants to have this perspective. There were a total of four responses for "mandatory" - one teacher (Happy Hands) and three parents-and were all private center participants. This dynamic also lends to the possible deduction that experiences in private centers were superior to experiences in public sites. No public site participants responded that 
they felt the program should be mandatory, presenting the question as to whether they value personal decision for participation more highly or have concerns about the program in public sites that need addressed. It will be important to establish the underlying reasons for each side of this dynamic and determine if it is replicable in future studies.

WV Universal Pre-k System is currently orchestrated by requiring that half of the programs are operated in collaborative settings with child care centers, private prekindergarten centers and Head Start agencies. It is estimated that one-third of all state pre-k participants attend a program in a private setting, whereas in WV, $60-69 \%$ of children are served in a private setting (Hustedt \& Barnett, 2011). Based on the findings from this research, it is recommended that other parents and teachers be interviewed to determine if they express the same viewpoints when asked the question, "What pre-k structure would be the best for your child or family?" If on-going research confirms the preference for private pre-k experiences, the WV UPK program could be restructured to provide ample opportunities for children to be enrolled in these settings. In one of the rural sites (West End) for this study, parents did not have the option to choose between public and private, because no private centers were open for business in their community. Though there must be a space provided for all four-year-olds, access is not equitable, some families have no choice in the style of the program that their child attends.

One reason expressed by many of the parents in public settings as to why they did not enroll in a private center was because of the tuition charged by private centers. The state only covers the cost of care during the hours of operation as determined by the county school system. Nonetheless, if parents do not participate in before or afterschool care there would not 
be a fee charged to parents. However, one of the centers in this research charged a supplementary fee for art supplies and for field trips. Within the typical school day hours, attendance would be free; many parents in this study were unaware of this alternative. A question arising from this research is if centers provide school-day-only attendance as an option, or if they only offer it solely as a childcare package, offering UPK to families who need to utilize child care (before and after school care) services in addition. Below is one conversation that confirms the misunderstanding or miscommunication about how UPK families are served in private centers. This mother is currently only utilizing the program for pre-k services and does not need or wish to utilize the childcare services that are offered before and after the pre-k operational times.

Interviewer: You mentioned that there are other parents that aren't utilizing the full time care available, why aren't you doing that as well?

Parent: I actually just, it's been ten days that I haven't been working full-time. My one position ended, so now I'm home.

Interviewer: If it had been like that at the beginning of the school year would your opinion have changed?

Parent: I think I would have tried to negotiate. Maybe a different price for less time in the classroom.

Interviewer: Between the hours of about, nine and two it's free, right?

Parent: No, it's not. It's $\$ 75$ a week per child. (Happy Hands, Parent 1)

When exploring this phenomena more directly, questions would need to be included that asks how care in a private vs. public setting preferences for before and after school care as 
well as Friday and break care, possibility of having one teacher instead of a teacher and an aide, not having access to the bus system, and being in a setting with younger children instead of older children would influence their opinions. This recommendation is based upon the data that arose from the interviews with families in private settings concerning the reasons why they selected private over public programs.

\section{Socialization}

Socialization was identified as a primary reason for participation in UPK by thirteen participants (81\%). This theme brings to light the potential differences in how people define, perceive, or deem socialization. In the casual and intellectual sense of this word, there is vagueness in this term. There were defining keywords and categories that were assigned to this theme according to how it is defined in research and by the researcher, but a tension in the findings materialized. Participants valued the power of choice-having the opportunity to select the program that they believed was the best fit for their child, or oftentimes, identifying the program they desired for their child, but were unable to acquire for various reasons. This research indicates that parents expressed a preference for privatization over public programming, but identified socialization as a primary reason for enrollment. Future studies could solicit particular individual definitions on this term. Is socialization regarded as a method of preparing children to negotiate school, imparting values, establishing rapport with fellow classmates or teachers, etc.? Furthermore, socialization encapsulates various components including diversity, which was also addressed in this study. To allow state policy makers to proceed with establishing an optimal educational complex that garners the endorsement of 
parents, teachers, and society, socialization needs to be clarified so that the family's feeling of wariness towards government institutions displayed in this study is minimized in the future.

\section{Organizational challenges}

When queried about the barriers to complete satisfaction, what would they change, or to describe their optimal experience, participants' responses could be categorized into three recurrent themes: UPK under wraps, enrollment process and transitions, communication and ratios.

\section{$\underline{\text { UPK under wraps }}$}

Firstly, parents expressed that there was a general public lack of understanding about and awareness of the program. Parents disclosed that they stumbled upon the opportunity or became aware of it through word of mouth. One mother summarized the sentiments of several other participants, "The important thing to do is to get that word out. I don't think people fully know that UPK even exists. I just happened upon it by talking to people" (Novell, Parent 3). This is particularly disconcerting because this mother has three older children in public school.

This finding started to present itself in the fourth parent interview and it was almost comical to me at the time, but then it started to repeat as a recurring theme. The first and second parent interviews were Head Start families and referred to pre-k through that program, the third parent interview was a private center family whose children had been in the center for two years already and they were transitioning into the UPK in their current setting.

Parent: The whole program could probably do with a better opening up to the public. Some PR! 
Interviewer: How would they communicate with the public?

Parent: Let people know the benefits.

Interviewer: How do you share that?

Parent: Maybe send out representatives to where people are employed.

Interviewer: Do you really think there are parents who don't know that pre-k is offered?

Parent: They may be like, "there is nothing wrong with letting family watch the kids all

day," but the family is not teaching them how to sit still and be quite and other things

like that that they are getting in pre-k. It could be presented to parents in that light.

They probably know that it is there but haven't seen why it is so much more beneficial.

Upon investigating this finding on the internet and specifically the county schools

website, there does seem to be a disconnect between pre-k and K-12. Public education is

established and well-known for the higher grades, but for parents with young children who are not aware of this opportunity, it is difficult to unearth adequate information in the areas where the research occurred. Parents are accustomed to asking questions about education for their children who are about to enter kindergarten, but with UPK being a relatively new program they may not know to begin asking questions when their children are turning four instead of five. This is a point in the research where I would like to annihilate my former knowledge to put myself in the same situation as these parents. How does information sharing occur if your child does not participate in any programs? Phone calls were made to the pre-k offices that are administered by the county board of education offices. The research was conducted in two neighboring counties in northern WV. One office said that they promoted the program during open enrollment time in February via the local newspaper, radio stations, and the community 
channel on television. There is also the online presence on the county schools website. When the other office was asked how they let parents in their county that pre-k is available, they responded that they can come in and fill out an enrollment application. When questioned about how it is advertised, they also run advertisements in the local newspaper during open enrollment and have an online presence. It should also be noted that the phone number for the pre-k office on this county's website was incorrect and they were not aware of the error when I brought it to their attention. My deduction is that pre-k is most widely used by parents who know to ask and look for this opportunity. Families that move from out of the state or miss the

publicity during open enrollment period may miss the opportunity to participate all together for this reason. More than likely there are children not being served simply because parents are not aware that UPK is available.

WV moves forward this year to meet their goal of full implementation next school year. 42\% of eligible children in WV are not participating in UPK as of 2010-11 (Barnett et al., 2011), which could be explained by this detail that the parent participants supplied. Lack of public awareness could be isolated on a county-by-county basis, but this happening needs to be explored more fully.

\section{Enrollment process and transitions}

Another recurring theme that merits attention is the troublesome enrollment and transition process. Parents in private and public centers alike discussed their quandaries with the method in which they had to enroll their child in the UPK program and the forthcoming kindergarten transition. 
Some parents felt that the communication between the family and the county was not adequate, informative, or correct while others questioned the credibility of the program because of the inaccuracies they experienced with enrolling. Meeting teachers and observing classrooms was voiced as a desire and the process was described as stressful. "I had asked for him to be put on the wait list but he was assigned a different place that I didn't want. So then he did get on the wait list but I didn't know that at the time... They give you a check list of places that you would go, it was a place that I hadn't even selected" (Novell, Parent 3). Information sharing needs to be more timely, accurate, and detailed according to several parents. It is unknown whether the problematic communication will be corrected during full implementation when there are no longer wait lists, or if it is a matter that needs to be foundationally addressed. It is recommended that a user-friendly website is easily accessible and maneuverable for parents searching for information about WV UPK in general, particularly in their county. The screening in and of itself was viewed positively by teachers and parents, but the process in which enrollment occurs was regarded in a negative light.

The screenings offer parents and teachers an insight on the specifics of the child as they are entering the program, "They offered it in the summer this year before they started school to be prescreened for any issues be it speech, hearing, etc. so they did have that if they were signed up for the pre-k program. I think the pre-k screenings are helpful to the families and the teacher to provide them with the services that they need" (Teacher, Cottage). The negative light arises from the counties communicating effectively with the parents and there was some misunderstanding about what the screenings entailed, 
We were disappointed when we did the pre-k screening. They didn't tell us anywhere in the paper work to bring our child. We thought we were supposed to fill out the paper work. We didn't know that they did a hearing test, and the sight, the reading vocabulary. We had to go to the doctors, get their dental records, have their teeth checked. We did all that stuff and we had to sit in a big auditorium with all these people. This information wasn't dispersed well enough for us...That was done through the state and through the county. I made a comment here later to the board in [our] county that I don't think some of the crazy things they assume you know, you don't know. They sent you the paper work and said please go to the doctor's office and do all this. We did all this. We had everything up to date and the records, it didn't say to bring your kid. We didn't know what we were going for. We thought we were going to bring in the paperwork and they would give us information as to what to expect in your children as the advance. (Cottage, Parent 1)

Administration should consider being at the level of understanding of the parents. It is difficult to correspond effectively assuming that one party knows what the other party knows. Parents may be less confused if paperwork, materials, and accompanying information were clearer and less assumptive. Parents were put off by the size of the screening days and it was reported that children were intimidated with this first pre-k experience as well. It is advised that there are additional locations or times arranged to accommodate children and families during this screening process in more intimate manners.

Although parents were interviewed less than one-half way through the school year, many were apprehensive about how their child would transition to kindergarten. The 
apprehension was greatest for parents of children in private centers, most likely because they had not made the initial transition to the school building setting and do not know what to expect.

I don't know how kindergarten works; I know we visit the schools but at [Cottage] that's one of the things would do. We could go in one day and observe and get to know the teacher beforehand. Some of that would be nice. I guess they do parent teacher conferences. If they did those things up front, it would make a difference. You're sending your child there every day, and you'd like to know what they are doing when your mind wanders, 'Oh, I wonder what they are doing today.' At [Cottage] I have an idea, with kindergarten, I don't know. (Parent 2) In a study that explored the transition-related activities of pre-k and kindergarten, pre-k was found to provide a lesser range of activities and poorer support for families and children when compared to kindergarten transitions. Activities that were provided during transition events were typically informational via a dissemination of flyers. Teachers' perceptions of readiness and transition practices revealed that communication about the transition process was less than optimal and a barrier to a successful transition (Gill et al., 2006).

Children in public and private settings have similar experiences across the board, but the one that might be the most variable is the setting. Being in a pre-k in a private setting and being in one in a school building provide parents and children very different familiarities with the public school system. Children have the opportunity to exit pre-k socialized and prepared for kindergarten expectations, but focusing more heavily the transitions for children and families in private centers is advised. Transition plans are a tool that has been successfully utilized by other 
districts to assist positive communication between the families, pre-k, and kindergarten teachers about the child. If used correctly and with the goal of enhancing communication and preparedness, it can serve as a dialogue between the pre-k and kindergarten teachers that can be shared across all settings (Gill et al., 2006).

\section{Communication}

A considerable subject that emerged from the data was that there appeared to be a better communicative connection between families and teachers in private centers compared to the teacher-parent relationship in public centers. Parents reported communication as something that they like the most or as a successful element for private and as something they like the least or as a challenging element for public. Data reinforced the value of face-to-face interaction as being the missing link in the public sector. At least one parent or caregiver has a daily connection to the child's childcare, but some parents had never stepped foot inside their child's classroom when situated in a school setting. There is research evidence linking parentschool relationships with children's school readiness. A recent study support that parents' participation in school activities is positively associated with a child's outcomes, specifically their social outcomes and mathematics. Perceptions of teacher responsiveness were also studied and positive parent ratings of teachers predicated a child's social outcomes and early reading skills (Powell et al., 2010). Generating a classroom that can accomplish a positive communicative connection with all families is challenging because of the 'fragmented society' in which we live. Our children's families and their needs are so multidimensional it is difficult to 
maneuver the individual needs to establish an exchange of communication and school-home relationships (Rinaldi, 2006).

Teachers acknowledged that one of their roles is to create the initial relationship with the parents and their child's education. The importance of connecting a parent to their child's learning, especially for such young learners, needs to be addressed with UPK parents at the enrollment stage and continually throughout the year so they fully understand and value their responsibility.

\section{$\underline{\text { Ratios }}$}

Parents deemed ratios in different lights depending on the setting of their child's experience. Ratios in private centers were considered to be an asset and providing more oneon-one attention. Public sites were thought to be more overwhelming for children and parents reported they wanted more teacher support or fewer children. Parents at the public sites did however, comment positively on the aid in the classroom. The ratio mandates are exactly the same at 1:10-both private sites had only one teacher and the public settings had a teacher and an assistant teacher. Maximum group size not present in all classrooms and was group size was reduced to 18 in Novell, the classroom that accommodated multiple special needs children. The only teacher that did not mention being limited by ratios or instructional support was the teacher at Happy Hands. The teacher at Cottage most desires continuity of care for her children while in the childcare part of their day so that communication about the child is enhanced. She also was in favor of having a colleague to assist in her instructional planning. The two public sites teachers were most concerned about the number of children they were serving; one 
teacher preferred another adult and the other teacher preferred fewer children in her classroom. Research supports that having smaller class size and aides are associated with positive gains in performance (Mosteller, 1995).

Ratios will always be a hot topic in early childhood education. Children are demanding of more time and attention that what can be provided, but WV falls within the national guidelines for recommendations for ratios and maximum group size. Ratios are major determinants of quality and expense of care and I do not expect for them to change in the near future, for the better or worse. Intriguingly, perceptions of ratios are different and appear to be more satisfactory according to both parents and teachers when there is a smaller class size, as opposed to larger class with more teachers.

\section{Collaborative/Inclusive Classrooms}

The final topic of discussion is the contention of having children with special needs inclusive in the same classroom as typical learners. Participants responded to this research generated theme with separate concerns. One of the three emergent matters were that it is difficult to meet the needs of all students' needs in public settings that serve children with special needs. The teacher at Novell shared, “I don't think there are the resources in the classroom to meet the needs of special needs children who need the constant supervision. To meet their needs and the needs of the other children in the classroom is very difficult and I don't think that is happening optimally." She followed up with her suggestion on how to better serve all children who participate in programs like the one she teaches in: 
When they go to kindergarten, they have and aid and the teacher. If they have a child with special needs, there is going to be a special needs aid or a special needs teacher pull him out, so why can't that be the case with preschool? I understand that they are younger, but sometimes they have more needs because they might not be potty trained or they aren't communication as much. If you could have those supports in place in higher grades why can't you have those supports in place here?

In a separate study, researchers' perceptions about inclusion were quantitatively collected using Head Start and Pre-k teachers as the participants. Teachers reported considerably that young children with and without special needs are more similar than dissimilar and believe that learning alongside one another is important in pre-k. These teachers reported that they felt confident in their ability to accommodate both styles of learners by adapting the classroom environment, but identified the need for more training opportunities (Bruns \& Mogharrean, 2007). This study did not examine teachers' perceptions as to if they felt additional adult support or lower ratios would allow them to serve all children better. The perceptions about inclusion in this study and my research are not entirely unrelated, participants acknowledged the importance and benefit of inclusion, but the two groups produced varying solutions to the challenge.

The desire to separate three-year-olds and four-year-olds was also discussed by parents and teachers. One mother commented, "I think ages should have separate classrooms. I've always been confused by Head Start and pre-k. I think that there should be a class for three year olds, or whatever, that makes them operate at the level of a three year old. Four and five year olds are ok, but the littler kids should be kept separate" (West End, Parent 3). This was 
after she also shared about how she felt guilty about subjecting her son to this experience because of the severity of needs of his peers and the curriculum being below his ability since he was the oldest child in his class. The blended age and abilities is more common in public settings than private settings. Parents and teachers raised valid opinions and justified them as to why they did not feel that the current pre-k experience was optimal. These ideas can be explored to see if other key informants express the same opinions and the pre-k classroom could be considered more like an elementary classroom, meaning that additional supports may be necessary for special needs learners. In these circumstances, abilities can supersede ratios to impart an optimal experience for all children in the classroom.

Specific to private settings, teachers and parents agree that it is difficult to meet the needs of special needs students. One participant spoke specifically on the challenges she faced trying to identify and receive services for her son. She had to assume the role as advocate because the private sector was not well aligned with the services provided to school children. This became a substantial topic of her interview and her aggravation was sensed, but the love for her child was stronger. Overall, she reported a positive experience; however, she would have liked to have seen the system supporting her family more effectively.

I think the staff and the services that they provide are the best, overall there could be more integration for kids with special needs. Trying to get [my son] screened for autism and what not has been extremely difficult. I remember at one point we felt like we were taking the correct course of action and was expecting certain results but didn't exactly obtain those. But I think that was more to do with the school board, I don't think that was any fault of [Happy Hands] or the staff there. I think we've had to do a lot more 
independent leg work and led to places that could've been cleared up by some straight forward yes or no answers. (Parent 3)

The teacher at Cottage likewise shared her distress in providing services to a child with behavioral challenges. Safety for herself and the children in her classroom were her primary concern, but she also feared that the child was not being adequately prepared for what would be expected of him in kindergarten. A behavioral specialist with the county visited her classroom on several occasions and provided feedback, but ultimately she was the only one available to deal with this child and the other peers when he went into a rage. Being in a childcare setting does not allow for the teacher to seek the help of another teacher, specialist on site, or provide the safety of another space when a child needs special attention. Though private centers are not the primary facility to care for children with special needs, there are instances in which reasonable accommodations are made, but are not the best for all involved. Attention must be brought to the need to work more successfully with the county and family to assure a smooth transition to special education services in the current facility and future public school setting. Establishing the capacity for all children to learn and succeed at their own undertakings could also be beneficial in creating an atmosphere where all learners are supported to their full potential. While focusing on the roles of the teachers and learners, Malaguzzi posed this idea, "We must give enormous credit to the potential and the power that children possess. We must be convinced that children, like us, have stronger powers than those we have been told about, powers which we all possess-us and children, stronger potential than we give them credit for. We must understand how, without even realizing it, we make so little us of the energy potential within each of us" (Rinaldi, 2006, p. 55). Kindness and patience 
must also be imparted so that all children and adults are accepted for who they are, what they are capable of so these collaborative classrooms can be mutually beneficial for all. However, the appropriate support mechanisms are essential for making this symbiotic relationship effective.

\section{Generalizability}

The results and implications from this study can be examined to determine if there are any cross references between these findings for pre-k that can also be linked to higher grades. The topics discussed as outcomes of this research lend it to be associated with education across all levels, not specifically connected with only pre-k. Parents and teachers can participate in a similarly designed study to establish if there is a correlation and if the findings can be generalized to other stages of public education. If it is established that there are parallel matters that prevail from pre-k through twelfth grade or even into higher education, these issues need to be addressed and discussed at all sectors regarding how it effects a child's education.

\section{Recommendations for future research}

Results from this research encourage and suggest several additional follow-up studies. Recommendations for future research and calls for attentiveness were introduced in the discussion above and will be summarized in this section. An interesting happening that surfaced in the preliminary research process crosses all disciplines as a potential research topic-which traits constitute willing participants? In this study there was one rural site and one public site 
that had good consent returns/participation rates. Out of these two sites, at least half of the participants contacted agreed to be willing participants. However, the other rural and public sites had poor consent returns/participation rates, requiring teacher intervention at both points. There was no data collected from the non-respondents and families who refused to participate, so a comparative data analysis could not be conducted. This question emerged in the beginning and was not resolved, thus remaining an interesting dynamic to consider throughout the study as to whether it had any influence on the results.

A second question for further investigation is if UPK perceived by parents and educators as primarily care or education. Participants shared why children were participating, but were not asked to identify how they categorized the experience. Parents and teachers report that the service is being utilized for both child care and educational preparation, but what do they feel is the greater outcome-that their child is being cared for or that they are being educated? It would also be interesting to establish if there is a relationship between income and how pre-k is classified. This research had families representing working-class and stay-at-home households as well as those from all income ranges. In particular, there were two stay-at-home mothers who reported to have upper-middle incomes who enrolled their children in the public school settings. Is this a common connection and what are the rationales for this decision? This inquest may not be significant, but it may affect perspectives of experiences and could potentially have some bearing on the discrepancy between stories for private and public settings.

Nearly $32 \%$ of four-year-olds in WV are not participating in WV UPK, despite it being one year away from full implementation in which a space is provided for every child. A study similar 
to this research design needs to be conducted focusing on parents of children who did not participate in a universal pre-k program. It is recommended that the study is conducted during the year of the child's eligibility to determine rationales as to why parents prefer not to enroll their children. This research will need to explore whether it is a result of the participants in this study making known that that they felt the program was kept under wraps or if it is for other unidentified reasons.

Possibly the research topic in most need of consideration related to this study is if the private vs. public interpretations can be replicated. Do a broader range of participants in different areas of $\mathrm{WV}$ and even the nation share the same preference for private pre-k experiences compared to those housed in public sites? What are the reasons they share and can they be validated? Once it is determined if this finding is specific to this research or if it is generalizable, conclusions can be made as to whether it should influence future UPK programming.

Dynamics to explore in future research emerged from the data and interpretations as well. To establish a richer understanding of the preference for private setting over public setting, one could examine the ECERS-R ratings of the participant classrooms in future studies. Is the classroom environment rating related to the parent and teacher perceptions of preference for the setting?

\section{Implications}

I suggest that a four-pronged approach is taken with moving forward with this research data. Firstly, the results of this study should be examined closely to determine if it is within the 
realm of WV UPK to address some of the pressing issues and challenges raised by the participants. Secondly, once feasibility of forward movement is ascertained, this study should be replicated in other areas of the state to establish if the conditions and results are generalizable to other participants and regions. If divergent research is collected, it is just as important to critically examine the counties in which this study was conducted to address some efforts that parents and teachers reported to be challenging. Thirdly, if findings are duplicated, then it is important to work on these issues from the outside in and from the inside out. Since each county is responsible for implementation of a state program, the approach needs to be seamless and universal so that all children are provided equitable opportunities for a pleasurable and valuable UPK experience.

Finally, WV is still a national leader in the UPK endeavor. While there are still ten states that have not developed a four-year-old program, we are at the occasion in which we are critically examining program components and public investments. Parents and teachers need to be considered as key informants regarding what is effective and what is ineffective. There are few people more qualified to rate and improve a program than those who have a direct lived experience and personal investment in the success of the program and the children who are participants. 


\section{Table 6: Summary of Key Findings}

1. The parents' descriptions of reasons that children participate in pre-k are often the same as the perceived outcomes of their participation.

2. There are some overlaps in positive and challenging elements experiences (philosophy \& program structure) that seem to be related to personal experiences for parent and teacher participants.

3. Participants have not come to a consensus about whether the state should provide education, care, or other services to children less than four years of age.

4. The majority of respondents reported that they desired for pre-k to remain optional.

5. Results describe pre-k experiences in a private setting to be more favored by parents and teachers when compared to experiences in a public setting. There was not substantial evidence nor recurring rationalizations to be able to indicate the reason for this preference.

6. Parents with children in private and public site programs expressed that there is a general public lack of understanding about and awareness of the program.

7. The enrollment and transition process for UPK is troublesome for families in both private and public programs.

8. There appears to be a better communicative connection between families and teachers in private centers compared to the parent-teacher relationship in public centers.

9. Parents deemed ratios differently depending on the setting of their child's experience. Ratios in private centers were considered to be an asset, providing more one-one-one attention. Public sites were thought to be more overwhelming for children and parents reported they wanted more teacher support or fewer children in a classroom.

10. It is difficult to meet the needs of special needs children who need constant supervision with only one teacher and one aide as detailed by parents and teachers in public settings. Teachers and parents agree that it is difficult to meet the needs of special needs children in private settings.

11. Parents and teachers desire to separate three-year-olds and four-year-olds, specifically in public setting inclusive classrooms. 


\section{Conclusion}

I entered the story of twelve parents and four teachers. They imparted their experiences and perceptions of conditions in which pre-k in WV is satisfactory and ways in which it can improve. These findings have been recorded and discussed, but more stories need to be studied. Professionals and parents are accountable for providing children a childhood rich in experiences, opportunities, merriment, and helping them to develop to their fullest potential. There is no life stage as remarkable as childhood and there should be no opportunities as exceptional as the ones that are bestowed.

A progressive approach is necessary to make sure that we are not disentangling one issue and creating a new dilemma. Early childhood is a continual period of growth and development. It does not start at four and end at kindergarten entrance. Moreover, education is also an unending process that does not have a start and end point. Universal prekindergarten is an undertaking that is gaining national dialogue, but is a mere solitary, albeit influential, year of a child's educational experience. The endeavor to provide care and education to our upcoming generations should not value any age more than another. A systematic and holistic approach to supporting the success of children needs to be the priority for public funds and investment and the key informants as to what is best for children should be the teachers and parents who know and love children the most. 


\section{REFERENCES}

Adams, D., Edie, D., Riley, D., Roach, M., \& Ittig, M. (2004). What we know about prekindergarten outcomes for children: the top ten findings from early childhood research. Early Childhood Research Digest.

Akerman, D., et al. (2009). Providing preschool education for all 4-year-olds: Lessons from six state journeys. National Institute for Early Education Research.

Allen, A. T. (1988). Let us live with our children: Kindergarten movements in Germany and the United States, 1840-1914. History of Education Quarterly, 28(1), 23-48.

Barnett, W. S. (2007). Benefits and costs of quality early childhood education. Children's Legal Rights Journal 27(1), 7-23.

Barnett, W.S. (2008). Preschool education and its lasting effects: Research and policy implications (Tempe and Boulder: Arizona State, Education and Public Interest Center and University of Colorado, Education Policy Research Unit). Retrieved July 29, 2011 From NIEER.org/resources/research/PreschoolLastingEffects.pdf

Barnett, W. S., Carolan, M. E., Fitzgerald, J., \& Squires, J. H. (2011). The state of preschool 2011: State preschool yearbook. New Brunswick: National Institute for Early Education Research (NIEER).

Barnett, W. S., Epstein, D. J., Carolan, M. E., Fitzgerald, J., Ackerman, D. J., \& Friedman, A. H. (2010). The state of preschool 2010: State preschool yearbook. New Brunswick: National Institute for Early Education Research (NIEER). 
Barnett, W. S., \& Frede, E. (2010). The Promise of Preschool. American Educator, 34(1), 21-29.

Bartik, T. J. (2009). Why universal preschool is really a labor market program. Employment Research, 16(3), 8.

Begley, S. (1996, Febuary 19). Your child's brain. Newsweek , 55-61.

Bernard, S. (2007, April 4). Should preschool be a part of public school? \{Web log comment\}. Retrieved from http://www.edutopia.org/should-preschool-be-part-public-school

Bisanz, J., Morrison, F.J., Dunn, M. (1995). Effects of age and schooling on the acquisition of elementary quantitative skills. Developmental Psychology, 31(2), 221-236.

Bloch, M. N., Seward, D., \& Seidlinger, P. (1989). What history tells us about public schools for 4-year-olds? Theory into Practice, 28, 11-18.

Bracey, G.W. (1989). Age and achievement. Phi Delta Kappan, 70, 732.

Bruns, D. A. \& Mogharreban, C. C. (2007). The gap between beliefs and practices: Early childhood practitioners' perceptions about inclusion. Journal of Research in Childhood Education, 21 (3), 229-241.

Bryant, D., Clifford, D., Early, D., \& Little, L. (2005). NCEDL Pre-kindergarten Study. Early Developments, 9(1), 1-31. Retrieved August 12, 1011 from http://www.fpg.unc.edu/ assets/pdfs/eds/ED9_1.pdf

Bureau of the Census (1994). Who's minding the kids. Retrieved August 1, 2011 from http://www.census.gov/apsd/www/statbrief/sb94_5.pdf 
Camilli, G., Vargas, S., Ryan, S. \& Barnett, W. S. (2010). Meta-analysis of the effects of early education interventions on cognitive and social development. Teachers College Record, 112(3), 579-620. http://www.tcrecord.org/library ID Number: 15440, Date Accessed: $7 / 14 / 2011$

Campbell, F. A., Pungello, E. P., Miller-Johnson, S., Burchinal, M., \& Ramey, C. T. (2001). The development of cognitive and academic abilities: Growth curves from an early childhood educational experiment. Developmental Psychology. 37, 231-242.

Campbell, F. A., Ramey, C. T., Pungello, E. P., Sparling, J.J, \& Miller-Johnson, S. (2002). Early childhood education: Young adult outcomes from the Abecedarian project. Applied Developmental Science, 6, 42-57.

Carthum, H. L. (1987). A comparison of the effects of various preschool experiences on achievement of kindergarten students. Dissertation Abstracts International, 48-07A, 1651.

Cavalluzzo, L., Clinton, Y., Holian, L., Marr, L., \& Taylor, L. (2009). West Virginia's progress toward universal prekindergarten. Retrieved from http://ies.ed.gov/ncee/edlabs/regions/appalachia/pdf/REL_2009070.pdf

Children's Defense Fund. (2003). Prekindergarten initiatives: Efforts to help children enter school ready to succeed. Retrieved August 11, 2011 from http://cdf.childrensdefense.org/site/DocServer/keyfacts2003_prekindergarten.pdf?docl $D=589$ 
Children's Defense Fund. (2011). Children in West Virginia. Retrieved 8/18/2011 from

http://www.childrensdefense.org/child-research-data-publications/data/state-datarepository/cits/2011/children-in-the-states-2011-west-virginia.pdf

Children's Defense Fund. (2010). The state of America's children. Retrieved 8/18/2011 from http://www.childrensdefense.org/child-research-data-publications/data/state-ofamericas-children.pdf

The Clinton Administration and Child Care. Childcare accomplishments. (1997, October 23). Retrieved August 1, 2011 from: http://clinton2.nara.gov/WH/New/Childcare/acomplish.html

Cubberley, E. P. (1919). Public education in the United States: A study and interpretation of American educational history. Cambridge: Houghton Mifflin Company.

Datar, A . (2004). The Impact of Changes in Kindergarten Entrance Age Policies on Children's Academic Achievement and the Child Care Needs of Families. Retrieved August 13, 2011 from http://www.rand.org/pubs/rgs_dissertations/RGSD177.

Department of Health and Human Resources (DHHS). (2003). State-Funded Pre-kindergarten: What the evidence shows.

The Foundation for Child Development. (2003). Setting a Research Agenda for Prekindergarten. The Columbia Institute for Child and Family Policy.

Education Commission of the States (2003). Pre-kindergarten Quick Facts. Abstract retrieved August 5, 2011, from http://www.ecs.org.html/IssueSection.asp?issueid=184\&s=Quick+Facts. 
Elkind, D. (1987). Miseducation: Preschoolers at risk. Knoph: New York.

Encyclopedia of Children and Childhood in History and Society Kindergarten. (2008).

Kindergarten. Retrieved August 11, 1011 from: http://www.faqs.org/childhood/Ke$\mathrm{Me} /$ Kindergarten.html

Fred Rogers. (n.d.). Quotes.net. Retrieved August 1, 2011, from: http://www.quotes.net/quote/17012

Gelback, J. B., \& Pritchett, L. (2002). Is more for the poor less for the poor? The politics of means-tested targeting. Topics in Economic Analysis \& Policy, 2(1). Retrieved August 31, 2011 from http://www.bepress.com/bejeap/topics/vol2/iss1/art6

Gibbs, G. (2007). Analyzing qualitative data. Sage Publications: London.

Gill, S., Winters, D., \& Friedman, D. S. (2006). Educators' views of pre-kindergarten and kindergarten readiness and transition practices. Contemporary Issues in Early Childhood, 7 (3), 213-227).

Gilliam, W. \& Zigler, E. (2001). A critical meta-analysis of all evaluations of state-funded preschool from 1977 to 1998: Implications for policy, service delivery and program evaluation. Early Childhood Research Quarterly, 15, 441-473

Gormley, Jr. W. (2005). The universal pre-k bandwagon. Phi Delta Kappan, 87, 246-249.

Gormley, Jr., W. T. (2007). Early childhood care and education: Lessons and puzzles. Journal of Policy Analysis and Management, 26(3), 633-71.

Grubb, W. N. (1989). Young Children Face the State: Issues and Options for Early Childhood Programs. American Journal of Education, 97 (4), 358-397. 
Guzzetti, B. J. (2003). Literacy in America: An encyclopedia of history, theory, and practice. Santa Barbara: ABC-CLIO.

Hinkle, D. (2000). School Involvement in Early Childhood. National Institute on Early Childhood Development and Education. U.S. Department of Education Office of Educational Research and Improvement.

Isaacs, J. (2008). Research Brief \#1: State Pre-kindergarten. Impacts of early childhood programs.

Kagan, S. L. (1989). The care and education of America's young children: At the brink of a paradigm shift? Proceedings of the Academy of Political Science, 37(2), 70-83.

Land, K. C. (2004). 2004 Report: The Foundation for Child Development Index of Child WellBeing (CWI), 1975-2002, with Projections for 2003. Retrieved August 3, 2011 from http://www.soc.duke.edu/ cwi/fcd_cwi_report_04.pdf

Laughlin, L. (2010). Who's minding the kids? Child care arrangements: Spring 2005/Summer 2006. Household Economic Studies, p. 70-121.

Lester, S \& Russell, W. (2010). Children's right to play. An examination of the importance of play in the lives of children worldwide. Working papers in Early Childhood Development, 57. Retrieved August 15, 2011 from http://www.fairplayforchildren.org/pdf/1308611992.pdf Lindlof, T. R. \& Taylor, B. C. (2002). Qualitative Communication Research Methods (second ed). Sage Publications, Thousand Oaks, CA. 
Marshall, C., \& Rossman, G. B. (2011). Designing qualitative research. Retrieved September 16, 2011 from http://books.google.com/books?hl=en\&lr=\&id=RbqXGjKHALoC\&oi=fnd\&pg= $\mathrm{PR} 1 \& d q=$ qualitative+research+theories\&ots=BLeHrpSa40\&sig=DqlvaK8Rd3QVns9wJWg xyRGQC-U\#v=onepage \&q=qualitative\%20research\%20theories\&f=false

Magnuson, K., Meyers, M., Ruhm, C., \& Waldfogel, J. (2004). Inequality in preschool education and school readiness. American educational Research Journal, 41, 115-157.

Magnuson, K., Ruhm, C., \& Waldfogel, J. (2007). Does pre-kindergarten improve school preparation and performance? Economics of Education Review, 78, 22-51.

McCabe, L. A., \& Frede, E. C. (2007). Challenging behaviors and the role of preschool education. National Institute for Early Education. Policy Brief, 16. Retrieved August 11, 2011 from http://nieer.org/resources/policybriefs/16.pdf.

Merriam-Webster.com. (2011). Universal. Retrieved August 26, 2011, from http://www.merriam-webster.com/dictionary/universal

Mitchell, A. (2001). Pre-kindergarten programs in the states: Trends and issues. Early Childhood Policy Research.

Mondale, S. \& Patton, S. (Eds.). (2001). School: The story of American public education. Boston: Beacon Press.

Montes, G. (1997). Public Funding and Institutional Reorganization: Evidence from the Early Kindergarten Movement. Nonprofit Management and Leadership, 7 (4), 405-420.

Mosteller, F. (1995). The Tennessee study of class size in the early school grades. The Future of Children, 5 (2), 113-127. Retrieved May 31, 2012 from http://www.jstor.org/stable/1602360 
National Association of Child Care Resource \& Referral Agencies (NACCRRA). (2007). The high price of child care: Parents are forced to choose between quality and cost. Retrieved July 29, 2011 from http://www.naccrra.org/news/press-releases/37/

National Association of Child Care Resource \& Referral Agencies (NACCRRA). (2011). 2011 Child care in the state of: West Virginia. Retrieved July 29, 2011 from http://www.naccrra.org/randd/data/docs/WV.pdf

National Association for the Education of Young Children. (2009). Developmentally appropriate practice in early childhood programs serving children from birth through age 8. Retrieved August 14, 2011 from http://www.naeyc.org/files/naeyc/file/positions/position\%20statement\%20Web.pdf National Governors' Association. (1990). Text of statement on education goals adopted by governors. Education Week.

Obama for America. (n.d.) Education. Retrieved August 11, 2011 from http://www.barackobama.com/issues/education/

Office of Education. (1966). Nursery-kindergarten enrollment of children under six. Washington, DC: U.S. Department of Health, Education, and Welfare.

Perry, B.D. \& Pollard, D. (1997). Altered brain development following global neglect in early childhood. Society for Neuroscience: Proceedings from Annual Meeting, New Orleans Quality Counts 2002. Education Week, 17, January 10, 2002. 
Quality Pre-kindergarten for All: State Legislative Report. Washington, DC: The Trust for Early Education, 2004. Retrieved August 1, 2011 from http://www.pewtrusts.org/uploadedFiles/wwwpewtrustsorg/Reports/Prek_education/early-ed-LR-904.pdf

Powell, D. R., Son, S., File, N., \& San Juan, R. R. (2010). Parent-school relationships and children's academic and social outcomes in public school pre-kindergarten. Journal of School Psychology, 48, 269-292.

RESULTS (n.d.) Early Childhood Education. Retrieved August 12, 2011 from http://www.results.org/issues/us_poverty_campaigns/early_childhood_development/h ead_start

Rinaldi, C. (2006). In dialogue with reggio emilia: Listening, researching, and learning. London and New York: Routledge.

Ryan, J. E. (2006). A Constitutional right to preschool. California Law Review, 94(1), 49-99.

Scarr, S. (1998). American child care today. American Psychologist, 53(2), 95-108.

Schweinhart, L.J., Barnes, H. V., \& Weikart, D. P. (1993). Significant benefits: The High/Scope Perry preschool study through age 27. Monographs of the High/Scope Educational Research Foundation, 10. Ypsilanti, MI: High/Scope Press.

"Socialization." Encyclopedia of Identity. Thousand Oaks: Sage Publications, 2010. Credo Reference. 15 Oct. 2010. Web. 11 Apr. 2012. <http://www.credoreference.com/entry/sageidentity/socialization>. 
The state of America's children. (2010). Retrieved August 2, 2011 from.

http://www.childrensdefense.org/child-research-data-publications/data/state-ofamericas-children.pdf

Strauss, A. and Corbin, J. (1990). Basics of qualitative research: Grounded theory procedures and techniques. London: Sage.

Swartout-Corbeil, D. (2006) "Preschool." Gale Encyclopedia of Children's Health: Infancy through adolescence. Retrieved July 14, 2011 from Encyclopedia.com: http://www.encyclopedia.com/doc/1G2-3447200463.html

Templeton, R. A., Dozier, J., \& Boswell, L. (2009) Universal Access to Pre-k in West Virginia. Report for the West Virginia Department of Education.

The Trust for Early Education. (2004). Quality Pre-kindergarten for All: State Legislative Report. Retrieved August 6, 2011 from http://www.pewtrusts.org/uploadedFiles/wwwpewtrustsorg/Reports/Prek_education/early-ed-LR-904.pdf

Uphoff, J. K. \& Gilmore, J. (1985). Pupil age at school entrance-How many are ready for success? Educational Leadership, 43 (1), 86-90.

West Virginia Department of Education (WVDE). (2003). WV Code §18-5-44 Frequently asked questions. Retrieved August 2, 1011 from http://www.wvdhhr.org/oss/pieces/ta/faq.asp

West Virginia Department of Education (WVDE). (2011). Building intentionality in a collaborative design and implementation for West Virginia universal pre-k. Retrieved August 2, 2011 from http://wvde.state.wv.us/osp/wvprek/PreKOverview_4.20.11.pdf 
The White House President Barack Obama (n.d.). Education.

Retrieved August 3, 2011 from: http://www.whitehouse.gov/issues/education

The White House President George W. Bush (n.d.). Early childhood education initiative.

Retrieved August 3, 2011 from:

http://georgewbushwhitehouse.archives.gov/infocus/earlychildhood/

Who's minding the kids? (1994, April). Retrieved from Bureau of census statistical brief website: http://www.census.gov/apsd/www/statbrief/sb94_5.pdf

Widmer, E. L. (1967). Why kindergarten? Peabody Journal of Education, 44(4), 210-215.

Winterer, C. (1992). Avoiding a "Hothouse System of Education": Nineteenth-Century Early Childhood Education from the Infant Schools to the Kindergartens. History of Education Quarterly, 32(3), 289-314

Wong, V. C., Cook, T. D., Barnett, W. S. \& Jung, K. (2008). An effectiveness-based evaluation of five state pre-kindergarten programs. Journal of Policy Analysis and Management, 27 (1): 122-154.

Zigler, E. \& Muenchow, S. (1994). Head start: The inside story of America's most successful educational experiment. 


\section{APPENDICES}

\section{Appendix A}

\section{RESEARCH AND INTERVIEW QUESTIONS}

TINKERING AT THE EDGES OF PUBLIC EDUCATION

Teacher and Parent Perceptions of West Virginia Universal Pre-kindergarten

Research Questions, With the Interview Questions that will address the Research Questions

Why are children participating in UPK programs in WV?

- What are the needs of pre-kindergarten-aged children?

- Is WV UPK meeting the needs of pre-kindergarten aged children? How?

- Parent: What is the primary reason your child attends a pre-kindergarten program? Explain. Teacher: What do you feel is the primary reason a child attends a prekindergarten program? Explain.

- What are the needs of parents of pre-kindergarten-aged parents?

- Is WV UPK meeting the needs of parents? How?

- Parent: Why did you make the decision for your child to participate in UPK? Explain. Teacher: Why do you feel parents make the decision for their child to participate in UPK? Explain.

- Parent: Did you have any reservations about enrolling your four-year-old child in a public pre-kindergarten program? Explain. Teacher: Do you have any reservations about four-year-old children attending a public pre-kindergarten program? Explain.

How would parents and teachers adapt the structure of the WV UPK program?

- Parent: Is your child having the pre-kindergarten experience that you would optimally want them to? Explain. Teacher: Are children having the pre-kindergarten experience that you would optimally want them to? Explain.

- Parent: How would you rate your child's UPK experience thus far on a scale of 1-5? Teacher: How would you rate a child's UPK experience on a scale of 1-5?

- What are the barriers to your complete satisfaction with UPK?

- What would you change about WV UPK?

- How do you feel pre-kindergarten should be incorporated into the public school system? Explain.

- What public pre-k structure would be the best for your child or family? Why?

- Public schools

- Private child care centers

- Other 
- Do you feel any public services should be provided to children less than four-years-of age? Explain.

- Parent: Is there another form of familial support/early education initiative that would better suit the needs of your family? Teacher: Is there another form of familial support/early education initiative that would better suit the needs of the families in your program?

What do parents and teachers perceive as the outcomes of WV UPK?

- Do you think that the outcomes of UPK participation will extend beyond kindergarten readiness? In what ways?

- Do you feel that children who participate in a UPK have an upper advantage to those who do not? In what ways?

- What do you feel is the most beneficial outcome of children participating in a UPK program?

- Are there adverse outcomes of UPK on children? What are they?

What is perceived as successful elements of the WV UPK program?

- What do you like the most about the WV UPK system?

What is perceived as challenging elements of the WV UPK program?

- What do you like the least about the WV UPK system?

How do parents and teachers think that the WV UPK program should proceed in the future?

- Do you feel that UPK participation should be optional or mandatory? Explain.

- Will your opinion change in the future? How?

- How would you feel if UPK participation became mandatory? Explain.

- How would your opinions change if three-year-olds were encouraged to participate in a public preschool system? Why?

- Do you think that there should be a lower age limit to being served by the public school system? What is it? Why?

These research questions are not all-inclusive. Additional interview questions will be asked as appropriate. 


\section{Appendix B}

\section{TEACHER CONSENT LETTER}

\section{W Westhignhuhineresily \\ College of Human Resources and Education}

Date:

Dear

You are invited to participate in a research study that will examine parents' and teachers' perspectives of the WV universal pre-kindergarten program. The research will be conducted by Bethanie Morris Stiles, a doctoral candidate from the Department of Curriculum and Instruction (with an emphasis in Early Childhood Education) at West Virginia University.

The qualitative research study will involve participation from pre-kindergarten teachers and parents in four pre-k sites and will data will be gathered through open-ended, semi-structured interviews. You will receive a copy of the questions that you will be asked to respond to during the audio-recorded interviews. The interviews will seek insights pertaining to your personal experiences with the WV universal pre-kindergarten program and will last approximately one hour.

Audio recordings and written notes will be obtained during this research study will be securely maintained in a locked file box, accessible only to the doctoral candidate and committee chair. Anonymity will be assured through the use of pseudonyms and a coding system that replaces individual names. Once the research is completed, audio recordings will be erased and transcriptions will be destroyed to assure anonymity.

Any research results from this study may be used for dissertation, scholarly article or report, and conference presentations. Removing any identifying information and using pseudonyms will provide assurances of confidentiality.

Participation in the research study will be totally voluntary and you may abandon the project participation at any time, and for any reason, without ramification. If you chose not to participate or to withdraw, there will be no impact upon your position within the UPK system. You are also free to refuse to answer any questions that you wish to not answer. Participants must be 18 years of age of older to participate. West Virginia University's Institutional Review Board (IRB) has acknowledgement of this study on file.

You will receive a $\$ 15.00$ gift card as compensation for your participation in this research, which will be bestowed at the completion of the interview. 
For questions regarding this study, please contact Bethanie Morris Stiles by telephone at 304-276-2621 or through email at bethanie.stiles@mail.wvu.edu

Sincerely,

Bethanie M Stiles

Enclosures

I have read and understand the above stated information and do voluntarily agree to participate in the research study described above. I have received a copy of the interview questions and will be given a copy of this signed consent form.

Printed name

Signature

Date

Phone number Email 


\section{Appendix C}

\section{PARENT CONSENT LETTER}

\section{West VirginiaUniversity}

College of Human Pesources and Education

\section{PARENT CONSENT LETTER}

Date:

Dear

You are invited to participate in a research study that will examine parents' and teachers' perspectives of the WV universal pre-kindergarten program. The research will be conducted by Bethanie Morris Stiles, a doctoral candidate from the Department of Curriculum and Instruction (with an emphasis in Early Childhood Education) at West Virginia University.

The qualitative research study will involve participation from pre-kindergarten teachers and parents in four pre-k sites and will data will be gathered through open-ended, semi-structured interviews. You will receive a copy of the questions that you will be asked to respond to during the audio-recorded interviews. The interviews will seek insights pertaining to your personal experiences with the WV universal pre-kindergarten program and will last approximately one hour.

Audio recordings and written notes will be obtained during this research study will be securely maintained in a locked file box, accessible only to the doctoral candidate and committee chair. Anonymity will be assured through the use of pseudonyms and a coding system that replaces individual names. Once the research is completed, audio recordings will be erased and transcriptions will be destroyed to assure anonymity.

Any research results from this study may be used for dissertation, scholarly article or report, and conference presentations. Removing any identifying information and using pseudonyms will provide assurances of confidentiality.

Participation in the research study will be totally voluntary and you may abandon the project participation at any time, and for any reason, without ramification. If you chose not to participate or to withdraw, there will be no impact upon your position within the UPK system. You are also free to refuse to answer any questions that you wish to not answer. Participants must be 18 years of age of older to participate. West Virginia University's Institutional Review Board (IRB) has acknowledgement of this study on file.

You will receive a $\$ 15.00$ gift card as compensation for your participation in this research, which will be bestowed at the completion of the interview. To participate in this study, please return this signed consent letter to your child's teacher by in the enclosed envelope.

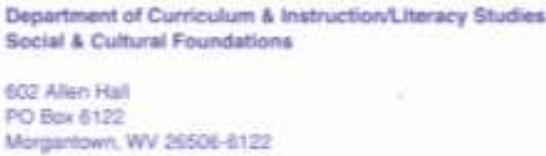


For questions regarding this study, please contact Bethanie Morris Stiles by telephone at 304-276-2621 or through email at bethanie.stiles@mail.wvu.edu

Sincerely,

Bethanie M Stiles

Enclosures

I have read and understand the above stated information and do voluntarily agree to participate in the research study described above. I have received a copy of the interview questions and will be given a copy of this signed consent form.

Printed name

Signature Date

Phone number Email 


\section{Appendix D}

\section{PRINCIPAL/DIRECTOR CONSENT LETTER}

\section{West VirginiaUniversity}

College of Human Pesources and Education

PRINCTPR CONSENT LITTER

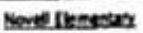

Henilod tanecar

semancosise

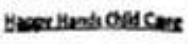

Date:

Deat

Pre-knoergarten teachers and parents from your school are invited to particlpate in a research project that will examine parents' and teachers' perspectives of the WV universal pre-kindergarten prozram. The research will be conducted by Bethanie Morris Stles, a doctoral candidate from the Department of Curriculum and instruction (with an emphasis in Early Childhood Education) at West Virginia Universiny.

The qualitative research study will involve participotion from one pre-kindergarten teacher and three pre-kindergarten parents in your school and will involve a semt-structured interview and open-ended interview. You will receive a copy of the questions that teachers and parents will respond to during the audio-taped interviews. The intervews will seek teacher and parant insights pertaining to perspectives of the $W V$ universal pre-kinderzarten program.

Audiotapes and written notes will be obtained during this research study will be securely maintained in a locked file box, accessible only to the doctoral candidate and committee chair. Anonymily will be assured through the use of pseudonyms and a coding system that replaces individual names. Once the research is completed, audlotapes will be erased and transcriptions will be destroyed to assure anonymity.

Any research results from this study may be used for dissortation, scholarly article of report, and conference presentations. Assurances of confidentiallty will be provided by removing any identifying information and using pseudonyms.

Participation in the research study will be totally voluntary and your teachers and parent participants may abandon the project participation at any time, and for any reason, without ramiffeation. If they chose not to participate or to wlthdraw, there will be no impact upon their position within the UPX system. They are also free to refuse to answer any questions that they wish to not answer. Participants will receive a $\$ 15.00$ gift card as compensation for their participation in the research, which will be bestowed at the completion of the interview.

For questions regarding this study, please contact Bethanie Morris stiles by telephone at 304-276-2621 or through email at bethanie. stilesomail.wvu.edu

Enciosures

I hove read and understand the above stated information and do voluntarily agree to permit selected teachers from my school to participate in the research study described above. I have received a copy of the interview questions and a pppy of this signed consent form.

Signature .

Date. 


\title{
Appendix E
}

\section{Participant Demographic Questionnaire Form}

Age

What is your month and year of birth? (MM/YYYY)

Sex

What is your sex?

$\square \quad$ Male

$\square \quad$ Female

\section{Race/ethnicity}

How do you describe yourself? (Please check the one option that best describes you)

$\square$ American Indian or Alaska Native

$\square \quad$ Hawaiian or Other Pacific Islander

$\square$ Asian or Asian American

$\square$ Black or African American

$\square \quad$ Hispanic or Latino

$\square \quad$ Non-Hispanic White

$\square \quad$ Prefer not to answer

\section{Marital status}

Are you:
$\square \quad$ Married
$\square \quad$ Divorced
$\square \quad$ Widowed
$\square \quad$ Separated
$\square \quad$ Never been married
$\square \quad$ A member of an unmarried couple
$\square \quad$ Prefer not to answer

\author{
Employment status \\ Are you currently... \\ $\square$ Employed for wages \\ $\square \quad$ Self-employed \\ $\square \quad$ Out of work for more than 1 year \\ $\square \quad$ Out of work for less than 1 year \\ $\square \quad$ A homemaker \\ $\square \quad$ A student \\ $\square \quad$ Retired \\ $\square \quad$ Unable to work \\ $\square \quad$ Prefer not to answer
}




\section{Education completed}

What is the highest grade or year of school you completed?

$\square \quad$ Never attended school or only attended kindergarten

$\square \quad$ Grades 1 through 8(Elementary)

$\square \quad$ Grades 9 through 11 (Some high school)

$\square$ Grade 12 or GED (High school graduate)

$\square \quad$ Some college credit, but less than 1 year

$\square \quad 1$ or more years of college, no degree

$\square$ Associate degree (for example: AA, AS)

$\square$ Bachelor's degree (for example: $B A, A B, B S$ )

$\square$ Master's degree (for example: MA, MS, MEng, MEd, MSW, MBA)

$\square$ Professional degree (for example: MD, DDS, DVM, LLB, JD)

$\square \quad$ Doctorate degree (for example: PhD, EdD)

$\square \quad$ Prefer not to answer

\section{Family size}

How many children live in your household who are...

- Less than 5 years old?

- 5 through 12 years old?

- 13 through 17 years old?

\section{Household income}

What is your total household income?
$\square \quad$ Less than $\$ 10,000$
$\square \quad \$ 10,000$ to $\$ 19,999$
$\square \quad \$ 20,000$ to $\$ 29,999$
$\square \quad \$ 30,000$ to $\$ 39,999$
$\square \quad \$ 40,000$ to $\$ 49,999$
$\square \quad \$ 50,000$ to $\$ 59,999$
- $\$ 60,000$ to $\$ 69,999$
- $\$ 70,000$ to $\$ 79,999$
$\square \quad \$ 80,000$ to $\$ 89,999$
$\square \quad \$ 90,000$ to $\$ 99,999$
- $\$ 100,000$ to $\$ 149,999$
$\square \quad \$ 150,000$ or more
$\square$ Prefer not to answer 
Only complete this section if you are a PARENT participant.

Please only answer the questions in which you are comfortable answering.

Other children in the family

How many of your children have attended a....

- Private pre-k?

- Publicly funded pre-k?

\section{Parent occupation(s)}

What is your occupation?

What is your child's other parent's occupation(s)? Please identify occupations of all of your child's parents, including stepparents if applicable and known.

\section{Pre-k child participant}

For your child that is currently enrolled in WV's universal pre-kindergarten program, please identify:

- Their month and year of birth? (MM/YYYY)

- What is their sex?

$\square \quad$ Male

Female

- Where was your child cared for and educated prior to enrollment in WV's universal pre-kindergarten program?

$\square \quad$ By a parent at home

$\square$ By a relative caregiver

$\square \quad$ By a non-relative caregiver

$\square \quad$ By an in-home provider

$\square \quad$ By a childcare/daycare center

\section{Only complete this section if you are a TEACHER participant. \\ Please only answer the questions in which you are comfortable answering.}

Teaching experience \& certification

How many years of experience do you have as a teacher?

- Overall years of teaching experience:

- Years of experience in a private setting:

- Years of experience in a public setting:

- Years of experience in WV UPK:

What is your teaching certification?

What other ages or grades have you taught? 